\title{
Development of Methodologies for Technology Deployment for Advanced Outage Control Centers that Improve Outage Coordination, Problem Resolution and Outage Risk Management
}

\author{
Shawn St. Germain \\ Ronald Farris \\ Heather Medema
}

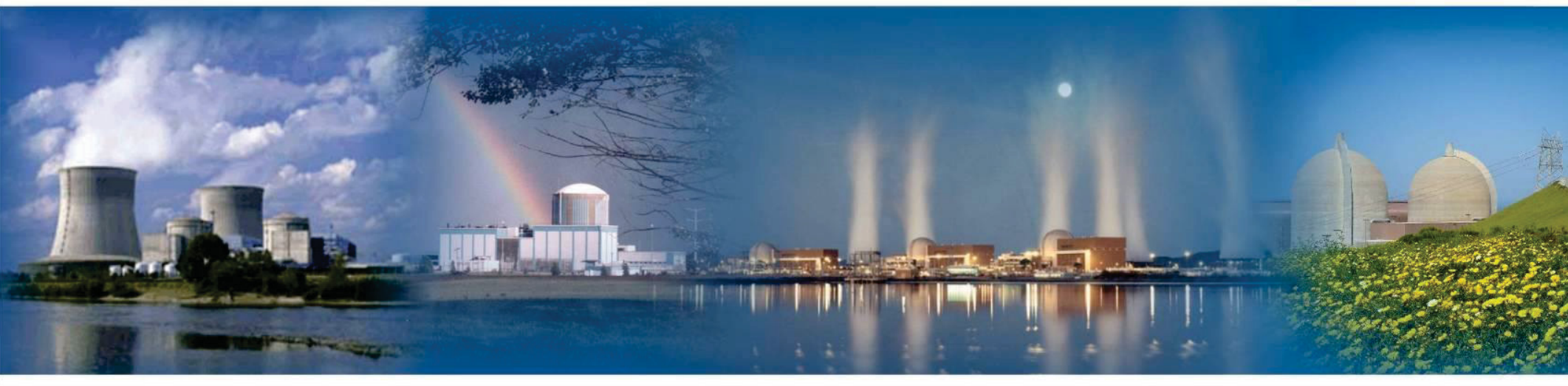

The INL is a U.S. Department of Energy National Laboratory operated by Battelle Energy Alliance 


\section{DISCLAIMER}

This information was prepared as an account of work sponsored by an agency of the U.S. Government. Neither the U.S. Government nor any agency thereof, nor any of their employees, makes any warranty, expressed or implied, or assumes any legal liability or responsibility for the accuracy, completeness, or usefulness, of any information, apparatus, product, or process disclosed, or represents that its use would not infringe privately owned rights. References herein to any specific commercial product, process, or service by trade name, trade mark, manufacturer, or otherwise, does not necessarily constitute or imply its endorsement, recommendation, or favoring by the U.S. Government or any agency thereof. The views and opinions of authors expressed herein do not necessarily state or reflect those of the U.S. Government or any agency thereof. 
INL/EXT-13-29934

Rev. 0

\section{Development of Methodologies for Technology Deployment for Advanced Outage Control Centers that Improve Outage Coordination, Problem Resolution and Outage Risk Management \\ Shawn St. Germain Ronald Farris Heather Medema}

September 2013

Idaho National Laboratory Idaho Falls, Idaho 83415

http://www.inl.gov

Prepared under Work Package L-12N060305

Prepared for the

U.S. Department of Energy

Office of Nuclear Energy

Under DOE Idaho Operations Office

Contract DE-AC07-05ID14517 


\section{Executive Summary}

This research effort is a part of the Light-Water Reactor Sustainability (LWRS) Program, which is a research and development $(\mathrm{R} \& \mathrm{D})$ program sponsored by Department of Energy (DOE) and performed in close collaboration with industry $R \& D$ programs that provides the technical foundations for licensing and managing the long-term, safe, and economical operation of current nuclear power plants. The LWRS program serves to help the U.S. nuclear industry adopt new technologies and engineering solutions that facilitate the continued safe operation of the plants and extension of the current operating licenses.

The long term viability of existing nuclear power plants in the U.S. will depend upon maintaining high capacity factors, avoiding nuclear safety issues and reducing operating costs. The slow progress in the construction on new nuclear power plants has placed in increased importance on maintaining the output of the current fleet of nuclear power plants. Recently expanded natural gas production has placed increased economic pressure on nuclear power plants due to increased cost competition. Until recently, power uprate projects had steadily increased the total output of the U.S. nuclear fleet. The large cost of recovery from component issues have now removed three nuclear power plants from the U.S. fleet and economic considerations have caused the permanent shutdown of a fourth plant. Additionally, several utilities have cancelled power uprate projects citing economic concerns. For the past several years net electrical generation from U.S. nuclear power plants has been declining. One of few remaining areas where significant improvements in plant capacity factors can be made is in minimizing the duration of refueling outages.

Managing nuclear power plant outages is a complex and difficult task due to the large number of maintenance and repair activities that are accomplished in a short period of time. During an outage, the outage control center (OCC) is the temporary command center for outage managers and provides several critical functions for the successful execution of the outage schedule. Essentially, the OCC functions to facilitate information inflow, assist outage management in processing information and to facilitate the dissemination of information to stakeholders. Currently, outage management activities primarily rely on telephone communication, face to face reports of status and periodic briefings in the OCC. It is a difficult task to maintain the currency of information related to outage progress and discovered conditions.

Several advanced communication and collaboration technologies have shown promise for facilitating the information flow into, across and out of the OCC. The use of these technologies will allow information to be shared electronically, providing more real time information to the decision makers and allowing OCC coordinators to meet with supporting staff remotely. The current reliance on manually reporting progress will be reduced by passively monitoring status electronically through advances in the areas of mobile worker technologies, computer based procedures and electronic work packages. The use of these technologies will also improve the knowledge capture and management capabilities of the organization.

The purpose of this research is to improve management of nuclear power plant (NPP) outages through the development of an advanced outage control center (AOCC) that is specifically designed to maximize the usefulness of communication and collaboration technologies for outage coordination and problem resolution activities. Many OCCs currently in use were not specifically designed for this purpose, rather they are converted conference rooms or temporarily set up in facilities normally used for some other purpose. This project will create a methodology for conducting an outage process analysis through a function and task analysis to optimize the use of technology and to determine an optimum deployment of the outage organization and OCC physical layout. The final product of this research will 
be a technical report for industry implementation that outlines methods and considerations for the establishment of an AOCC.

This report describes previous and current research, including activities conducted through FY 2013 and plans for continuing work through FY 2014. An outline of the method that will be used to accomplish the goal of the pilot project is presented. The status of developed technologies for an AOCC that improves outage coordination, problem resolution, and outage risk management is also presented. 


\section{Acknowledgements}

The Advanced Outage Control Center research team would like to acknowledge the efforts of the following individuals and organizations that made this research possible.

Michael Grigsby, Carlos Williams and members of the Arizona Public Services Palo Verde Nuclear Generating Station staff for hosting the research activities,

Michael Hildebrandt and the staff of the OECD Halden Reactor Project,

Dr. David Gertman, Ken Thomas, Dr. Bruce Hallbert and Jacques Hugo for technical review of the research methodology. 


\section{CONTENTS}

EXECUTIVE SUMMARY ...........................................................................................................

ACKNOWLEDGEMENTS ....................................................................................................................VI

CONTENTS................................................................................................................................ VII

FIGURES..................................................................................................................................... VIII

TABLES.............................................................................................................................................. VIII

ACRONYMS ....................................................................................................................................

1. INTRODUCTION..................................................................................................................

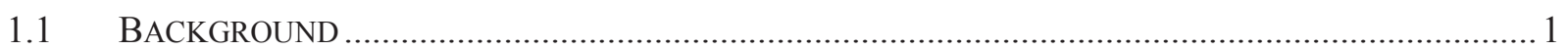

1.1.1 Previous pilot project results related to an AOCC ...................................................... 2

2. ADVANCED OUTAGE CONTROL CENTER IMPLEMENTATION STRATEGY -

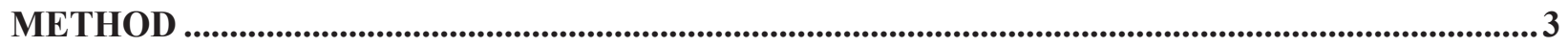

2.1 STEP 1, IDENTIFY OUTAGE PROCESSES THAT HAVE THE GREATEST POTENTIAL FOR

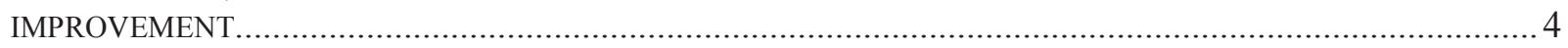

2.1.1 Advanced Outage Control Center LWRS Pilot Project Research Plan ……........................ 5

2.1.2 High level functions of an OCC ..................................................................................... 6

2.1.3 Selected processes for the AOCC Pilot Project ……........................................................ 6

2.2 STEP 2, EVALUATE COLLABORATION/COMMUNICATION TECHNOLOGY OPTIONS THAT SHOW PROMISE FOR OCC APPLICATION …………………………………………………………...

2.2.1 Enabling technologies that may benefit OCC staff ........................................................... 7

2.2.2 Advanced OCC functions enabled by technology improvements....................................... 8

2.3 STEP 3, ANALYZE THE CURRENT OUTAGE STAFFING DEPLOYMENT USING HUMAN FACTORS

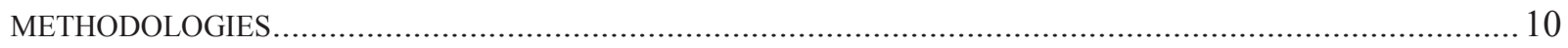

2.3.1 Results from observation of Palo Verde's spring 2013 outage........................................ 11

2.4 STEP 4, EVALUATE SELECT POTENTIAL TECHNOLOGY APPLICATIONS BASED ON FUNCTION

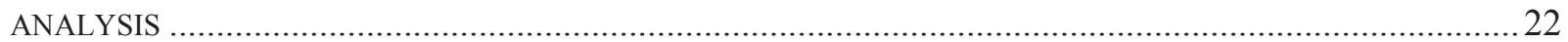

2.4.1 Demonstration scenarios utilizing the INL Human Systems Simulation Laboratory

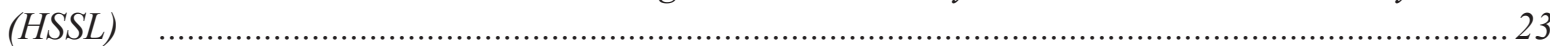

2.4.2 Demonstration scenarios at Palo Verde .................................................................... 24

2.4.3 Implementation of technology for evaluation at Palo Verde during the fall 2013 outage.. 24

2.5 STEP 5, DETERMINE TO WHAT EXTENT FUNCTIONS SHOULD BE REALLOCATED UTILIZING

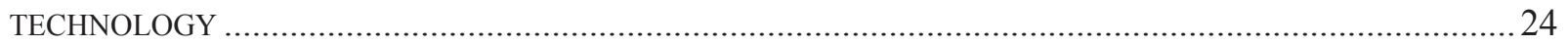

2.6 STEP 6, DEVELOP A NEW PHYSICAL OCC LAYOUT BASED ON FUNCTION REALLOCATION, TECHNOLOGY INTEGRATION AND HUMAN FACTORS CONSIDERATIONS ……………………………........ 25

2.7 STEP 7, ANALYZE THE EFFECTIVENESS OF THE NEW ARRANGEMENT AND MAKE NECESSARY

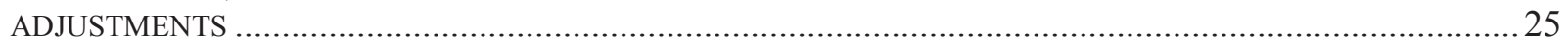

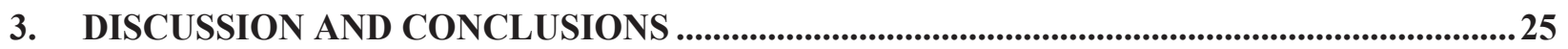

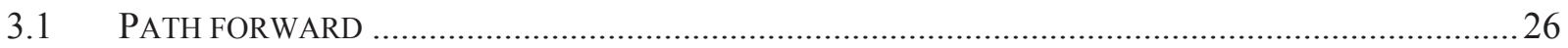

4. REFERENCES...........................................................................................................................

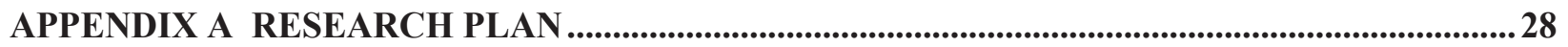

APPENDIX B PALO VERDE SPRING 2013 OUTAGE OBSERVATION DATA ............................52

APPENDIX C COMPREHENSIVE IRT PROCESS MAPS...................................................................63 


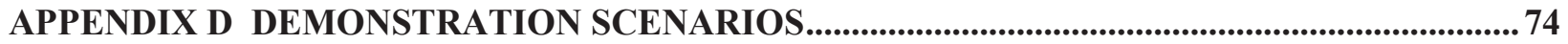

\section{FIGURES}

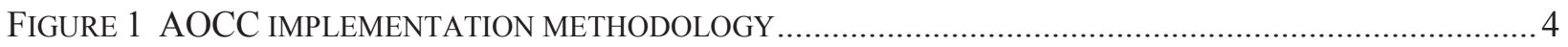

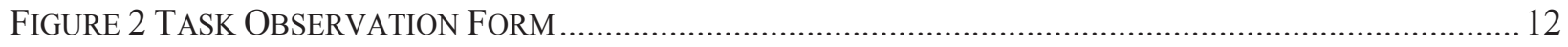

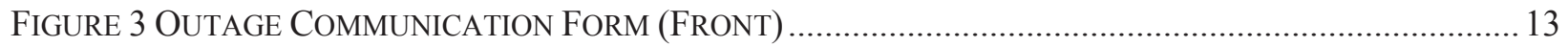

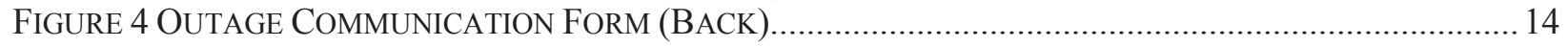

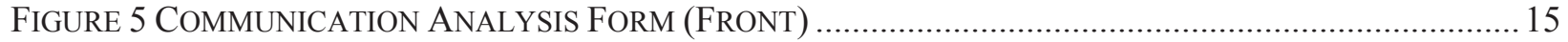

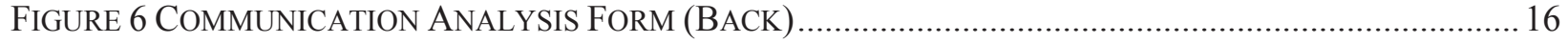

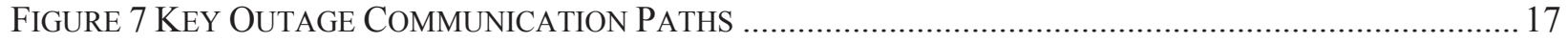

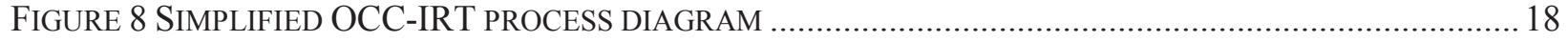

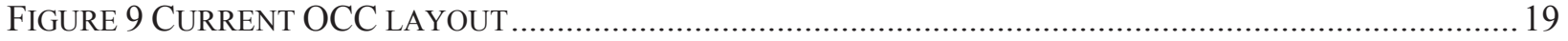

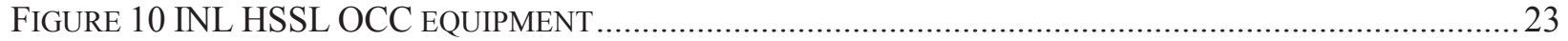

TABLES

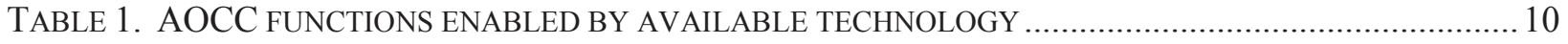




\section{ACRONYMS}

\begin{tabular}{|c|c|}
\hline $\mathrm{AOCC}$ & Advanced Outage Control Center \\
\hline AWP & Automated Work Packages \\
\hline MCRCBP & Computer-Based Procedures \\
\hline COTS & Commercial Off-The-Shelf Technology \\
\hline CRADA & Cooperative Research and Development Agreement \\
\hline DOE & Department of Energy \\
\hline EPRI & Electric Power Research Institute \\
\hline EWP & Electronic Work Packages \\
\hline HFE & Human Factors Engineering \\
\hline HMI & Human Machine Interface \\
\hline HSI & Human Systems Interface \\
\hline HSSL & Human Systems Simulation Laboratory \\
\hline $\mathrm{HU}$ & Human Performance \\
\hline ICC & Information \& Communication Center \\
\hline $\mathrm{II} \& \mathrm{C}$ & Instrumentation, Information, and Control \\
\hline INL & Idaho National Laboratory \\
\hline INPO & Institute of Nuclear Power Operations \\
\hline IRT & Issues Response Team \\
\hline IT & Information Technology \\
\hline LWRS & Light Water Reactor Sustainability \\
\hline MCR & Main Control Room \\
\hline NEO & Nuclear Equipment Operator \\
\hline NPP & Nuclear Power Plant \\
\hline
\end{tabular}




$\begin{array}{ll}\text { OCC } & \text { Outage Control Center } \\ \text { OE } & \text { Operating Experience } \\ \text { PBP } & \text { Paper-Based Procedure } \\ \text { PSC } & \text { Plant Status Control } \\ \text { QC } & \text { Quality Control } \\ \text { R\&D } & \text { Research and Development } \\ \text { RFID } & \text { Radio-Frequency Identification } \\ \text { SIG } & \text { Special Interest Group } \\ \text { SME } & \text { Subject Matter Expert } \\ \text { SOD } & \text { Shift Outage Director }\end{array}$




\section{INTRODUCTION}

This research effort is a part of the Light-Water Reactor Sustainability (LWRS) Program, which is a research and development $(\mathrm{R} \& \mathrm{D})$ program sponsored by Department of Energy (DOE) and performed in close collaboration with industry $R \& D$ programs that provides the technical foundations for licensing and managing the long-term, safe, and economical operation of current nuclear power plants. The LWRS program serves to help the U.S. nuclear industry adopt new technologies and engineering solutions that facilitate the continued safe operation of the plants and extension of the current operating licenses.

One of the major research pathways in the LWRS program is the Advanced Instrumentation, Information, and Control (II\&C) research pathway. The purpose of this research pathway is to enable the modernization of the legacy instrumentation, information, and control systems in a manner that creates a seamless digital environment encompassing all aspects of plant operations and support - building a threedimensional information architecture that integrates plant systems, plant processes, and plant workers in an array of interconnected technologies. Within this pathway, a number of pilot projects are being conducted as a means for industry to collectively integrate these new technologies into nuclear plant work activities.

One major area selected for research into enabling capability is in outage safety and efficiency. This pilot project, Advanced Outage Control Center, is a two year effort targeted at Nuclear Power Plant (NPP) outage improvement. The purpose of this pilot project is to improve management of NPP outages through the development of an Advanced Outage Control Center (AOCC) that is specifically designed to maximize the usefulness of communication and collaboration technologies for outage coordination and problem resolution activities. The final product of this research will be a technical report for industry implementation that outlines methods and considerations for the establishment of an AOCC.

This report describes previous and current research, including activities conducted through FY 2013 and plans for continuing work through FY 2014. An outline of the method that will be used to accomplish the goal of the pilot project is presented. This methodology is currently being applied and refined through collaboration with a utility partner. Palo Verde Nuclear Generating Station agreed to participate in the evaluation and refinement of the methodology. Preliminary observations from early studies at the Palo Verde NPP are discussed. The status of developed technologies for an AOCC that improves outage coordination, problem resolution, and outage risk management is also presented.

\subsection{Background}

NPP refueling outages create some of the most challenging activities the utilities face in both tracking and coordinating thousands of activities in a short period of time, and occur in a short period of time, usually twenty to thirty days. Outage work requires a supplemental workforce, including hundreds of contract personnel, adding to the complexity of communication and information flow. Other challenges including nuclear safety concerns arising from atypical system configurations and resource allocation issues can create delays and schedule overruns, driving up outage costs.

The current technologies employed at most NPPs to communicate critical information are slow, inaccurate at times, and rely upon the physical presence of outage staff and key personnel to obtain and

validate critical system and status information. Today the majority of the outage communication is done 
using processes and technologies that do not take advantage of advances in modern technology. Some of the common practices include: runners that deliver paper-based requests for approval, radios, telephones, desktop computers, daily printouts of the schedule and static white boards that are used to display information. There is a large amount of static information that is displayed and requires an evaluation to determine its validity. The current methods of displaying and tracking information will not be adequate to process the increased use of real time information that will be available with the increased use of handheld technology, electronic work packages, or computer programs that passively track work completion and readiness. In general, industry has not yet taken full advantage of advancements in mobile technologies that enable communication, collaboration, data streaming, and information sharing to and from the field. Many gains have been made to reduce the challenges facing outage coordinators, however; new opportunities can be realized by utilizing modern technological advancements in communication and information tools that can enhance the collective situational awareness of plant personnel leading to improved decision-making.

\subsubsection{Previous pilot project results related to an AOCC}

\section{LWRS Human Performance Pilot Project, 2011-12:}

The objectives of this project were to address situational awareness, error reduction, human performance, and plant status control (PSC) for field worker in commercial nuclear power plants. This project was positioned to bring three parties together - nuclear power plants with urgent and long-term needs, vendors and other entities with commercial off the shelf technology (COTS) solutions, and third party facilities centered between the needs and solution-driven positions. The approach was to access, refine and demonstrate the ability of new technologies that would enable maximum the collective situational awareness of the NPP staff to improve decision-making. The research concluded that employing the technology afforded significant opportunities for improving both accuracy in positioning plant components (plant status control) and decision-making by providing plant personnel with rich data (e.g. electronic forms, diagrams, annotated photos, video and voice) in real-time. In addition, this project and its findings have informed the LWRS program (AOCC and CBP projects) and EPRI Electronic Work Packages (EWP) project. Additionally, commercial nuclear new builds have inquired about the project and are taking on similar approaches to solve the issues identified by the research team at the INL (Farris \& Weatherby, 2011).

\section{LWRS Computer-Based Procedure, ongoing:}

The primary objective of this research pilot project has been to develop the technical guidance the nuclear industry can use in their discussions with potential computer-based procedure (CBP) system vendors. The emphasis has been on how to best design the graphical user interface and underlying data structure, user interface, and human performance improvement. By deploying CBPs in lieu of the current paper-based procedures (PBP) the researchers believe an overall improvement in efficiency, productivity, and safety can be achieved. The research and development for this project will continue with industry partners through fiscal year 2014 (Le Blanc, 2012, Oxstrand \& LeBlanc, 2012).

\section{LWRS Advanced Outage Coordination, 2012:}

In the previous phase of this project the research project successfully developed and deployed new technologies that were designed to assist NPP outage managers in conducting more efficient and errorfree outages. The Smart Boards were deployed and the software company Ovalpath was recruited to collaboratively develop tools that enabled real-time data transfer (work status) from the field using wireless handheld technology and provided interactive displays for the OCC using Smart Board technology. Collaboration between the INL research team, Exelon Nuclear, and software company 
"Ovalpath" proved to be a successful combination as Ovalpath is currently contracted with Exelon to perform the vary activities the project set out to research, develop, and demonstrate. The INL researchers provided the research and direction, Exelon provided the facilities to demonstrate the technologies, and Ovalpath developed the database capabilities that supported the improved communication capabilities (Weatherby \& Tawfik, 2012).

\section{EPRI Electronic Work Packages, early stages of inception:}

EPRI and commercial utilities are in the process of designing, demonstrating, and documenting a defined method to convert the current paper-based maintenance work package to EWPs. Paper work packages present information in a static manner and limit the user's ability to navigate the work package with ease. In addition, the current system does not allow for dynamic information flow such as component status, transfer of data, connectivity with databases, on-demand information for field workers, or other real-time plant information. Currently there are a limited number of utilities and one DOE site that are in the process of converting to EWP system on a limited basis. If and when EWPs are an industry norm, the AOCC will be able to obtain real-time updates from the field using mobile devices. This real-time data transfer utilizing wireless mobile devices will likely improve the actual maintenance and plant status leading to increased safety, cost savings, productivity, efficiency, and reduced outage times. This project will be approached in a phased manner allowing industry time to adopt each phase as not to overwhelm the current system/infrastructure with considerations given to the basic principles of change management. The final product of this work will include an EPRI guidance document on deploying EWPs (Farris, 2012).

\section{ADVANCED OUTAGE CONTROL CENTER IMPLEMENTATION STRATEGY - METHOD}

The strategy for accomplishing the goals of this pilot project was to create a methodology for redesigning an OCC optimized to facilitate improved outage processes supported by advanced communication and collaboration technologies and to optimize the deployment of outage staff to maximize effectiveness and efficiency. This methodology is being been implemented in a structured manner on a trial bases with the utility partner, Palo Verde Nuclear Generating Station. Palo Verde has indicated they would like to update their OCC, and are interested in incorporating advanced communication and collaboration technologies. This methodology will be evaluated and refined throughout the research project and presented in a technical report for industry implementation. It is expected that some steps performed by INL during the development of the methodology would not need to be repeated by an organization following the methodology after its final publication. Figure 1 shows the methodology for the development of an AOCC. The project is currently in the middle of step 4 of the overall methodology. 


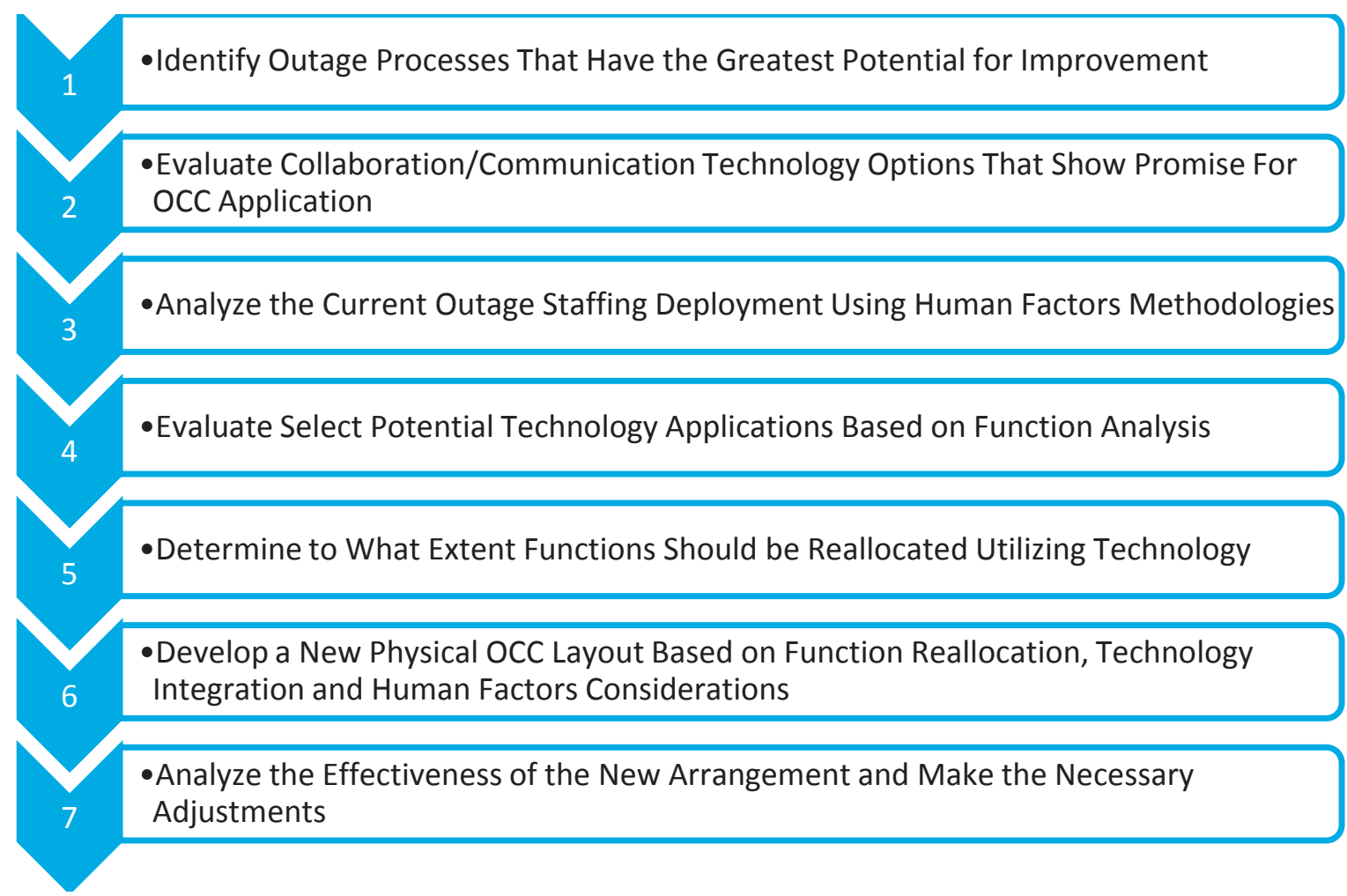

Figure 1 AOCC implementation methodology

The details of this methodology are presented in the following sections.

\subsection{Step 1, Identify outage processes that have the greatest potential for improvement}

The first step in the process of optimizing the function of the OCC was to determine outage processes that present the greatest opportunity for improvement. Enhancements in communication and collaboration technologies have the potential to improve numerous processes, but previous experience has shown that adding technology without tying the technology to specific processes often resulted in underutilization. The goal of this step of the approach was to identify areas that would most benefit from technology enhancements. These processes will then be modified to embed the use of the new technologies into the processes and speed the adoption of the new technologies. These initially selected processes will be evaluated first, but additional processes will likely be identified during step 3 that will be candidates for future application of these technologies. The results of this evaluation will be different for each plant, as some outage organizations have already made significant improvements in certain areas of outage management and outage management organization will vary from plant to plant. The methods for identifying areas for improvement, however, will be similar. The following methods were used to identify targeted areas for improvement:

\section{Prior to the Outage}

- Interviews with staff in the outage organization. Both those involved in planning and those involved in execution. Identify those areas the plant self identifies as routinely struggling with during execution. 
- Review of post outage reports and lessons learned from previous outages, with a focus on causes for schedule delays.

- Compare the plants performance for individual window durations to the top quartile performance of the Westinghouse Owners Group data.

- Review industry wide operating experience (OE) such as INPO OERs and SOERs to identify industry wide issues and best practices.

\section{During the outage}

- Observe outage activities to identify areas for improvement.

The first four methods were done prior to observation of outage activities. Due the limited amount of outage time and required attention of outage staff during the outage, it was beneficial to use the information gathered using the first four methods to focus the efforts of the research team during the outage observation period on processes that likely required additional effort.

Some of the insights gained by the above activity were not related to enhancements for the OCC, but may still be worth addressing as a separate improvement activity by the organization. This step is an iterative process, processes are identified initially for increased focus during Step 1, but observations made during actual outage activities in Step 3 will likely lead to the identification of additional processes for evaluation.

\subsubsection{Advanced Outage Control Center LWRS Pilot Project Research Plan}

A formal research plan was developed and approved for the LWRS AOCC pilot project. The research plan presents methods to collect and analyze data to characterize the existing function and task allocation (See Appendix A). The research plan preceded the first outage observation and provided a toolkit of HFE techniques to assist in performing a function and task analysis. Not all methods of data collection or analysis have been used at this point. The team has used function, task, and communication link analyses to date. A variety of data collection methods supported these analyses such as interviews, surveys, naturalistic observations, and reviews of various process description documents provided by Palo Verde. The analyses of this data will help the INL team make recommendations to the nuclear utilities that will enhance their current processes and conceptual design of future outage work centers designed to maximize the effectiveness of all of the various technologies being evaluated to support plant operations.

The specific elements of the research plan that the research team find most useful, as well as recommended data collection forms and specific analysis techniques will be integrated into the final technical report. Since application of the research plan and the methodology is still in progress, final recommendations regarding analysis techniques are will not be made at this time and the research plan is presented as a separate document in the appendices.

The primary purpose of the data collection at this point was to develop a baseline analysis of the required functions and tasks currently performed in the Outage Control Center (OCC). The results of this analysis will continue to be used to evaluate alternative methods of performing these functions utilizing advanced communication and collaboration technologies. Additionally, the results of this data collection will be utilized in the design of Human-System Interfaces (HSIs) and an optimized physical layout for an AOCC in accordance with generally accepted Human Factors Engineering (HFE) guidance and criteria in later steps. The data collected from this process was primarily used in Step 3 of the methodology, 
however information derived from the data collection effort was used to characterize the required functions of the OCC and to identify initial processes for study so it is presented here.

\subsubsection{High level functions of an OCC}

In evaluating outage processes for potential enhancement utilizing modern technology, it has been useful to group individual tasks or ideas for improvement by the high level OCC function they support. The following high level functions of the $\mathrm{OCC}$ were derived from the initial function analysis. These high level functions should be similar for any NPP outage organization.

1. Process Information Inflow
a. Status of scheduled activities
b. Reports of new emergent issues
c. Status of emergent issue resolution
d. Requests for assistance

2. Manage Work Schedule
a. Status of ongoing work tracking
b. Revisions to schedule due to delays
c. Coordination of required support

3. Manage Emergent Issues
a. Create and manage recovery plan
b. Manage schedule impacts

4. Manage Plant Conditions
a. Technical specification and mode change requirements
b. Defense in depth, protected systems and plant risk monitoring

5. Process Information Outflow
a. Overall outage schedule status
b. Resource requests/notifications
c. Communicate schedule changes to affected parties
d. Requests for status

\subsubsection{Selected processes for the AOCC Pilot Project}

Based upon initial interviews with Palo Verde staff and a review of previous outage reports, several processes were selected for evaluation of enhanced communication and collaboration technology. The large footprint of the Palo Verde site creates inefficiencies when face to face communication is relied on, therefore processes that require frequent travel were initial candidates. Processes that require 
intensive, frequent communications were also initial candidates for the application of enhanced communication and collaboration technologies.

The Issues Response Team (IRT) process was identified as a candidate for process improvement. The IRT is a temporary team of individuals assembled to understand and facilitate the recovery actions for significant issues. The IRT is assigned emergent issues by the OCC that require the coordination of several groups for resolution or for issues that challenge the outage critical path. The IRT is primarily tasked with the development and communication of a recovery plan and following the plan until a clear success path is apparent.

Several processes that related to OCC functions were also identified as candidates for the application of technology. The OCC functions identified for technology evaluations include: tracking the readiness for retests and mode change, communication of work status into the OCC, communication of discovered conditions from the field to the OCC and dissemination of information out of the OCC.

Another communication intensive process involves the function of the maintenance OCC (MOCC) satellite organization. The MOCC receives updates several times per shift from the individual maintenance shops regarding work status. These updates are currently conducted via face-to-face communication and require stakeholders to travel to the MOCC from various locations around the site. Communication and collaboration technology would allow these updates to occur remotely, saving transit time and allowing staff to focus on outage execution for their respective areas. This process will be the analyzed in detail during the next phase in the project.

\subsection{Step 2, Evaluate collaboration/communication technology options that show promise for OCC application}

Several promising technologies are already being implemented in NPPs for various purposes. While these technologies are being implemented for use outside of outages, some of the functions enabled by these technologies could be leveraged to improve outage execution. Other industries are also utilizing technologies that show potential for the nuclear industry. Some of these technologies have been demonstrated on a limited basis in previous LWRS pilot projects completed at the INL, some have not yet been developed and others have been developed by other industries. With the help of human factors analyses these applications could be adopted by NPP outage personnel and processes. Many of these technologies require an information technology (IT) infrastructure that may not be available at a particular NPP. The future utility of some of these outage management functions may be helpful in determining the total benefit of undertaking a large IT upgrade project. Since the goal of this methodology is to provide a redesign of an OCC within an existing organizational structure, it is helpful to understand the potential technologies that may be utilized prior to evaluation of the current state in Step 3 to help focus observations on areas where potential solutions have already been identified.

\subsubsection{Enabling technologies that may benefit OCC staff}

Based on previous pilot projects and a review of technology use in related industries, the following technologies may be used to improve the various functions of the OCC:

- Large format multi-touch boards utilizing collaboration software to assist with organizing information, that enables collaborating and communicating the status of emergent issues 
resolution. These boards may also be used to display and track routine issues within the OCC and allow remote viewing and updating of presented information. Additionally, these boards may be used for adding visual content to routine briefings and facilitate remote participation and sharing of routine and non-routine briefings.

- Mobile worker technologies capable of establishing instant real-time video communication from the field to the OCC. Mobile worker technologies will also enable remote verification of critical tasks reducing errors and freeing up resources.

- Automated work packages (AWPs) or EWPs that are performed by field workers on a tablet computer.

- Computer-based procedures (CBPs) performed on tablet computers, status are updated into real-time schedule monitoring.

- Use of flags in CBPs and EWPs to notify support staff of pending requirements via mobile technologies.

- Use of WiFi enabled remotely controlled cameras for monitoring job site work performance (i.e. Emergent Issue real-time monitoring). For critical jobs, a camera could be installed near the job site allowing OCC staff to see actual progress without relying solely on reports from the field.

- Plant wide WiFi. Plant wide WiFi will enable the connection of mobile workers to the OCC, allowing real-time status updates from CBPs and AWPs, pending support notifications and remote camera monitoring of critical jobs and evolutions.

- Use of bar codes, character recognition technology and/or radio-frequency identification (RFID) to identify components. Electronically identifiable components may reduce operator errors, allow for real-time tracking of clearance order processing and provide an input into a real-time risk monitor or readiness display.

\subsubsection{Advanced OCC functions enabled by technology improvements}

Depending on the level of IT infrastructure available, and the level of integration with existing processes, various advanced OCC functions will become available. The AOCC functions that will be enabled by technology improvements include but are not limited to:

- Real-Time Collaboration for Emergent Issues - Using multi-touch boards and high quality audio and video conferencing equipment deployed in various coordination centers, staff will be able to simultaneously work on complex problems by sharing real time pictures, diagrams, schedule information and notes. This technology will also facilitate communicating the product of the collaboration effort to the OCC, subject matter experts or other mangers. An electronic record of the resolution of the issue will also assist in knowledge management. The use of technology may reduce the need for face to face meetings saving time and richer data may increase the level of comprehension of complex problems.

- $\quad$ Real-Time Work Status - The use of CBPs will allow OCC staff instant status of work packages and procedures. The system will allow outage managers to call up and view the actual steps of a procedure as they are signed off or to simply notify the OCC automatically when certain tasks are completed. When tied into scheduling software, it will provide a real time picture of schedule adherence. Portable wireless cameras installed near critical job sites will also allow outage managers to monitor job status without relying on field workers to call in status updates.

- Automatic Pending Support Notifications - Utilizing embedded triggers in CBPs and EWPs; notifications to support staff can be automatically routed to required personnel via calendar, text or email notifications at predetermined time points alerting them of pending tasking. For example, a trigger may be set 30 minutes prior to a quality control (QC) hold point notifying 
the assigned QC inspector of an upcoming required inspection. Automated notifications will allow for more efficient resource allocation and real-time planning by staff.

- Improved Communication of Discovered Conditions From the Field - Using mobile technologies, field workers identifying issues in the field would be able to set up an instant video conference with the OCC or a supervisor in the field at the point of the problem. This would provide OCC staff with an instant understanding of the nature of the issue and allow further interaction between outage managers and the person discovering the issue. Further interaction may include directing the worker to send back video or annotated photograph of the surrounding area, component, or more carefully describing some aspect of the problem.

- More Efficient Dissemination of Information from the OCC - Utilizing advanced conferencing software and multi-touch boards, OCC managers can establish interactive status briefings in which stakeholders may participate from any location, on site or off, using a variety of devices including desktop computers, laptops, smart phones, and tablet computers.

- Real-Time Requirements Monitor - Utilizing a combination of information pulled from the status of procedures, real time plant status from the plant computer and plant logs, the OCC managers will be able to more easily display status and readiness for key activities or tasks.

- Mobile Alerts - Utilizing a messaging system similar to instant messaging used by most smart phones, NPP personnel could be updated by the OCC managers when important milestones are met or plant conditions change. Alerts for such events as window closures, plant risk level changes, protected system changes, industrial or radiological hazards, etc. These messages would consist of a simple statement of the condition, but also provide more detailed information for those that require it through use of an information icon. These alerts could be sent to handheld devices, desktop computers and large screen displays throughout the plant.

Table 1 links these advanced OCC functions with the required enabling technologies. Some functions may be partially available without the enabling technology, but the full capability may not be realized until the IT infrastructure is improved. 
Table 1. AOCC functions enabled by available technology

\begin{tabular}{|c|c|c|c|c|c|c|c|}
\hline \multirow[b]{2}{*}{$\begin{array}{c}\text { Enabling } \\
\text { Technologies }\end{array}$} & \multicolumn{7}{|c|}{ AOCC Functions and Features } \\
\hline & $\begin{array}{l}\text { Information } \\
\text { Inflow }\end{array}$ & $\begin{array}{l}\text { Collaboration } \\
\text { Within OCC }\end{array}$ & $\begin{array}{l}\text { Collaboration } \\
\text { With Groups } \\
\text { Outside OCC }\end{array}$ & $\begin{array}{l}\text { Real } \\
\text { Time } \\
\text { Work } \\
\text { Status }\end{array}$ & $\begin{array}{l}\text { Real Time } \\
\text { Requirements } \\
\text { Monitor }\end{array}$ & $\begin{array}{l}\text { Automated } \\
\text { Pending } \\
\text { Support } \\
\text { Routing }\end{array}$ & $\begin{array}{l}\text { Inform- } \\
\text { ation } \\
\text { Outflow }\end{array}$ \\
\hline $\begin{array}{l}\text { Interactive } \\
\text { Displays } \\
\text { (multi-touch } \\
\text { Boards) } \\
\end{array}$ & $X$ & $X$ & $X$ & $X$ & $X$ & $X$ & $X$ \\
\hline $\begin{array}{l}\text { Mobile } \\
\text { Technologies } \\
\text { (Handheld Tablets) }\end{array}$ & $X$ & & & $X$ & $X$ & $X$ & $X$ \\
\hline $\begin{array}{l}\text { Computer Based } \\
\text { Procedures }\end{array}$ & & & & $X$ & $X$ & $X$ & \\
\hline $\begin{array}{l}\text { High Quality } \\
\text { Video } \\
\text { Conferencing }\end{array}$ & $X$ & & $X$ & & & & $X$ \\
\hline $\begin{array}{l}\text { Conferencing } \\
\text { Integration } \\
\text { Software }\end{array}$ & $X$ & & $X$ & & & & $X$ \\
\hline $\begin{array}{l}\text { Plant Wide } \\
\text { Wireless Network } \\
\text { Coverage }\end{array}$ & $X$ & & & $X$ & $X$ & $X$ & $X$ \\
\hline $\begin{array}{l}\text { How } \\
\text { Developed? }\end{array}$ & & & & & & & \\
\hline $\begin{array}{l}\text { Demonstrate at } \\
\text { INL's HSSL }\end{array}$ & $X$ & $X$ & $X$ & $X$ & $X$ & $X$ & $X$ \\
\hline $\begin{array}{l}\text { Demonstrate at } \\
\text { Palo Verde }\end{array}$ & $X$ & $X$ & $X$ & & & & $X$ \\
\hline $\begin{array}{l}\text { Demonstrated in } \\
\text { Another Pilot }\end{array}$ & & & & & & X & \\
\hline
\end{tabular}

\subsection{Step 3, Analyze the current outage staffing deployment using human factors methodologies}

The purpose of this step was to collect and analyze information through a function and task analysis as described in the research plan introduced in Step 1. During this step a human factors analysis was conducted to define the information, communication and human performance requirements for outage tasks that support the functions of the OCC. Additionally, observation of the current OCC was used to identify ergonomic issues that should be designed out of the AOCC. Processes that were identified in Step 1 were given additional time, but the goal of this step is to characterize all the important interactions that support the functions of the OCC. 
Human Factors Engineering (HFE) is an established science that uses many disciplines (such as anatomy, physiology, physics, systems engineering, and ergonomics) to understand how people perform under different circumstances. A simple HFE definition is: the study of all the factors that make it easier to do the work in the right way. Another definition of human factors is the study of the interrelationship between humans, the tools and equipment they use in the workplace and the environment in which they work (Kohn, Corrigan and Donaldson, 1999).

This is a new approach in applying formal HFE methodologies to the design of an OCC. This approach will provide an OCC design that eliminates ergonomic issues, incorporates technology tools to assist the outage staff and optimizes outage staffing deployment. The various functions that the OCC must perform will be retained, but the methods to accomplish these functions (function allocation) may be changed utilizing technology. The staffing of the OCC should also be a consideration when reengineered, this is a methodical approach to determining who should be in the OCC and what they should be doing based on the increased use of technology for assistance.

\subsubsection{Results from observation of Palo Verde's spring 2013 outage}

INL research staff visited Palo Verde to observe outage activities during the weeks of April $1^{\text {st }}$ through the $4^{\text {th }}$ and April $15^{\text {th }}$ through the $19^{\text {th }}$. Additionally, staff from the Halden Reactor Project visited during the second week and INL staff served as escorts for the Halden researchers. The purpose of these visits was to gather data to support a function and task analysis of the OCC and to assess human factors aspects of the physical OCC layout.

Several data collection forms were utilized to record INL researchers' observations, document communication channels and to solicit information from Palo Verde staff. The use of both direct observation and interviews with staff was required to adequately characterize the outage activities, and communication channels should be viewed from both ends. Figure 2 shows an example of a completed observation form utilized to record outage activities. The use of a data collection form allowed information to be quickly collected allowing closer observation of the activities. 


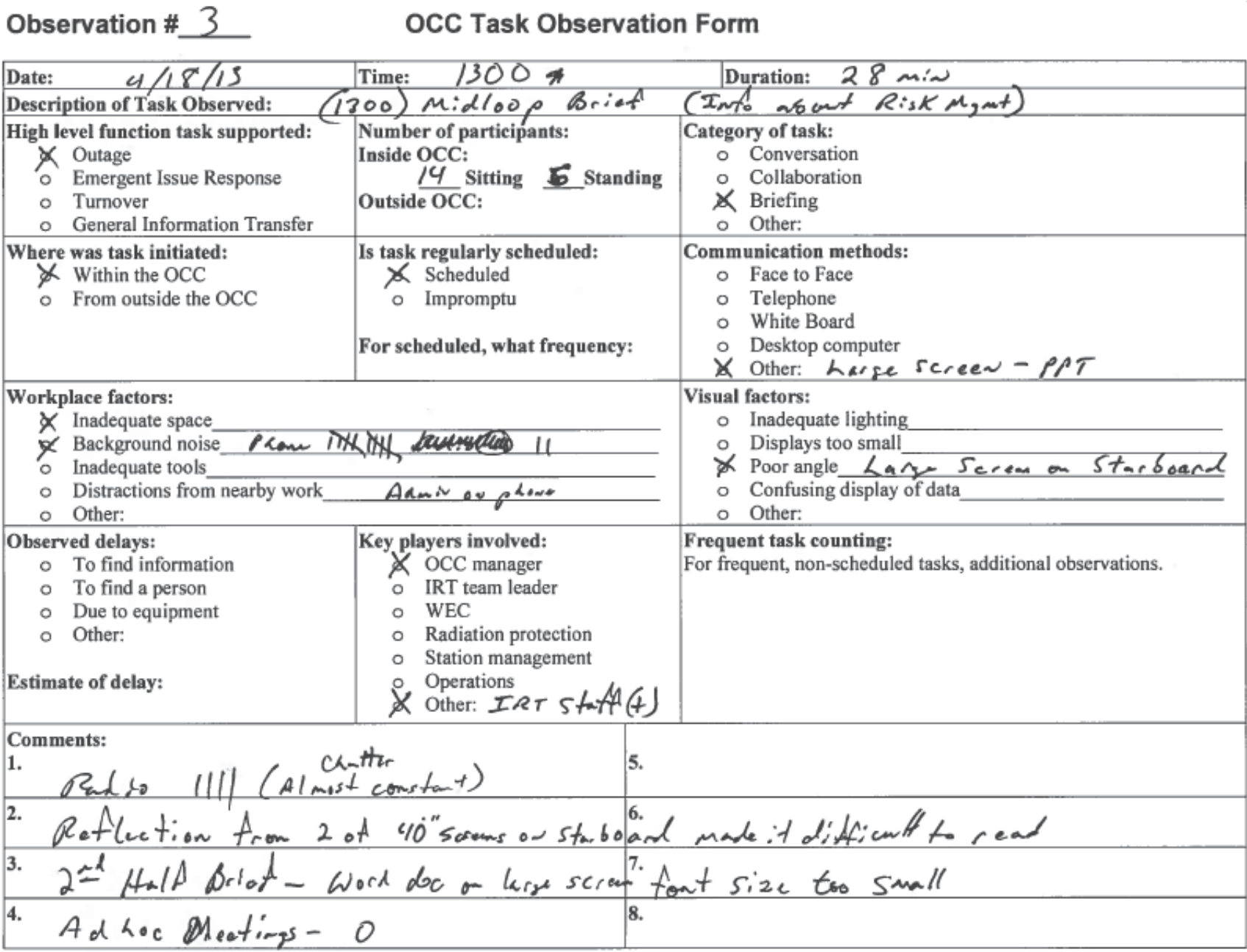

\section{Figure 2 Task Observation Form}

The results of the task observation forms are presented in Appendix B. This data will primarily be used to eliminate ergonomic issues in the AOCC design but also identified several areas where technology application would likely improve performance. Results of this analysis were used to create alternative OCC displays used in the demonstration scenarios created in step 4.

Communication between the various outage groups is essential for outage execution. Most of the OCC functions identified in step 1 are related to communication and information flow. One important data collection effort was to characterize the essential communication channels utilized during the outage. Figures 3 and 4 shows an example of a data collection form used to capture the interactions between the various satellite outage organizations and scheduled meetings. This form was used while interviewing various stakeholders across the outage organization. 


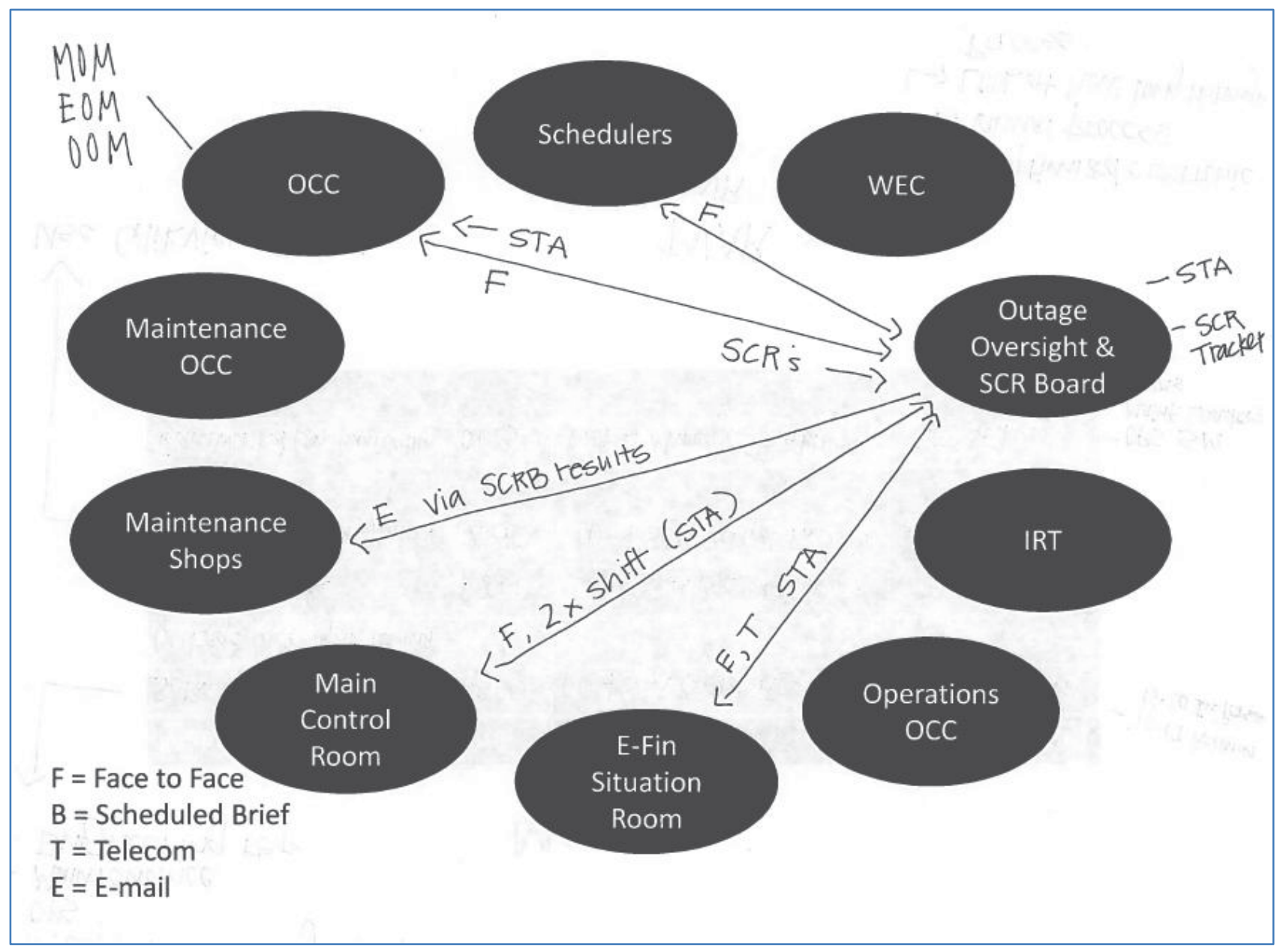

Figure 3 Outage Communication Form (Front) 


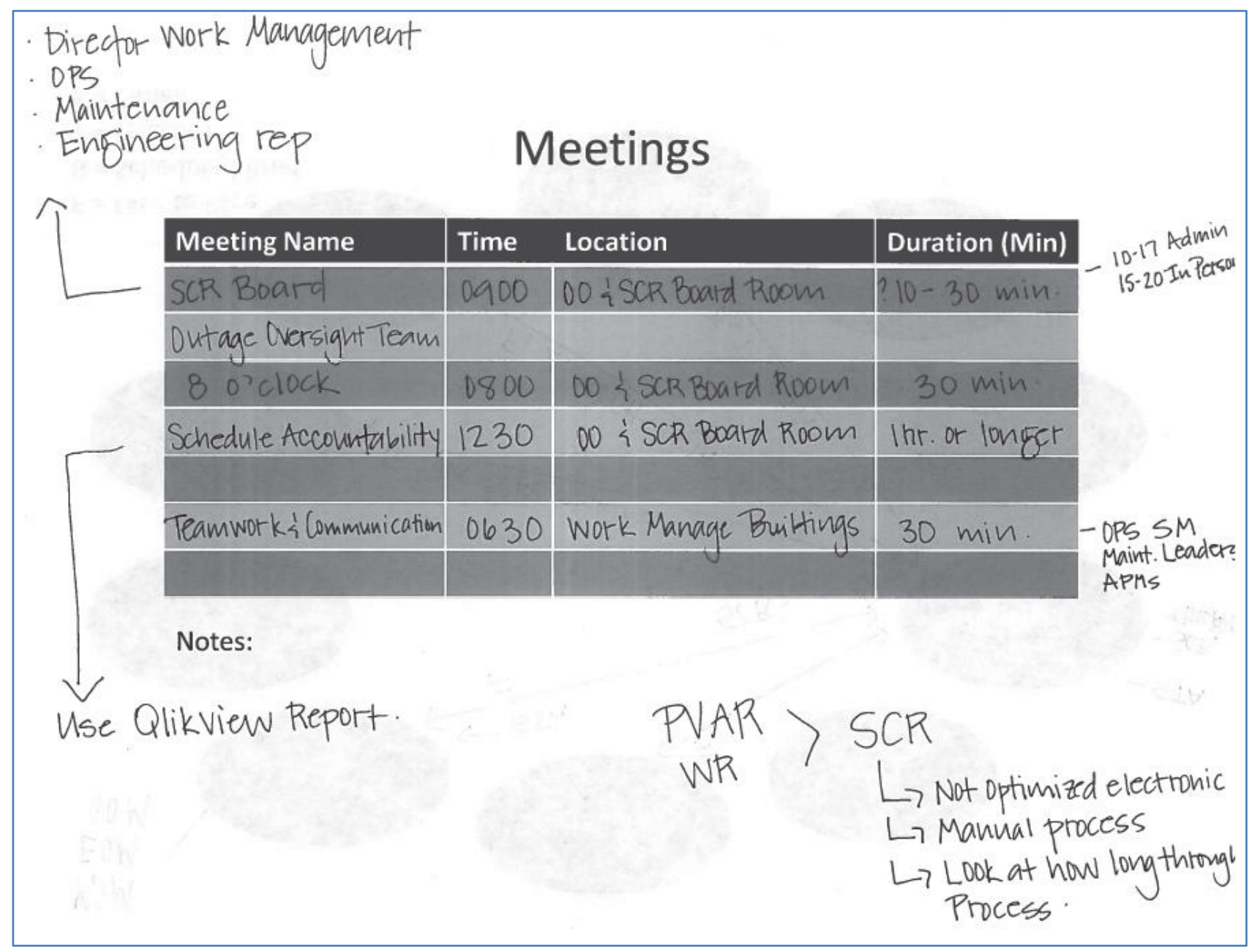

Figure 4 Outage Communication Form (Back)

For several key stakeholders, a communication survey was given to Palo Verde staff. Outage staff were left with the survey, which was later collected to allow them to fill is out without time pressure. Use of the survey in addition to direct observation of actual activities provides a complete picture of the required communications. An example of a completed communication analysis form is presented in Figures 5 and 6. 


\section{Outage Communication Analysis Form}

In the context of conducting plant outages, please identify and describe the following:

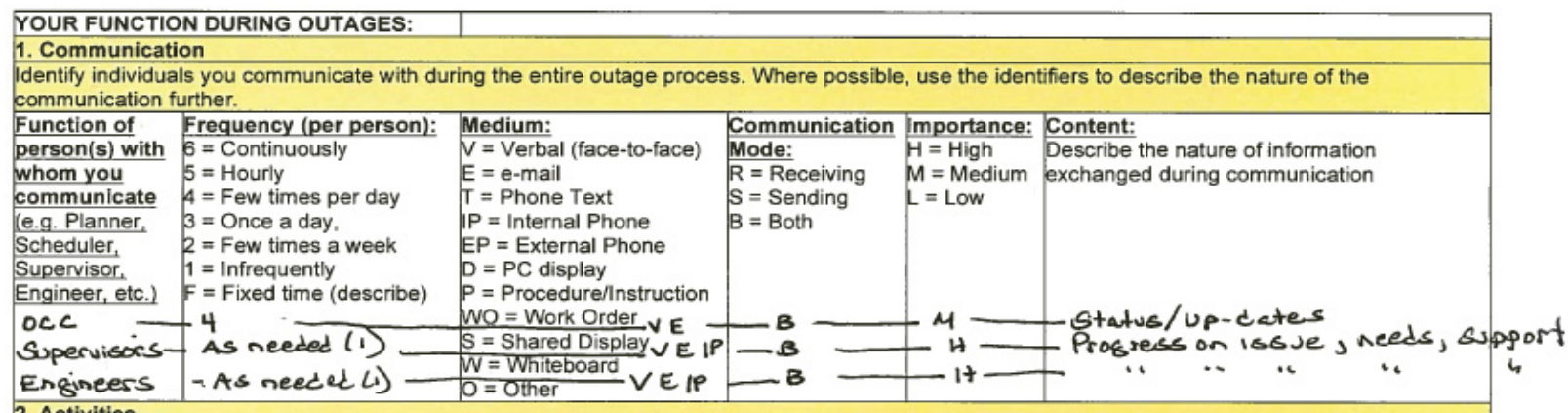

2. Activities

Provide a brief description of the main activities you Location:

perform during outage planning and execution (max List the $\quad$ List the tools or equipment you use to perform the activities listed (including one sentence, use keywords where possible) location(s)/Area(s) communication devices)

Issue Response Team where the activity

L PIt) is performed

$\begin{array}{lll}\text { Read } & \text { Read electionic ani, PItD, } \\ \text { procedores, etc } & \text { IRT ROOM }\end{array}$

Write Maintain electronic log

\begin{tabular}{|c|c|c|c|}
\hline Write & $\begin{array}{l}\text { Maintain electronic log } \\
\text { of incident responses }\end{array}$ & 11 & notes as needed electronic \\
\hline \multicolumn{4}{|l|}{$\begin{array}{l}\text { Visually } \\
\text { Inspect }\end{array}$} \\
\hline \multicolumn{4}{|c|}{ Manipulate } \\
\hline Monitor & $\begin{array}{l}\text { Monitor the assembled } \\
\text { teamis response to issue. }\end{array}$ & IRT ROOM & \\
\hline Observe & $\begin{array}{l}\text { Observe activitas in the } \\
\text { field as recessary. }\end{array}$ & $\begin{array}{l}\text { IAT ROOM/ } \\
\text { Field }\end{array}$ & \\
\hline Supervise & & & \\
\hline
\end{tabular}

Figure 5 Communication Analysis Form (Front) 


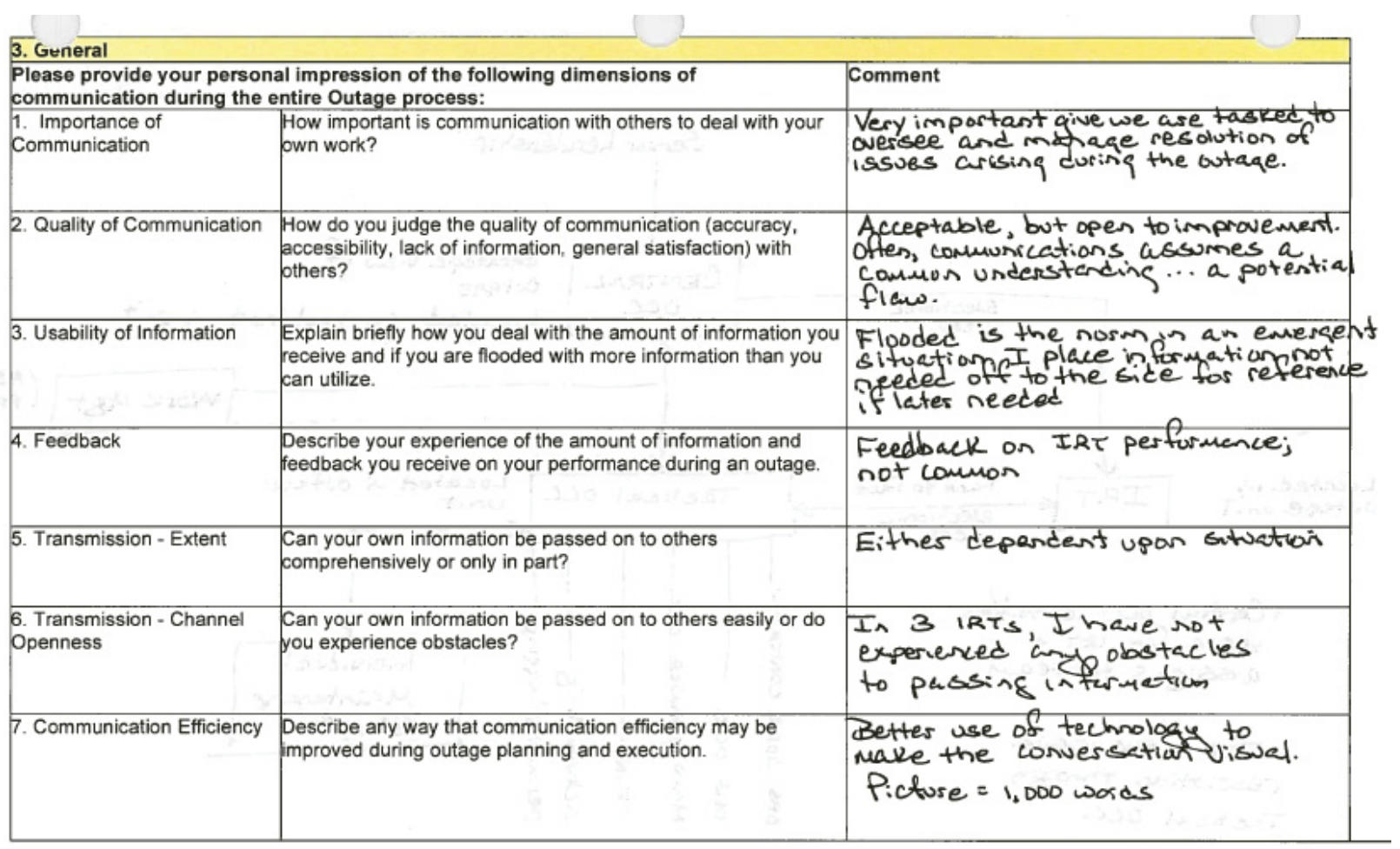

Figure 6 Communication Analysis Form (Back)

Using the information collected through these forms, an overall communication diagram was created. (See figure 7) This diagram will be used to group similar communication functions for evaluation of technology application, and is part of the function analysis. This diagram will also be useful if part of the decision in setting up an AOCC is where to locate the facility, this will be especially important for multiunit sites. While the overall communication diagram does not contain the details of each communication channel, this information is available on the data sheets. 


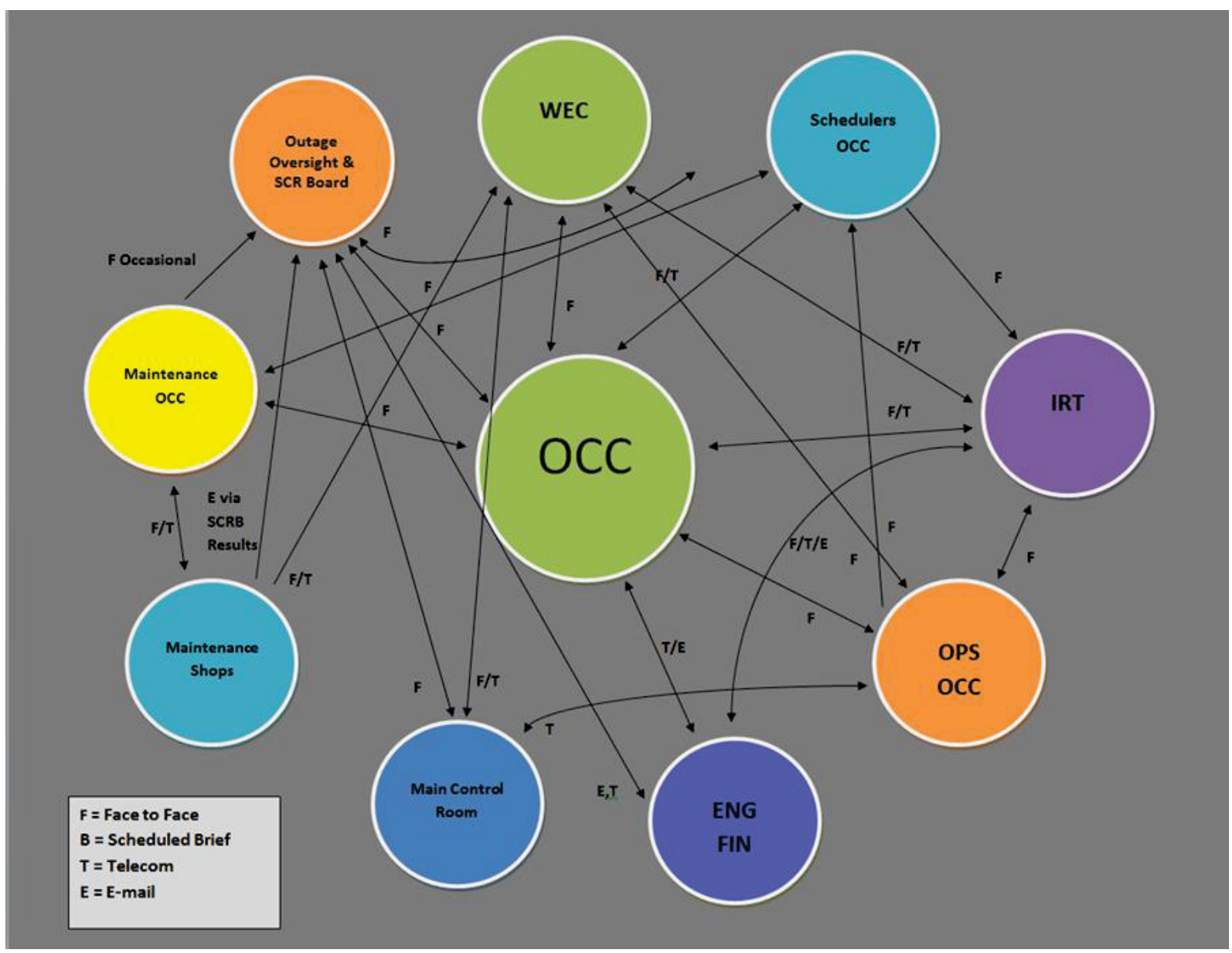

\section{Figure 7 Key Outage Communication Paths}

Another method of documenting the observed outage functions is the use of a process diagram. The process diagrams will be used to graphically show the current and proposed tasks to accomplish various outage functions. Figure 8 shows a simplified IRT process diagram including assignment of the issue by the Shift Outage Director (SOD). Based on observations made during the outage, tasks that are candidates for technology application are highlighted in yellow. These tasks primarily support the functions of collecting information, organizing information and communicating status. A more detailed version of the IRT process diagram is shown in Appendix C, again those tasks that where identified for potential technology application are highlighted in yellow. This information was used in step 4 to develop the technology enhanced tools for the IRT that are used and evaluated in the demonstration scenarios Additional process diagrams will be created for additional processes that are selected for function reallocation. 


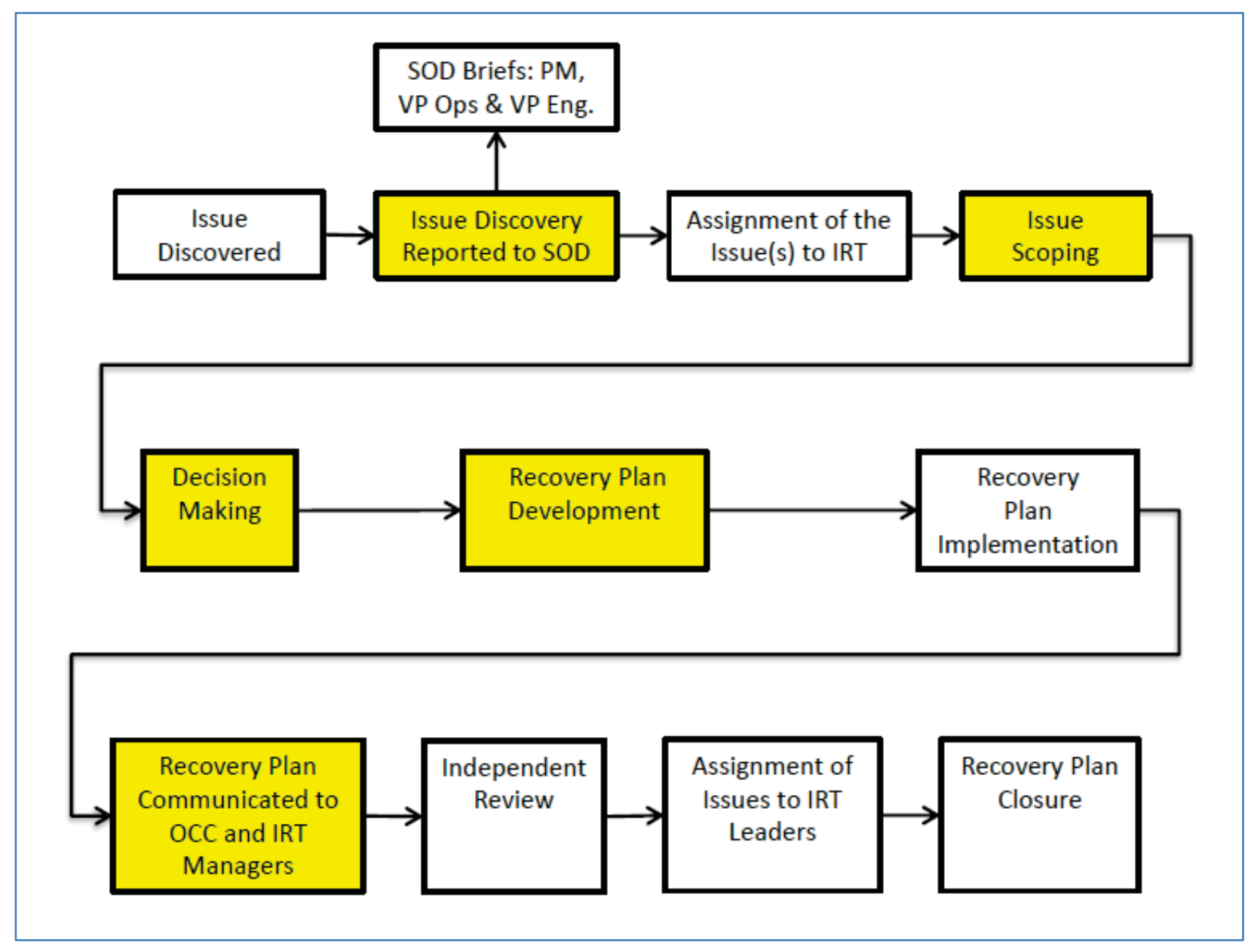

Figure 8 Simplified OCC-IRT process diagram

\section{Initial recommendations based on outage observations}

Based on the data gathered and observations made during the two spring 2013 outage visits, the INL research team identified several areas where the use of communication and collaboration technologies may benefit outage coordination activities. Initial potential applications of the technologies identified in step 2 are identified here, however further evaluation of the application of technology will be performed and documented in step 4. Summary of Observations:

1. Numerous OCC update briefs were observed. The following relate to these briefs.
a. Inadequate space/ difficult room configuration for briefing
b. Large number personnel in attendance
c. Distractions in briefing area
d. Lack of visual display of critical information

2. General observations of routine OCC activities. 

a. Minimum information transfer
b. Lack of knowledge capture
c. Collaborative technology
d. Other technology suggestions

3. IRT observations
a. Minimum information transfer
b. Lack of knowledge capture
c. Collaborative technology

\section{Inadequate space/ room layout}

Observations made by the INL researchers during Palo Verde outage briefings suggested a lack of necessary space hindered the outage briefing process. It was noted that the current briefing area was not intended for briefings, but rather served initially as a conference room. The current physical space is small and oddly shaped for use as a control center. Layout of the room limits both the optimal viewing conditions and the information exchange between key personnel.

There are numerous small scale collaborations that occur within the OCC. These meetings are vital and the OCC layout should better support them. Currently they are held in the space between the center island of workstations and the wall so that traffic must pass through the meetings. Additionally, there is no available desk space or wall space to support the use of visual aids for collaboration during these meetings.

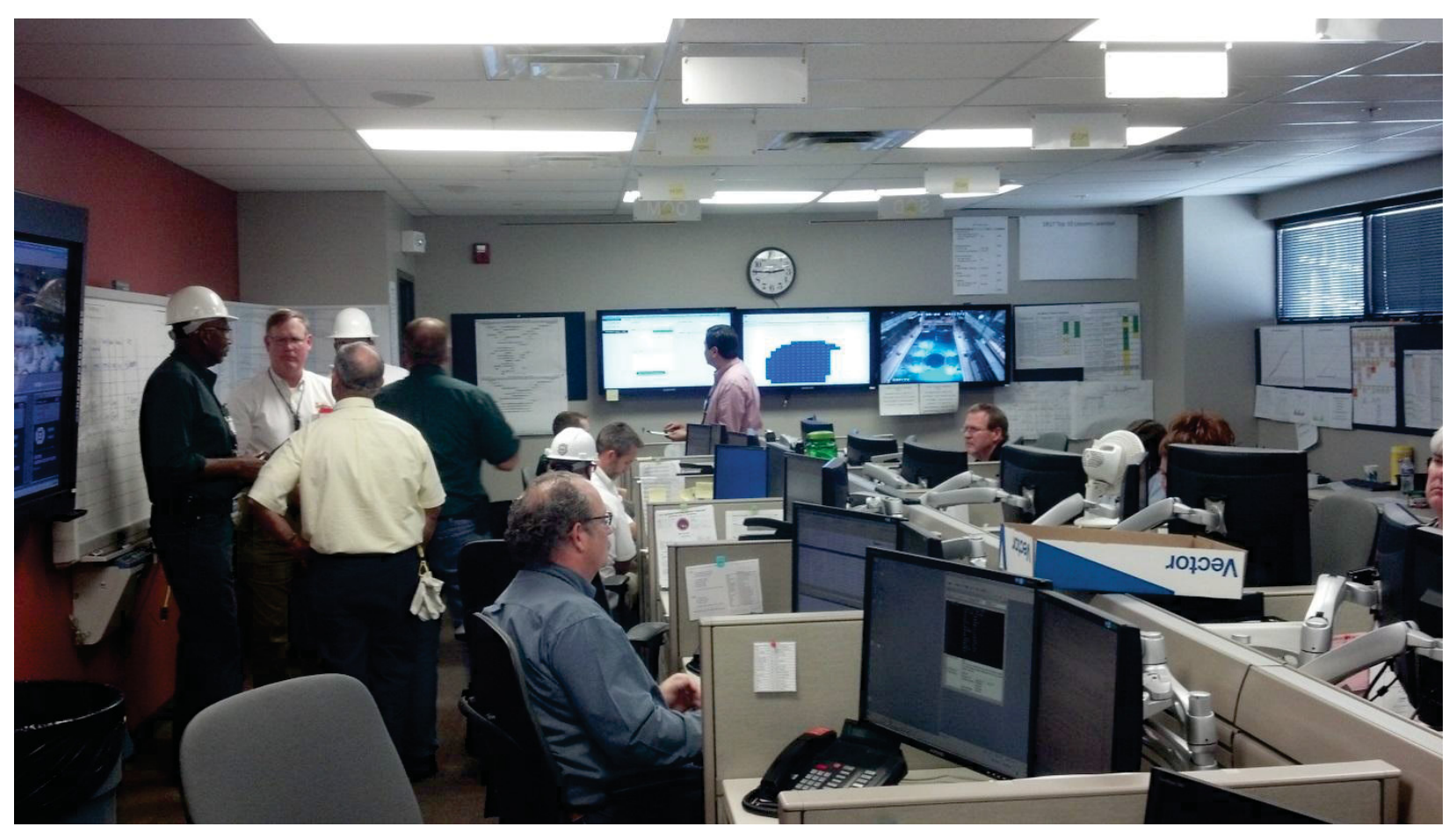

Figure 9 Current OCC layout 


\section{Large number of personnel in attendance}

A large number of outage personnel attended the briefings with a range between 17 and 34 individuals. Of the 34 individuals attending the briefing with the greatest room capacity, 19 of those individuals were standing (See Appendix B). It may be valuable to analyze how these numbers affect critical information exchange. Additionally, it may be beneficial to identify and distinguish between the crucial core personnel required and the small group of personnel who would serve best to be relocated nearby. Personnel relegated to this second group may be available for clarification or further discussion following the briefing. Proposed redesigns to the Palo Verde briefing area could afford smaller conference rooms for such relocation. An AOCC would benefit from several small, private areas with collaboration tools to facilitate these meetings while keeping the overall noise level in the AOCC to a minimum.

While these routine briefings are relied upon to share information, more efficient methods may be available to process information inflow and outflow. These briefing occur every three hours, have an average attendance of 25 persons and with travel time take approximately 30 minutes to attend. The daily resource cost of these briefing is 100 staff hours per day, or 3,000 staff hours during a typical outage. Use of technology could reduce the number of persons attending the brief, reduce the duration of the briefs and reduce the required frequency of these briefs. The use of real time or recorded streaming of briefings or mobile alerts as described in step 2 are candidates for technology application.

\section{Distractions}

INL researchers observed and recorded numerous distractions during the briefings including as many as seven calls received during the outage briefings (See Appendix B). While the administrative assistant worked well to answering them quickly and talk quietly, the calls still pose a significant distraction. These distractions may impede the flow of communication leading to either failure of intended information delivered or misinterpretations by either party. It may be effective to modify the current system such that the phone displays incoming calls visually rather than audibly when the OCC is in the process of briefing. Additionally, an outgoing message could instruct callers that a briefing is in process and prompt callers to leave a recorded message for non-emergency situations.

\section{Lack of Visual Display of Critical Information}

Researchers from INL noted that large format touch boards and similar technology present in the OCC were not routinely employed during the outage briefings. Rather, one of three presentation types was employed. First, large pieces of white paper with information displayed in font too small for the researchers to read were taped or otherwise secured at the front of the room. Information was also displayed via Power Point presentation for one special evolution, but not used during routine briefs. Information was primarily presented verbally with no visual information accompanying the briefing.

These types of information presentation may impede information flow. For the two visual displays, the information is static and out of date as soon as it is printed out for the briefing. For those presenters who routinely share detailed data via verbal briefing, such as Nuclear Safety and Radiological Safety, the use of visual displays would improve communication. Indeed for all strictly verbal briefing, it may be valuable to consider significant research data indicating that visual information is processed significantly more effectively than audible information. Specific parts of the brain are activated with visual images, allowing individuals to store detailed visual information in their working memory (Sciencedaily.com, 2012).

The INL team proposed a more dynamic system of information display using large format multitouch technology. These displays feature a variety of screens displaying a range of current and critical outage information. As new information is received, the screens change in real time to reflect status changes and newly acquired data. 
Few, if any, of the OCC personnel present knew how to use the large, interactive displays available. Currently it is not within the procedures to learn how to use them, there is no training to help employees learn how to use it, and no system experts have been brought in to demonstrate the use of the system. Training for any installed technology is a critical step for improving outage briefings. It would be valuable to adopt a policy for future technology and equipment as well, with an appointed Subject Matter Expert (SME) present until knowledge transfer regarding the new tool is captured.

Additionally, it may prove effective to create a template for the presentation of visual information during the briefing. Each group in attendance would have the ability to feed data to the administrator in order to present the current and updated information visually at each briefing.

Based on these observations, improved OCC information displays utilizing large multi-touch boards where developed for further evaluation in step 4. These displays are integrated into the demonstration scenarios, and will be investigated further for plant implementation.

\section{Minimum information transfer}

The whiteboards and sheets of paper displayed during briefings are ineffective methods of information transfer. White boards are written and rewritten with data and the information remains within the briefing area, rather than distributed throughout the facility. The paper sheets remain in the OCC as well with no transfer of information. Capturing and presenting information electronically would facilitate the sharing of information through remote displays, remote participation in briefs and electronically sharing documents through email. The use of collaboration technology could allow sharing the information presented in the brief with a larger audience, either real time or through a packaged summary of the meeting posted to the network shortly after the meeting.

Based on these observations, templates for displaying and capturing this same information via a large format multi-touch display were created for further evaluation in step 4 .

\section{Lack of knowledge capture}

The whiteboards and sheets of paper displayed in the OCC and IRT team rooms are ineffective methods of knowledge capture. White boards are written and rewritten with data and the information is not retained. The paper sheets remain in the OCC as well with no transfer of information. The use of large format multi-touch displays would allow all entries made to be retained for future reference. The details of how an issue was resolved may help future outage managers. At the end of the outage, an electronic package of all the issues tracked during the outage could be bundled and archived.

The same templates for information display created above would also facilitate the storage of this information for future use.

\section{Collaborative Technology}

There are numerous, regularly scheduled meeting that require participants to travel from their normal work locations to another satellite control center. The use of collaboration technology could allow these meetings to take place remotely and save transit time and the disruption in work flow required to attend. Remaining in their normal work location could also reduce the body count and noise level in the OCC. The use of 3 OCCs may not be required if greater use of collaboration technology was implemented. A new, common OCC could be constructed that was designed to utilize technology to support outage management. The current OCCs could remain in case of a forced outage at a running unit while another unit is in an outage. A new OCC could be designed to eliminate the human factors issues with the current OCCs. There are quite a few people stationed in the OCC who do not seem to have a high level of interaction on a continual basis. The use of collaboration technology could allow these 
people to perform their work at their normal work location and connect to the OCC only when information is needed.

\section{Other technology suggestions}

The use of Qlikview software shows promise. Qlikview is a software application used at Palo Verde to visually display schedule issues such as work that has started late or has not finished on time. There is a wide gap in knowledge regarding the use of the tool among users. The software itself could benefit from some relatively simple modifications such as the ability to drill down into work activities without having to go to another application. Additionally, several staff members indicated that the Scope Change Request process still relies on processing paper documents and could be streamlined and enhanced through an electronic process.

\subsection{Step 4, Evaluate select potential technology applications based on function analysis}

In order to minimize the risk of unnecessary capital investments, trials of technologies that look promising for OCC application should be tested prior to large scale deployment. These tests are to verify both the technology and its application within the process. It has been seen numerous times in the past that simply placing technology in a room will not guarantee its use, and if attempts are made to utilize new equipment without training or familiarity poor results are often encountered. Poor experiences with technology deployment will likely increase user resistance to future technology improvement projects and delay the probable benefits that could have been realized by proper execution. The purpose of this step is to verify that potential technology applications identified in the previous steps can be effectively implemented in actual use. Processes identified by the function analysis may be grouped by their similar attributes and a representative process selected for evaluation during this step. If the application of technology is proven effective during this step, it may be applied to similar processes.

For this pilot project, it was decided that the development of scenarios based on actual plant events would be an effective method of evaluating the relative benefits of technologies under consideration compared to current practices. To allow INL staff to conduct research on proposed methods and technologies on a development test bed that is not intrusive to the plant, equipment was installed in INL's Human Systems Simulation Laboratory (HSSL). It is believed that embedding new technologies in existing processes will increase the acceptance and usage of the new equipment. For this pilot demonstration, the emergent issues resolution process was selected for study. The IRT was selected based on the function and task analysis performed in step 3. Initial evaluation of the IRT process indicated it would likely benefit from the addition of advanced communication and collaboration technology. To assist in the integration of the new technologies, templates for use by the IRT where developed to create a standardized format for displaying and communicating the status of emergent issues. After the evaluation in the INL's HSSL, these same scenarios will be used to help familiarize Palo Verde staff with the use of the equipment prior to actual use. It is believed that since the scenarios are based on recent operating experience, it will provide a more relatable experience than just running through equipment functions. The templates created for the INL HSSL demonstrations will be given to Palo Verde staff for use during the fall 2013 outage for evaluation. 


\subsubsection{Demonstration scenarios utilizing the INL Human Systems Simulation Laboratory (HSSL)}

Communication and collaboration technologies have been assembled in the INLs HSSL to assist in the evaluation of AOCC concepts. Two large format multi touch panels by SMART technologies are utilized to represent the OCC and the IRT team room. The SMART boards can interact with each other, with desktop computers and with tablet computers through SMART technologies Bridgit ${ }^{\mathrm{TM}}$ collaboration software. While these products were selected for the INL demonstration, alternative large format touch displays and collaboration software may also be used to accomplish the same tasks. A mockup of a valve station will be used to represent an emergent issue discovered in the field. Tablet computers will be utilized for mobile worker technologies and a WiFi network established to facilitate remote communication.

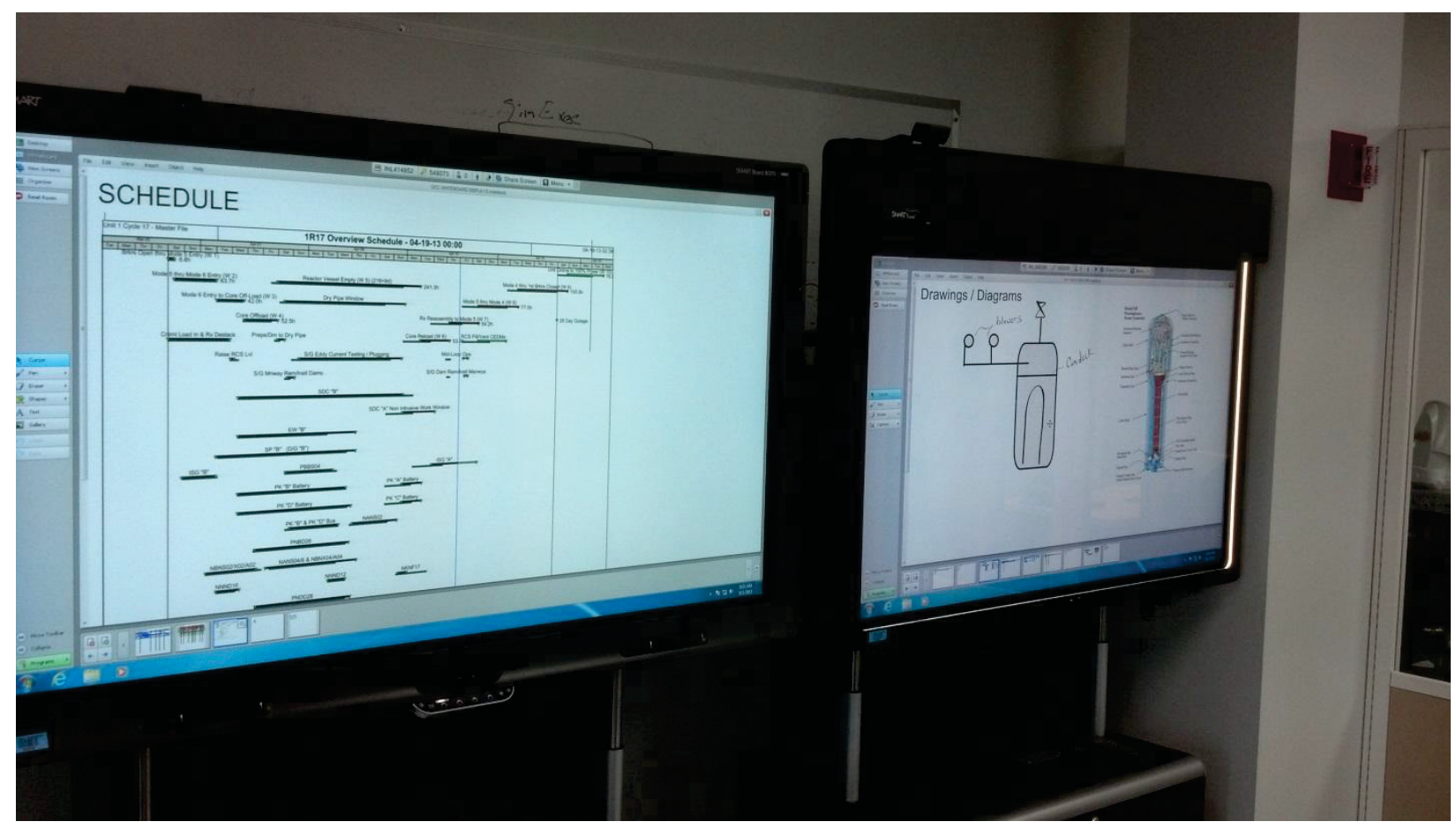

\section{Figure 10 INL HSSL OCC equipment}

Two scenarios were initially created to evaluate the initial selection of collaboration and communication technologies and to allow comparisons to be made between current methods and proposed methods of task accomplishment. The demonstration also included several examples of AOCC displays that may be used to more effectively present current status and support routine briefings.

The use of the HSSL to perform these demonstrations provided an additional use for the purposes of this method development. Since most plant do not yet have the required IT infrastructure to implement all the potential AOCC functions described in section 2.2.3, use of the HSSL allows for an evaluation of how these advanced functions might be integrated. Implementation of an AOCC need not wait for implementation of all the enabling technologies, but consideration for future capabilities should be built into the design to prevent rework in the future as additional capabilities are added. 
The demonstration scenarios including a comparison of current and proposed methods are presented in Appendix D.

\subsubsection{Demonstration scenarios at Palo Verde}

After these scenarios are demonstrated for Palo Verde staff at the INL, portions of the scenarios related to the IRT will be utilized to train and familiarize IRT staff at Palo Verde with the use of the new tools. The templates created for the INL demonstrations may be used as starting point for IRT staff in building a standardized issues resolution package that will facilitate status updates and improve knowledge management for future outage work. Demonstrations at Palo Verde will be performed just before the start of the fall 2013 outage to serve as just in time training for personnel scheduled to staff the IRT during the outage.

\subsubsection{Implementation of technology for evaluation at Palo Verde during the fall 2013 outage.}

Based on initial evaluations performed at the INL and observations of spring 2013 Palo Verde outage the IRT was selected for initial technology deployment. To support the evaluation of the technology, a large format multi-touch board and supporting collaboration software will be installed in the IRT team room and the OCC. Templates for a standardized issues resolution package will embed the technologies into the processes to help ensure the utilization of the technology. INL staff will assist with the initial use of the equipment and evaluate its effectiveness. Evaluation of the technology deployment will be accomplished via staff interviews, direct observation and follow-up surveys of IRT staff members. The OCC display may also be utilized to enhance OCC update briefings or to support remote communication with Palo Verde management.

\subsection{Step 5, Determine to what extent functions should be reallocated utilizing technology}

This step in the process will re-evaluate the organizational structure of the outage staff stationed in the OCC. Based on function and task analysis performed in steps 1 and 3 and evaluations of the communication and collaboration technologies performed in step 4, a function reallocation analysis will be performed. This step will determine how AOCC should be performed with certain tasks reallocated utilizing technology. It is expected that with improved access to real time status and improved remote communication and collaboration options that some staff currently stationed in the OCC will be allowed to work out of their normal work station and still support the OCC functions. The results of this analysis will document the justification for revised staffing in the AOCC design that will be performed in step 6. Detailed methods for performing this analysis have yet to be developed. Work on this task will be performed in FY 2014. 


\title{
2.6 Step 6, Develop a new physical OCC layout based on function reallocation, technology integration and human factors considerations
}

\begin{abstract}
Based on the function reallocation performed in the above step, a new OCC layout can be designed. The new OCC layout will be designed to maximize the effectiveness of the communication and collaboration technology and allow for effective monitoring of real time outage status. Technology requirements for the $\mathrm{OCC}$ will depend on the level of function reallocation determined in previous evaluation. Human factors considerations will be made for the physical layout to ensure optimal Human Machine Interface (HMI). For this pilot project, INL will work with the Halden Reactor Project utilizing the HVRC CREATE software to evaluate layout options. The HVRC CREATE program allows for interactively designing and testing room and environment layouts from a human-centered perspective. Initial layout designs by INL staff will be provided to Halden staff for evaluation using the HVRC CREATE software for evaluation and optimization. Details related to the implementation within the framework of the methodology have yet to be developed. Work on this task will be performed in FY 2014.
\end{abstract}

\subsection{Step 7, Analyze the effectiveness of the new arrangement and make necessary adjustments}

Following any modifications to the organizational structure, technology deployment or OCC physical layout, a follow up analysis should be performed to evaluate the results. The baseline data collected during the initial organizational studies can be used to evaluate the effectiveness of changes. Initial evaluations may be useful for making minor adjustments, but the final judgment of the success of the implementation should not be made until some period of adjustment has passed. Initial issues with technology utilization and acceptance should improve with experience and the full benefits of the AOCC may not be initially realized during the learning process. For the purposes of this pilot demonstration, this step would occur outside of the scope of this project. For the technical report, recommendations for evaluating the effectiveness of the implementation will be provided.

\section{DISCUSSION AND CONCLUSIONS}

The initial results of the research effort to date were to create a methodology for establishing an AOCC that is specifically designed to maximize the usefulness of communication and collaboration technologies for outage coordination and problem resolution activities. This methodology is being refined through application at Palo Verde, the utility partner for this research. Specific conclusions for the work done to date at Palo Verde are presented in section 2.3.1. Various technologies have been evaluated on a trial basis and show considerable promise for AOCC application. This study is currently in progress at step 4 in the methodology and is expected to continue through FY 2014. Based on the work performed to date, it is apparent that NPP outage coordination still has room for improvement. One area for improvement is the physical OCC itself. Current OCCs typically have not taken advantage of advances in communication and collaboration technologies. These communication and collaboration technologies will allow a reallocation of tasks and personnel that will allow for more efficient outage staffing and execution. This research project has developed a methodology for implementation of an AOCC. The methods presented for assessing a current OCC could also be used to find areas for outage management improvement even if a new physical OCC is not desired. 
The proposed methodology is currently being refined through its application at the Palo Verde NPP. Initial indications are that the methodology will provide a structured, informed basis for task reallocation and provide an AOCC that is able to take advantage of communication and collaboration technologies. Additionally, the AOCC will be physically designed with human factors considerations such as minimizing distractions, optimum use of visual displays and adequate work space. At the conclusion of the project, the research team will publish a guidelines document for industry wide implementation of the AOCC.

\subsection{Path forward}

Moving forward, the research team will continue following the proposed methodology described above. Prior to Palo Verdes fall outage, equipment should be installed to evaluate its use in support of the IRT. The research team will utilize the demonstration scenarios to assist in familiarizing IRT staff with the use of the equipment and to finalize the design of the emergent issues templates. The research team will then evaluate the use of the technology during the fall outage. Based on the results of the initial implementation, an evaluation will be made to determine what other processes technology should be applied to in a larger scale evaluation for the 2014 spring outage. Additionally, work will begin on developing new physical layout options integrating technology and human factors considerations. Based on further evaluations of application of communication and collaboration technologies to the function and task analysis, recommendations of OCC staffing will be made. After proposed task reallocations based on technology upgrades, a final AOCC physical layout will be recommended. Finally, a technical report for implementation of an AOCC by industry will be published. 


\section{REFERENCES}

Droivoldsmo, A. et al. (2012). IO MTO Handbook (Draft). OECD Halden Reactor Project. Halden, Norway.

Farris, R.K. (2012).Human Performance Improvement for Field Workers - Automated Work Packages. INL/MIS-12-26863. Idaho Falls, Idaho National Laboratory.

Farris, R.K., \& Medema, H.D. (2012). Advanced Instrumentation, Information and Control (II\&C) Research and Development Facility Buildout and Project Execution of LWRS II\&C Pilot Project 3 (INL/MIS-12-25139). Idaho Falls, Idaho National Laboratory.

Farris, R.K. and Weatherby, G.D. (2011). Advanced Instrumentation, Information and Control (II\&C) Research and Development Facility Buildout and Project Execution of LWRS II\&C Pilot Projects 1 and 3. INL/EXT-12-23410. Idaho Falls, Idaho National Laboratory.

Kohn LT, Corrigan JM, Donaldson MS, eds. To err is human - building a safer health system. Washington, DC, Committee on Quality of Health Care in America, Institute of Medicine, National Academy Press, 1999.

Le Blanc, K.L. (2012). DOE LWRS. Computer-based procedure mock-up. INL/MIS-12-26424. Idaho Falls, Idaho National Laboratory.

Le Blanc, K.L. and Oxstrand, J.H.. (2012). DOE LWRS Computer-Based Procedure Project Successful study at Palo Verde Nuclear Generating Station. INL/MIS-12-27159. Idaho Falls, Idaho National Laboratory.

O'Hara et. al. (2004). Human Factors Engineering Program Review Model. NUREG/CR-0711. U.S. Nuclear Regulatory Commission. Washington, D.C.

Weatherby, G.D. \& Tawfik, M.S. (2012). Advanced Outage and Control Center: Strategies for Nuclear Plant Outage Work Status Capabilities. INL/EXT-12-26197. Idaho Falls, Idaho National Laboratory.

Why People Can Hold Visual Information in Great Detail in Their Working Memory. www.ScienceDaily.com, Retrieved February 6, 2012. 
Appendix A

Research Plan 
Research Plan

\section{Advanced Outage Control Center - LWRS Pilot Project Palo Verde Nuclear Generating Station}




\begin{abstract}
A Human Factors Engineering (HFE) study is being conducted as part of the Department of Energy (DOE) Light Water Reactor Sustainability (LWRS) project at Palo Verde Nuclear Generating Station (PVNGS). The study results will provide a baseline analysis of the required functions and tasks currently performed in the Outage Control Center (OCC). The results of this analysis will be used to evaluate alternative methods of performing these functions utilizing advanced communication and collaboration technologies. Additionally, the results of this study will be utilized in the design of Human-System Interfaces (HSIs) and an optimized physical layout for an Advanced Outage Control Center (AOCC) in accordance with generally accepted HFE guidance and criteria. Additional focus will be placed on evaluating PVNGS's emergent issues process through the use of the Issues Response Team (IRT). The IRT deals with complex issues requiring high levels of communication and collaboration. Any improvements that may be made to this process could be expanded to numerous other processes and interactions between outage stakeholders. This document, a formal research plan, provides tools and techniques to be used for the first phase of pilot project: Task and Function Analysis for a nuclear power plant OCC with a focus on the IRT.
\end{abstract}




\begin{tabular}{|c|c|c|c|c|}
\hline & & Print or Type Name/Organization & Signature & Date \\
\hline Performer/Author & $\mathrm{N} / \mathrm{A}$ & Ronald K. Farris & & \\
\hline Principal Investigator & $\mathrm{N} / \mathrm{A}$ & Shawn W. St. Germain & & \\
\hline Reviewer 1 & $\mathrm{R}$ & David I. Gertman & & \\
\hline Reviewer 2 & $\mathrm{R}$ & Ronald L. Boring PhD & & \\
\hline Approver & A & Kenneth D. Thomas & & \\
\hline Approver & A & Bruce P. Hallbert & & \\
\hline
\end{tabular}




\section{CONTENTS}

1. INTRODUCTION ERROR! BOOKMARK NOT DEFINED.

2. PURPOSE ERROR! BOOKMARK NOT DEFINED.

2.1 PRIMARY OBJECTIVE ERROR! BOOKMARK NOT DEFINED.

2.2 SECONDARY OBJECTIVES 38

\section{BACKGROUND ERROR! BOOKMARK NOT DEFINED.}

4. STUDY METHODOLOGY ERROR! BOOKMARK NOT DEFINED.
4.1 STUDY PREPARATION AND PLAN ERROR! BOOKMARK NOT DEFINED.
4.2 ANALYSIS TECHNIQUES 40
4.2.1
4.2.1.1
Overview
Error! Bookmark not defined.
Naturalistic Observation Error! Bookmark not defined.
4.2.1.2
Interviews Error! Bookmark not defined.
4.2.1.3
Focus Groups Error! Bookmark not defined.
4.2.1.4
4.2.1.5
4.2.1.6
4.2.1.7
4.2.1.8
4.2.1.9
4.2.1.10
Process Mapping Error! Bookmark not defined.
Task Performance Time Estimates Error! Bookmark not defined.
Performance Shaping Factor Analysis Error! Bookmark not defined.
Functional Analysis Error! Bookmark not defined.
Task Analysis Error! Bookmark not defined.
Communication Link Analysis Error! Bookmark not defined.
Operational Sequence Analysis (OSA)Error! Bookmark not defined.

5. ANALYSIS AND RESULTS ERROR! BOOKMARK NOT DEFINED.

5.1 2-D AND 3-D GRAPHIC MODELING ERROR! BOOKMARK NOT DEFINED.

5.2 VIDEO RECORDING ERROR! BOOKMARK NOT DEFINED.

5.3 REQUIREMENTS PERTAINING TO THE USE OF HUMAN SUBJECTS ERROR! BOOKMARK NOT DEFINED.

6. REFERENCESERROR! BOOKMARK NOT DEFINED.

7. APPENDICES ERROR! BOOKMARK NOT DEFINED.

7.1 Appendix A - Naturalistic Observation Data Collection SheEt ERror! BOOKMARK NOT DEFINED.

7.2 APPENDIX B - PERFORMANCE SHAPING FACTOR ANALYSIS ERROR! BOOKMARK NOT DEFINED.

7.3 APPENDIX C - OCC TASK OBSERVATION FORM ERROR! BOOKMARK NOT DEFINED.

7.4 APPENDIX D - COMMUNICATION LINK ANALYSIS DIAGRAM ERROR! BOOKMARK NOT DEFINED.

7.5 APPENDIX E - OUTAGE COMMUNICATION ANALYSIS ForM ERROR! BOOKMARK NOT DEFINED.

7.6 APPENDIX F - OPERATIONAL SEQUENCE DiAgRAM EXAMPLE ERROR! BOOKMARK NOT DEFINED. 
Appendix A - Research Plan

\section{REVISION LOG}

\begin{tabular}{|l|l|l|l|}
\hline Rev. & Date & Affected Pages & Revision Description \\
\hline & & & \\
\hline & & & \\
\hline & & & \\
\hline & & & \\
\hline & & & \\
\hline & & & \\
\hline & & & \\
\hline & & & \\
\hline & & & \\
\hline & & & \\
\hline & & & \\
\hline & & & \\
\hline
\end{tabular}




\section{ACRONYMS}

AOCC Advanced Outage Control Center

FA Functional Analysis

HF Human Factors

HFE Human Factors Engineering

HSI Human-System Interface

HSSS Human Systems Simulation Laboratory

I\&C Instrumentation and Control

INL Idaho National Laboratory

IRB Institutional Review Board

IRT Issue Response Team

LWRS Light Water Reactor Sustainability

NPP Nuclear Power Plant

NRC Nuclear Regulatory Commission

OCC Outage Control Center

OE Operating Experience

OSA Operational Sequence Analysis

OSD Operational Sequence Diagram (method)

PVNGS Palo Verde Nuclear Generating Station

PSF Performance Shaping Factors

SME Subject Matter Expert

TA Task Analysis

WEC Work Execution Center 


\section{INTRODUCTION}

To create a baseline for research activities related to the development of an Advanced Outage Control Center (AOCC), the Light Water Reactor Sustainability (LWRS) research team from the Idaho National Laboratory (INL) will perform a function and task analysis of the Outage Control Center (OCC) at the Palo Verde Nuclear Generating Station (PVNGS). The focus will be on the information flow into and out of the OCC as well as the internal communication and collaboration within the OCC. The OCC has very limited direct access to information and must rely on accurate and timely reports to succeed in keeping the outage on schedule. The OCC also provides a central location for representative from many different departments to collaborate on issues that may impact successful outage completion. Special emphasis will be placed on the function of the Issues Response Team (IRT) as this process requires intense communication and collaboration. Large amounts of outage and plant-related information including safety information, and proof of adherence to technical specifications and plant procedures that must be processed by the OCC, Work Execution Center (WEC), the IRT and field workers. Leaders in these work centers are challenged to provide accurate work status by the limitations of communication capabilities presented by the current infrastructure and physical barriers that exist within a nuclear power plant. Additionally, during outage execution, a delta often exists between the "known work status" and the "actual work status", inhibiting decision-making by the work center leaders. The increased use of technology has shown to reduce cost and improve efficiency in many various industries, in particular the oil and gas industry. Some of the technologies that have been evaluated for use in nuclear power plant operations include computer based procedures, plant wide wireless networks, mobile worker technologies, electronically coded plant equipment and the increased availability of electronic plant parameter data. The goal of this pilot project is to develop processes and methods for utilizing these technologies to improve the communication and collaboration capabilities of the OCC and to develop guidance for the implementation of an AOCC, that is designed to maximize the effectiveness of these communication and collaboration tools from a Human Factors Engineering (HFE) perspective. The use of some of these technologies will have some small benefit to the utility when implemented individually, but larger gains will be realized when the technologies are developed and leveraged together. It is expected that the results of this research will used to effectively implement these technologies with an eye towards future capabilities and the integration of these technologies for maximum effectiveness.

This Research Plan presents the methods used to collect and analyze data that will be used to evaluate the effectiveness of various communication and collaboration technologies and to make recommendations to the nuclear utilities, that will enhance their current processes and conceptual design of future outage work centers designed to maximize the effectiveness of all of the various technologies being evaluated to support plant operations.

\section{PURPOSE}

The purpose of this document is to summarize the research approach for the first phase of the AOCCLWRS research pilot project at PVNGS.

\subsection{Primary Objective}

The primary objective of this study is to improve outage performance through a methodical implementation of technology improvements in the OCC that are deployed to take advantage of both currently available and future technology driven capabilities. This object is supported by conducting human factors analyses that will define the information, communication, and human performance 
requirements for outage tasks that support the required functions an OCC performs.

\subsection{Primary project tasks}

The following tasks were formulated to support the primary objective:

1. Review operating experience (OE) related to IRT activities to determine challenges utilities are faced with while addressing emergent issues.

2. Perform a Function Analysis of the OCC to identify requirements and key process functional elements for effective outage schedule implementation.

3. Observe work activities performed in the OCC and dedicated outage support centers, especially the IRT.

4. Identify and record stressors upon the OCC and IRT personnel such as ergonomics, work cycles, task duration, workload imposed by tool and workplace characteristics and work practices that have the potential to increase physical and mental workload.

5. Collect information that will be used to develop scenarios for the purpose of capability demonstration using the INL Human Systems Simulation Laboratory (HSSL).

6. Utilize insights gained to create a 2-D and/or 3-D model of an AOCC designed to take advantage of technology improvements being considered.

These steps encompass many of the best human factors design practices from the nuclear industry as outlined in NUREG-0711(O'Hara et. al., 2004).

\section{BACKGROUND}

Nuclear power plant (NPP) refueling outages create some of the most challenging activities the utilities face in both tracking and coordinating thousands of activities in a short period of time, and occur in a short period of time, usually twenty to thirty days. Outage work requires a supplemental workforce, including thousands of contract personnel, adding to the complexity of communication and information flow. Other challenges including Nuclear Safety concerns arising from atypical system configurations and resource allocation issues can create delays and schedule overruns, driving up outage costs.

The current technologies employed at most NPPs to communicate critical information are slow, inaccurate at times, and rely upon the physical presence of stakeholders and key personnel to obtain and validate critical system and status information. Today the majority of the outage communication is done using processes and technologies that do not take advantage of advances in modern technology. Some of the common practices include: runners that deliver paper based requests for approval, radios, telephones, desktop computers, daily printouts of the schedule and static white boards that are used to display information. There is a large amount of static information that is displayed and requires constant evaluation to determine if it is still valid. The current methods of displaying and tracking information may be adequate for now, but will not be adequate to process the increased use of real time information that will be available with the increased use of handheld field devices, computer based work packages, or computer programs that passively track work completion and readiness. Although the use of some handheld devices by field operators making rounds are in use these devices do not provide real-time data transfer. There has also been an increase in the use of some video monitoring that allows for remote monitoring of field activities. However, the industry has not yet taken full advantage of advancements in mobile technologies that enable communication, collaboration, data streaming, and information sharing to 
and from the field. Many gains have been made to reduce these challenges, however; new opportunities can be realized by utilizing modern technological advancements in communication and information tools that can enhance the collective situational awareness of plant personnel leading to improved decisionmaking.

During a typical outage the outage managers deal with a continual stream of issues that may impact the schedule. These emergent issues are caused by problems, unexpected conditions, and deviations in planned activities (e.g., equipment or component problems, events, and coordination issues between work activities). Outage managers need to be able to assess issues and respond quickly to minimize safety challenges and to maintain the balance of work activities on schedule.

This project will study the current outage work processes and identify the needs of the outage management team. Process improvement opportunities and technologies that will improve communications, coordination, and collaboration activities will be identified. Functions that may be enabled by technology improvements include: real time remote collaboration, real time work status updates enabled by computer based procedures, automated notifications of pending support requirements, enhanced reporting from the field for discovered conditions, real-time requirements monitoring and more efficient dissemination of information out of the OCC. This project will study how an advanced OCC would be set up to take advantage of and maximize the utility of these technology enabled functions while preserving the existing required functions of the OCC and improving the human factors aspects of the physical layout. Certain aspects of the use of these technologies will be demonstrated and evaluated through scenarios in the HSSL at the INL and to the extent practical, at the participating utility's facility. A primary focus will be on creating a high degree of collective situational awareness and improved critical decision making by outage managers that leads to improved safety and reduced cost with minimal impact to the original outage schedule.

\section{STUDY METHODOLOGY}

\subsection{Study Preparation and Plan}

The outage organization is dispersed through numerous smaller centers supporting the OCC. At Palo Verde, in addition to the main OCC the outage support function is performed by the following satellite centers: an Operations OCC, Maintenance OCC (MOCC), Work Execution Center (WEC), Issues Response Team (IRT), Status Central (schedulers), Engineering Fix-It-Now (EFIN), Outage Oversight and Scope Change Request Board, the Main Control Room and each of the maintenance shops. To determine which functions should be handled in an Advanced OCC, it is necessary to understand how the overall outage management functions are performed through the allocation of tasks to the various satellite centers. It will also be necessary to understand the flow of information within and between each of these satellite centers and the OCC.

In support of the Task Analysis of the OCC and satellite centers, the following activities may be performed (depending upon the observed function):

Preliminary Activities

1. Attend orientation at Palo Verde and hold discussions with Palo Verde outage personnel to understand any known outage management issues or relevant organizational changes that are planned. 
2. Compile a human factors checklist, preselect a HF analysis method and prepare worksheets.

Initial Observations and Data Collection

1. Visit Palo Verde during an outage and observe tasks (naturalistic observations) as performed by outage personnel. Capture video (and audio) record of salient aspects of tasks.

2. Observe function allocation of process elements (whiteboards, desk-top computers, large screens, etc.)

3. Conduct Performance Shaping Factor analysis of outage activities observed.

4. Conduct group debriefing with outage personnel.

5. Conduct individual interviews with key outage personnel.

Analysis and Feedback

1. Review and edit video, annotate and highlight salient features.

2. Study Palo Verde outage written procedures and compare with observations.

3. Develop an IRT Process Map based on observations and information collected on data sheets.

4. Review process map with research team members and adjust where necessary.

5. Develop quantitative estimates of resources utilized performing tasks to support the required functions.

6. Review draft process map with Subject Matter Experts (SMEs), human factors analysts and outage personnel, and make inputs where necessary.

7. Perform a Communication Link Analysis and develop Communication Link Diagram

8. Perform an Operational Sequence Analysis based on observations and prepare Operational Sequence Diagram (OSD) as a category of task analysis.

9. Review OSD with team members and adjust where necessary.

10. Perform human factors analysis for communication and collaboration considerations, including workload and ergonomics.

Recommendations

1. Develop insights and recommendations for improvement of task performance including identification of potential supporting technologies capable of reducing outage staff workload while increasing outage task execution and configuration management.

2. Develop insights and recommendations to assist outage management in selecting and deploying technology upgrades in the OCC and satellite centers to improve communication and collaboration and support the future utilization of real time data that will be available when technologies such as computer based work packages and mobile worker technologies are implemented. 
Appendix A - Research Plan

\author{
Milestone Report
}

1. Document conclusions and recommendations (a report).

\title{
4.2 Data Collection and Analysis
}

\subsubsection{Overview}

A number of different data collection and analysis techniques will be employed during this research study. This is necessary because no single technique can address all objectives described earlier. The following sections provide a brief description of these techniques and how they will contribute to achieving the objectives presented in Sections 2.1 and 2.2 above. The basic research approach will include qualitative and quantitative data collection activities. Each activity will be designed to inform the next activity. Not all of these techniques will be used, and not every function will be analyzed by multiple methods. Select functions that are determined to be representative of others will be further analyzed by these methods.

\subsubsection{Naturalistic Observation}

Naturalistic observation is a research method commonly used by human factors researchers when it is necessary to observe subjects in their natural work environment. This type of research is often utilized in situations where conducting laboratory research is not practical, cost prohibitive or would unduly affect the subject's behavior. Because it is conducted in the actual work environment, it helps to support the external validity of the research.

Data collection methods will include audio and video recordings of each observation session, postobservation reviews using data collection sheets, subjective task assessment, self-assessment questionnaires, and interviews. It will not be practical to observe the entire outage, so representative sample periods will be observed. The results will be shared with PVNGS staff to ensure that the periods that were observed where indeed representative of typical outage performance. A flexible data sheet will be used to collect qualitative data during observation sessions outside of the OCC (see Appendix A).

\subsubsection{Interviews}

The researchers will conduct a variety of formal and informal interviews with outage staff and managers. It is expected that these interviews with outage personnel will be conducted after the observation phase of the research so as to not impact the current outage performance. The lines of inquiry will be based on improving the understanding of current processes.

\subsubsection{Focus Groups}

Focus group discussions may be held throughout the course of the qualitative study. The purpose of the focus groups will be to discuss current processes with an emphasis on Function and Task Analysis findings. The purpose of the focus groups in FY13 will be to discuss current work processes with emphasis on verifying Function and Task Analysis findings. This will be an iterative process to insure the accuracy of the defined analysis and subsequent diagrams. 


\subsubsection{Process Mapping}

Process mapping is a useful task analysis technique that visually describes the sequence of various tasks and subtasks for a given process. Process mapping distinguishes how work is actually done as opposed to how it should be done and thus can provide the analyst with insights for evaluating and reengineering aspects of the process. For example, responsibilities, boundaries, and bottlenecks can all be indentified via process mapping. It is possible to construct a high level process map that usually referes to core processes within an organization and low level process maps that present the sequence and interaction of various sub processes and work flow elements.

It is common with process mapping to shown the main activities, interconnections, and information flows. The resulting process map for outage activities will be used to depict a visual representation of the relationships between various process elements and sub elements. The evolution and sequence of activities performed will be captured by other analysis techniques and added to the baseline process map derived from the written procedure.

\subsubsection{Task Performance Time Estimates}

Task time requirements will be identified during task and subtask execution. When possible, feedback will be obtained from outage personnel, supervisors and managers on the impact of time constraints on outage personnel performance. In addition to specific task time requirements, the overall task and procedure times will be recorded on data collection sheets and depicted on the Operational Sequence Diagrams (OSDs).

\subsubsection{Performance Shaping Factor Analysis}

During the process of visual observations, interviews, and focus groups, various performance shaping factors (PSFs) that impact outage personnel performance during task execution will be collected and evaluated as part of the task analysis (TA).

At a high level, PSFs are human performance influences that can be categorized as being internal to the worker, external (aspects of the environment), and intrinsic to the task itself (complexity and work pace) and that result in good or poor human performance. PSFs work in conjunction with the sequence and timing of events, with the information and cues available, and with the guidance (formal and informal) provided to personnel. NUREG 1792, "Good Practices for Implementing Human Reliability Analysis (HRA)," considers the following performance shaping factors to be the minimum set to be evaluated in determining likelihood for human failure and success: training and experience, suitability of procedures and controls, equipment accessibility and operability, availability and clarity of instrumentation, time available, complexity of diagnosis and response (this can be reinterpreted as complexity of the task in terms of mental calculation, coordination, and concurrent events), work load, time pressure, stress, crew dynamics, available staffing and resources, communications, ergonomic quality of the Human Machine Interface (HMI), and attributes of the environment where work is to be performed (Kolaczkowski, 2005 ). P. 5-16. PSF analysis has been used in applications as varied as canal fuel handling (Hugo and Gertman, 2012), and in event analysis (in NUREG 6883 (Gertman et al., 2004)). It is equally applicable to most nuclear environments including the OCC.

See Appendix B. Performance Shaping Factor Analysis Examples 


\subsubsection{Functional Analysis}

A basic functional analysis (FA) will be performed to create a visual depiction of the various outage functional elements and subsequent functional requirements. This functional analysis will be required to determine if the accomplishment of the function could be shifted to a different resource (i.e. reallocating the tracking of required parts from a staff member in the OCC to the department). An initial draft functional diagram will be developed to depict what is known about outage functions. The draft functional diagram will be provided to key outage stakeholders to provide additional insights to the draft that will assist in finalizing the FA and FA diagram. Several high level functions have been identified as critical to successful outage management by OCC staff. These high level functions will be validated during the observation of the OCC and changes in the high level functional breakdown may be required based on data collected.

See Appendix C. OCC Task Observation Form

The identified high-level functions of the OCC that will initially be evaluated are:

6. Process Information Inflow
a. Status of scheduled activities
b. Reports of new emergent issues
c. Status of emergent issue resolution
d. Requests for assistance

7. Manage Work Schedule
a. Tracking the status of ongoing work
b. Revisions to schedule due to delays
c. Coordination of required support

8. Manage Emergent Issues

a. Create and manage recovery plan

b. Manage schedule impacts

9. Manage Plant Conditions

a. Technical specification and mode change requirements

b. Defense in depth, protected systems and plant risk monitoring

10. Process Information Outflow

a. Overall outage schedule status

b. Resource requests/notifications

c. Communicate schedule changes to affected parties

d. Requests for status 


\subsubsection{Task Analysis}

The TA will incorporate information gained through the naturalistic observations, interviews, focus groups, time estimates, PSF analysis, and process mapping. Observed tasks will be tied to the support of the identified high level functions described above. Tasks that cannot be assigned to a high level function, will be collected to determine if additional required functions are needed or if the tasks are truly not required to be performed within the OCC. Details regarding the performance of these tasks will be collected and quantified (who did it, how was it accomplished, how long did it take, etc.) The binning of tasks, that support various high level functions, will assist in the processing of the collected data.

Task analysis is a human factors technique with many uses including identifying performance requirements to be covered in training, assisting in assessing and reducing human error, as an aspect of interface design, to enhance productivity, and to reduce system unavailability. It is particularly useful in those instances where users cannot articulate what they actually do or have forgotten some aspects of what they do. Task analysis is to be conducted with people actually performing the job as opposed to interviews or focus groups with designers. People performing outage works, and all work for that matter, have specific goals in mind. Task analysis relates those goals to a series of actions. Task analysis also relates the operator intention, actions, tools, stimulus or cues, knowledge required, and feedback (cues, indication) people receive. One of the main outputs of a task analysis is the task list inventory. This constitutes the "what" of what people must do to meet system or process goals. How they achieve what they must do goes to the nature of the interface(s) available to them and the options that they have. Finally, another attribute of task analyses is that they are sequential and hierarchical. Tasks are routinely decomposed into subtasks and may consider a number of action verbs to aid the analysts in his or her description of work performed. These descriptors can be more cognitive in nature (e.g., compare, interpret, evaluate, plan, troubleshoot) or physical (e.g., turn on, adjust, activate, shutdown, reduce) (Gertman and Blackman, 1993).

\subsubsection{Communication Link Analysis}

\section{Purpose}

The purposes of the communication link analysis (see Appendix D) will be to help characterize the current interactions between the team members. This will be used to aid in the assessment of various design options and ensure traceability and rationale for technology deployment and process improvements.

\section{Procedure}

Utilizing the TA, subject matter experts (SMEs) will be asked to consider each task and assess which outage personnel will be involved in the communication in order to complete the task. For each task, this will produce a list of outage personnel engaged in the communication. An Outage Communication Analysis Form will be used to collect pertinent data. These forms (see Appendix E) for each task are used to record the judgments of the SMEs.

To complete the form the SMEs will be asked to consider each position on the list and determine;

- Function of the person with whom you communicate (e.g., planner, scheduler, supervisor, engineer, etc.)

- Frequency (e.g., continuous, hourly, daily, etc.) 
- Medium (e.g., verbal, email, phone, etc.)

- Communication mode (e.g., receiving, sending, both)

- Importance (e.g., high, medium, low)

- Content (e.g., description of the nature of information exchanged during communication)

- Provide a brief description of the main activities you perform during outage planning and execution (e.g., max one sentence, use keywords where possible)

- Location: List the location(s)/Area(s) where the activity is performed

- Equipment: List the tools or equipment you use to perform the activities listed (including communication devices)

- Other general information such as importance of communication, quality of communication, and usability of information will be gathered from personal impressions.

The aim of collecting data on team interaction will help determine the importance of the communication and ensure the analysis does not yield conflicting design requirements.

\section{Link Analysis Model Notation}

The following notations will be used in conjunction with the communication link analysis diagram:

- $\quad$ Size of entity $=$ relative/perceived importance or influence in process

- Line thickness $=$ relative importance of information (three thicknesses: heavy = very important, medium, low)

- Multiple lines $=$ frequency of information flow: 1 line $=$ low, $2=$ medium, $3=$ high

- $\quad$ Dashed lines =incidental/very infrequent information flow

- Distance between entities $=$ relative difference in function

- Text on line = essential content of information exchange

- $\quad$ Arrow $=$ direction of information flow

See Appendix D. Communication Link Analysis Diagram Example

\section{Basic Rules for Link Analysis:}

- A sending entity can be either the original source (creator) of information or a processor of information.

- Important entities with related functions should be collocated (i.e. physically or by direct linkage).

- Entities receiving/sending a lot of information must be important.

- Entities sending/receiving only occasional information need not be collocated.

\subsubsection{Operational Sequence Analysis (OSA)}

Operational Sequence Analysis is a unique task analysis technique that combines events, information, actions, decisions, and data to capture the sequence of operator tasks, in relation to other concrete or abstract entities.

The resulting graphic, the OSD, provides a visual representation of the relationships between tasks and contextual triggers that is easier to understand than textual reports or conventional flow diagrams. The evolution and sequence of activities performed by the various actors are shown on a vertical timeline and the interaction between entities is shown as arrows from one to the other. Software exists to improve 
the modelling efficiency and labor involved in producing operational sequence diagrams. In support of this task, INL staff will use Effex Sequence Diagram Editor TM.

See Appendix F. Operational Sequence Diagram Example

\section{RESULTS}

The final analysis and results of the human factors research activities will be reported in a milestone report. The report will summarize the Human Factors Engineering (HFE) study for the project at Palo Verde. The study results will provide a baseline analysis of the required functions and tasks currently performed in the OCC. The results of this analysis will be used to evaluate alternative methods of performing these functions utilizing advanced communication and collaboration technologies. Scenarios will be developed and run in the HSSL to demonstrate these new capabilities presented by these advanced technologies. Additionally, the results of this study will be utilized in the design of HSIs and an optimized physical layout for an AOCC in accordance with generally accepted HFE guidance and criteria. Additional focus will be placed on evaluating Palo Verde's emergent issues process through the use of the IRT. The IRT deals with complex issues requiring high levels of communication and collaboration. The results of the evaluation of these technologies applied to the IRT process will inform future considerations for the reallocation of functions between the AOCC and the satellite centers. Any improvements that may be made to this process could be expanded to include numerous other processes and interactions between outage stakeholders.

\subsection{2-D and 3-D Graphic Modeling}

The 2-D and/or 3-D models will provide visualization of the current outage work areas. After assessing the physical and ergonomic characteristics of outage activities, it will be possible for researchers to prescribe possible new physical variables that are judged to contribute to the performance of the various tasks. This might include changing the physical layout of existing workstations, information sharing tools, communication technology, exact work location, and types of tools and the method of handling them. Additionally, the 2-D and/or 3-D models will be employed to illustrate the recommended design and contrast against the current OCC.

\subsection{Video Recording}

Any video recording of the observations of the outage activities will be appended to the final report as a CD/DVD. This will be used to corroborate the observations described in the research report.

\subsection{Requirements pertaining to the use of Human Subjects}

Research conducted involving personnel as subjects shall be conducted in a manner that is compliant with institutional requirements and Executive Order for such research. All activities engaged by INL in support of this work including conducting interviews and debriefs, running focus groups and video-taping and audio-taping outage performance work will be conducted in accordance with INL requirements for the use of human subjects and will be subject to review by the INL Institutional Review Board (IRB). IRB approval is required by Executive Order. 


\section{REFERENCES}

Gertman, D. and Blackman, H. (1993). Human Reliability and Safety Analysis Data Handbook. John Wiley \& Sons.

Gertman et. al. (2004). "The SPAR-H Human Reliability Analysis Method". NUREG/CR-6883.

Washington, D.C.: U.S. Nuclear Regulatory Commission.

O’Hara et. al. (2004). "Human Factors Engineering Program Review Model”. NUREG/CR-0711.

Washington, D.C.: U.S. Nuclear Regulatory Commission.

Hugo, J. and Gertman, D. (2012). “A Multi-Methods Approach to HRA and Human Performance Modeling: A Field Assesment. In: PSAM 11 and ESREL 2012 Conference on Probabilistic Safety Assessment, June 25-29, 2012, Helsinki, Finland.

Kolaczkowski, A., Forester, J., Lois, E. and Cooper, S. (2005). "Good Practices for Implementing Human Reliability Analysis (HRA)". NUREG/CR-1792. Washington, D.C.: U.S. Nuclear Regulatory

Commission. No reference found in text)

\section{APPENDICES}

\subsection{Appendix A - Naturalistic Observation Data Collection Sheet}

\begin{tabular}{|l|l|}
\hline Topic & Observation (Example) \\
\hline Activity Observed & Briefing \\
\hline Number of Personnel Involved in Task & 5 \\
\hline Key Players & $\begin{array}{l}\text { IRT Manager } \\
\text { IRT team members }\end{array}$ \\
\hline Stakeholders Contacted & $\begin{array}{l}\text { MCR Shift Supervisor } \\
\text { Engineering Manager }\end{array}$ \\
\hline Information Processed & $\begin{array}{l}\text { Emergent work priorities } \\
\bullet \text { Actions to be taken for issue resolution } \\
\text { Decision-making }\end{array}$ \\
$\begin{array}{l}\bullet \text { Time available and temporal constraints (task } \\
\text { ordering) }\end{array}$ \\
\hline Response by Assigned Personnel & $\begin{array}{l}\bullet \text { Actions to be taken } \\
\bullet\end{array}$ \\
\hline
\end{tabular}




\begin{tabular}{|c|c|}
\hline & $\begin{array}{l}\text { - Time available and temporal constraints (task } \\
\text { ordering) }\end{array}$ \\
\hline Teamwork and Communication & $\begin{array}{l}\text { - Coordination needed between the team performing the } \\
\text { work activities } \\
\text { - Personnel communication for monitoring information } \\
\text { flow }\end{array}$ \\
\hline Workload & $\begin{array}{l}\text { - Cognitive } \\
\text { - Physical } \\
\text { - Overlap of task requirements (serial vs. parallel task } \\
\text { elements) }\end{array}$ \\
\hline Task Support & $\begin{array}{l}\text { - Job aids, procedures or reference materials needed } \\
\text { - Tools and equipment needed }\end{array}$ \\
\hline Workplace Factors & $\begin{array}{l}\text { - Workspace needed to perform the task } \\
\text { - Typical environmental conditions (such as lighting, } \\
\text { temp, noise) }\end{array}$ \\
\hline $\begin{array}{l}\text { Situational and } \\
\text { Performance Shaping Factors } \\
\text { (see PSF Data Form for additional PSFs) }\end{array}$ & $\begin{array}{l}\text { - Stress } \\
\text { - Time pressure } \\
\text { - Reduced staffing } \\
\text { - Extreme environmental conditions }\end{array}$ \\
\hline
\end{tabular}

\subsection{Appendix B - Performance Shaping Factor Analysis}

\begin{tabular}{|c|c|}
\hline $\begin{array}{l}\text { PSF Category (in Brewer, Hendrickson, } \\
\text { and Cooper 2011) }\end{array}$ & Evaluation / Observation (Example) \\
\hline Communication difficulties & $\begin{array}{ll}\text { - } & \text { Too many people } \\
\text { - } & \text { Confusing use of displays (white boards) } \\
\text { - } & \text { High background noise }\end{array}$ \\
\hline Visual challenges & $\begin{array}{l}\text { - Inadequate lighting } \\
\text { - White board markers hard to see } \\
\text { - Computer screens too small, etc. }\end{array}$ \\
\hline Limited indicators and job aids & $\begin{array}{l}\text { - } \quad \text { Job aides provided but not used } \\
\text { - } \quad \text { No job aides readily available } \\
\text { - } \quad \text { Job aid needed }\end{array}$ \\
\hline Unchallenging activities & $\begin{array}{l}\text { - } \text { Boredom } \\
\text { - Redundant activity, etc. }\end{array}$ \\
\hline Time pressure & $\begin{array}{l}\text { - Action described as "rush item" } \\
\text { - } \quad \text { Time limits identified, etc. }\end{array}$ \\
\hline
\end{tabular}




\begin{tabular}{|c|c|}
\hline $\begin{array}{l}\text { PSF Category (in Brewer, Hendrickson, } \\
\text { and Cooper 2011) }\end{array}$ & Evaluation / Observation (Example) \\
\hline Shift variables & 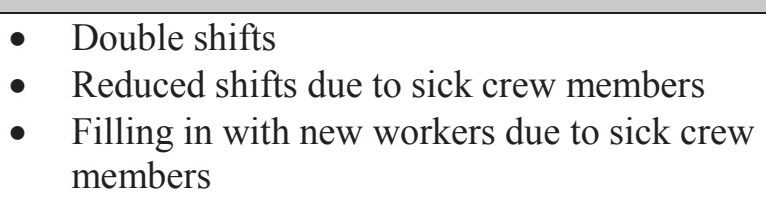 \\
\hline Improper or uneven task execution & $\begin{array}{l}\text { - Lost opportunities for checking } \\
\text { - Workload imbalance }\end{array}$ \\
\hline Inadequate verification & $\begin{array}{ll}\text { - } & \text { Incorrect redundant verification } \\
\text { - } & \text { Failure to use callbacks (repeat backs) }\end{array}$ \\
\hline Inadequate team coordination & - Different assumptions on task execution \\
\hline
\end{tabular}




\subsection{Appendix C - OCC Task Observation Form}

\begin{tabular}{|c|c|c|}
\hline Date: & Time: & Duration: \\
\hline \multicolumn{3}{|l|}{ Description of Task Observed: } \\
\hline $\begin{array}{l}\text { High level function task } \\
\text { supported: }\end{array}$ & $\begin{array}{l}\text { Number of participants: } \\
\text { Inside OCC: } \\
\text { Outside OCC: }\end{array}$ & $\begin{array}{cl}\text { Category of task: } \\
\circ & \text { Conversation } \\
\circ & \text { Collaboration } \\
\circ & \text { Briefing }\end{array}$ \\
\hline $\begin{array}{cl}\text { Where was task initiated: } \\
\circ \text { Within the OCC } \\
\circ \quad \text { From outside the OCC }\end{array}$ & $\begin{array}{l}\text { Is task regularly scheduled: } \\
\quad \begin{array}{ll}\text { Scheduled } \\
\circ & \text { Impromptu } \\
\text { For scheduled, what frequency: }\end{array}\end{array}$ & $\begin{array}{cl}\text { Communication methods: } \\
\circ \text { Face to Face } \\
\circ \text { Telephone } \\
\circ \text { White Board } \\
\circ & \text { Desktop computer } \\
\circ & \text { Other: }\end{array}$ \\
\hline $\begin{aligned} & \text { Workplace factors: } \\
& \circ \text { Inadequate space } \\
& \circ \text { Background noise } \\
& \circ \text { Inadequate tools } \\
& \circ \text { Distractions from nearby } \\
& \text { work } \\
& \circ \text { Repetitive/boring }\end{aligned}$ & $\begin{array}{cl}\text { Situational factors: } \\
\circ & \text { Time pressure } \\
\circ & \text { Complex problem } \\
\circ & \text { Shift change }\end{array}$ & 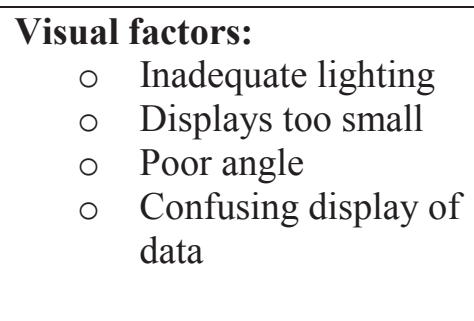 \\
\hline $\begin{array}{l}\text { Observed delays: } \\
\circ \text { To find information } \\
\circ \text { To find a person } \\
\circ \text { Due to equipment } \\
\circ \text { Other: } \\
\text { Estimate of delay: }\end{array}$ & $\begin{array}{cl}\text { Key players involved: } \\
\circ & \text { OCC manager } \\
\circ & \text { IRT team leader } \\
\circ & \text { WEC } \\
\circ & \text { Radiation protection } \\
\circ & \text { Station management } \\
\circ & \text { Operations } \\
\circ & \text { Other }\end{array}$ & $\begin{array}{l}\text { Frequent task counting: } \\
\text { For frequent, non-scheduled } \\
\text { tasks, additional observations. }\end{array}$ \\
\hline \multicolumn{3}{|l|}{ Comments: } \\
\hline
\end{tabular}




\subsection{Appendix D - Communication Link Analysis Diagram Example}

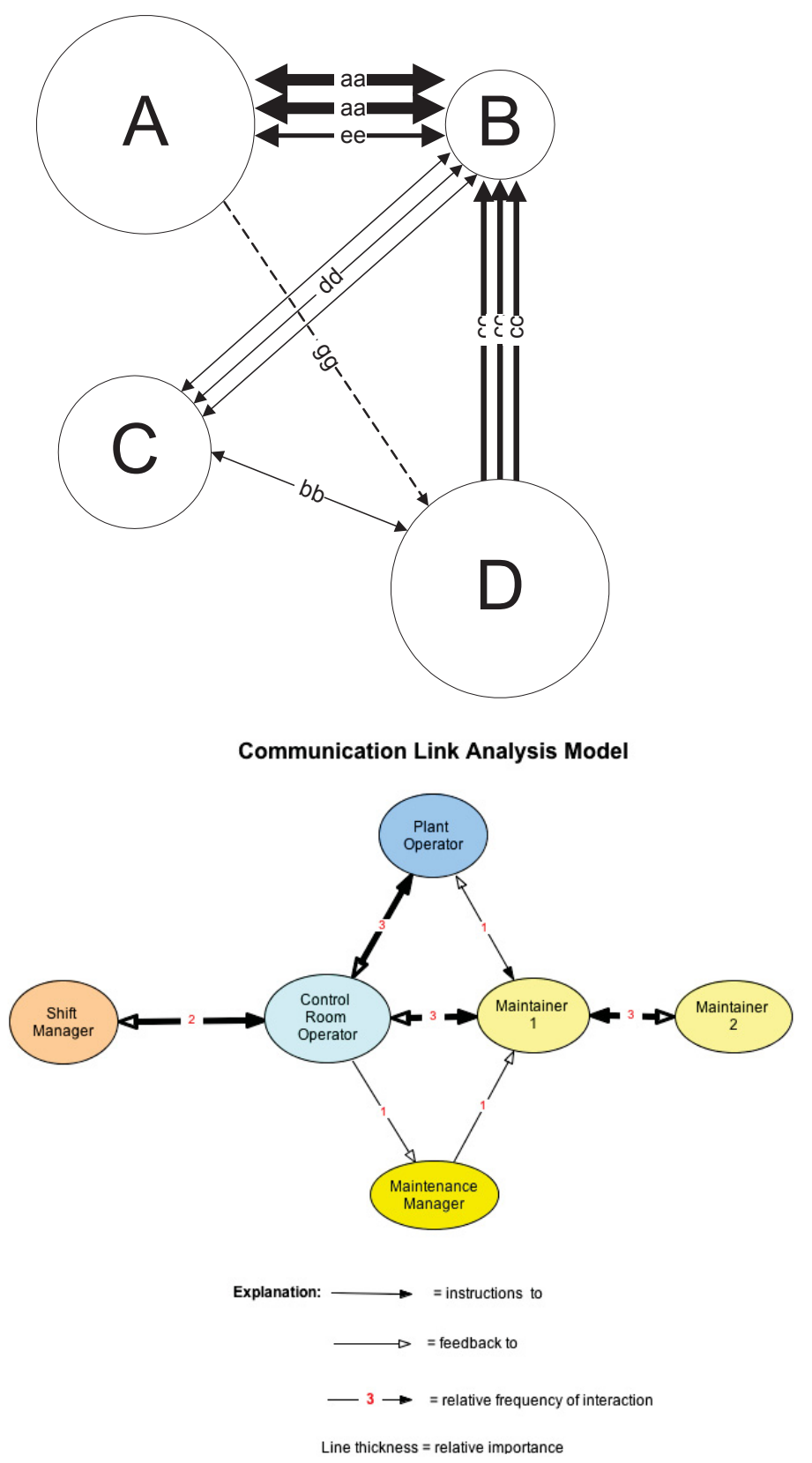




\subsection{Appendix E - Outage Communication Analysis Form}

In the context of conducting plant outages, please identify and describe the following:

\section{YOUR FUNCTION DURING OUTAGES:}

1. Communication

Identify individuals you communicate with during the entire outage process. Where possible, use the identifiers to describe the nature of the communication further.

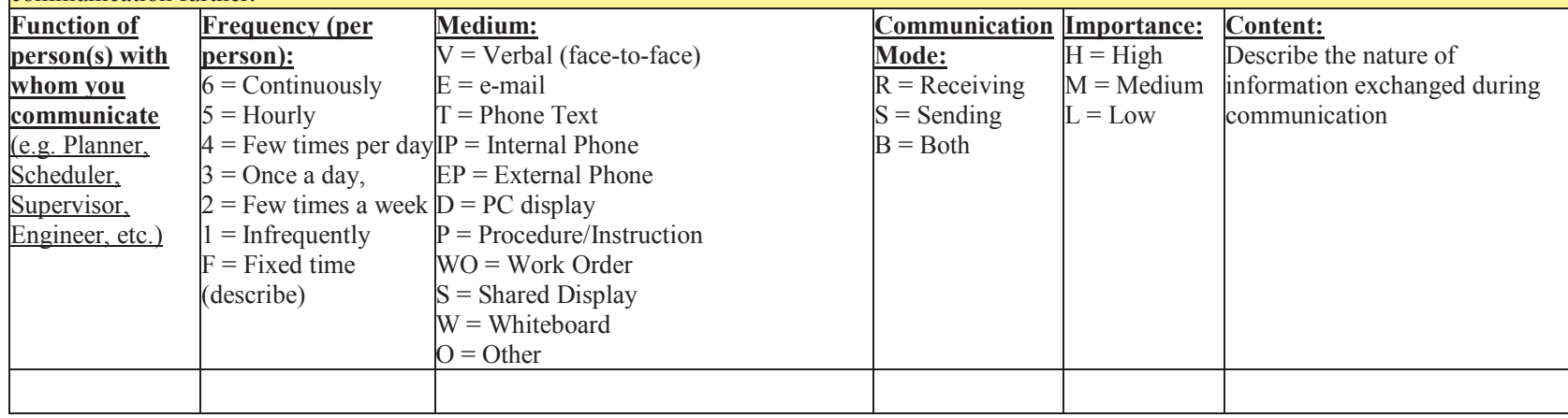

\section{Activities}

Provide a brief description of the main activities you Location:

perform during outage planning and execution (max one List the location(s)/area(s) where the sentence, use keywords where possible)

Equipment:

List the tools or equipment you use to perform the activities listed (including communication devices)

\begin{tabular}{|l|l|l|l|}
\hline Read & & & \\
\hline Write & & & \\
\hline Visually Inspect & & & \\
\hline Manipulate & & & \\
\hline Monitor & & & \\
\hline Observe & & & \\
\hline Supervise & & & \\
\hline
\end{tabular}

\section{General}

Please provide your personal impression of the following dimensions of communication during the entire Outage process:

1. Importance of How important is communication with others to deal with your own work?

Communication

2. Quality of

Communication

3. Usability of

Information

How do you judge the quality of communication (accuracy, accessibility, lack of information,

4. Feedback

general satisfaction) with others?

Explain briefly how you deal with the amount of information you receive and if you are flooded with more information than you can utilize.

Describe your experience of the amount of information and feedback you receive on your

5. Transmission - $\quad$ Can your own information be passed on to others comprehensively or only in part?

Extent

6. Transmission - $\quad$ Can your own information be passed on to others easily or do you experience obstacles?

Channel Openness

7. Communication Describe any way that communication efficiency may be improved during outage planning and

Efficiency execution. 


\subsection{Appendix F - Operational Sequence Diagram Example}

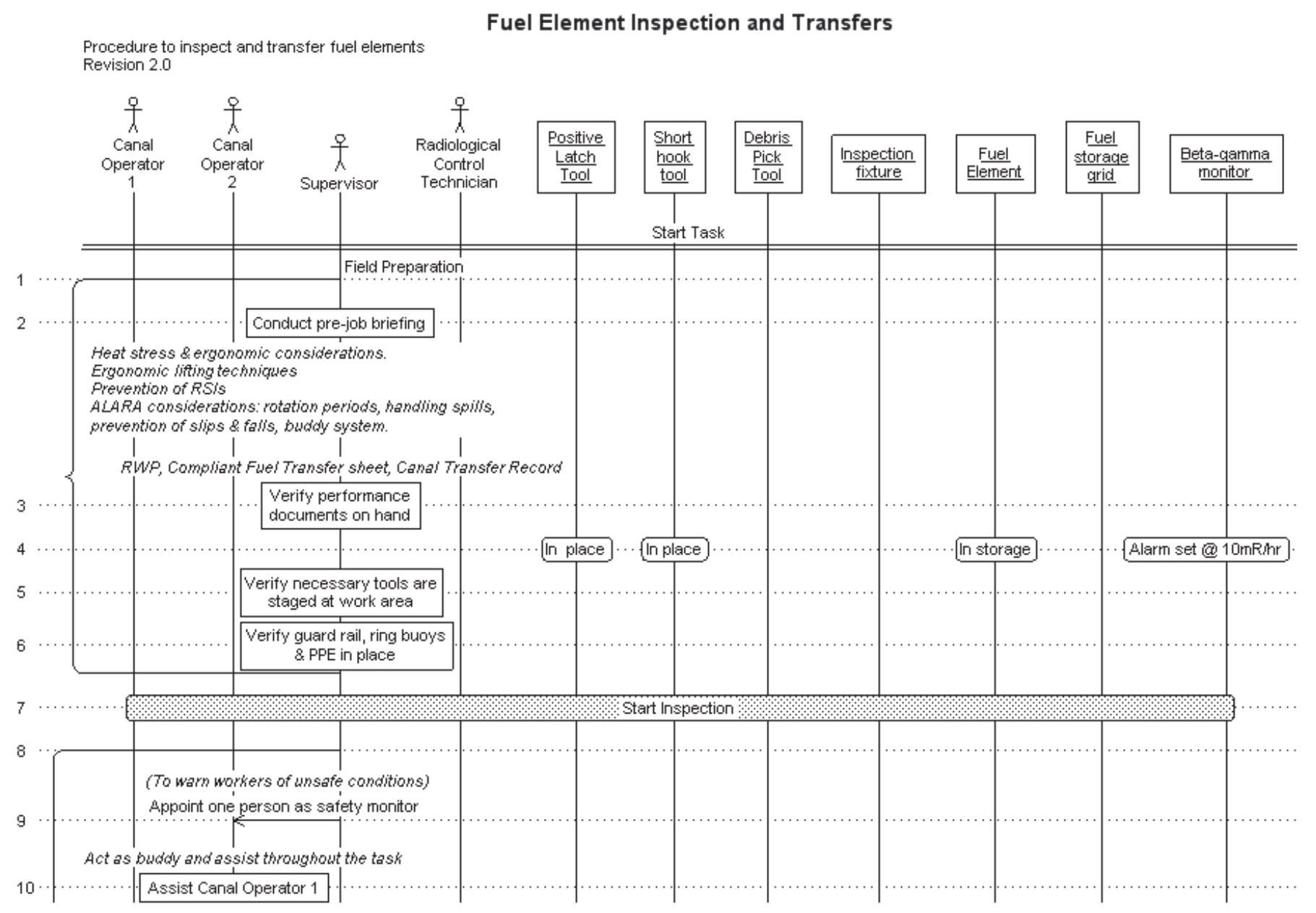




\section{Appendix B}

\section{Palo Verde Spring 2013 Outage Observation Data}


Appendix B - Palo Verde Spring 2013 Outage Observation Data

\section{Palo Verde Spring 2013 Outage Observation Data}

Data collected via self-report surveys between the dates of 4/1/2013-4/4/2013 during the 6/9/12/ 3 briefings.

\section{Responses: Dates/ Times Surveys Administered During Outage Briefings}

\begin{tabular}{|l|}
\hline $4 / 1(1630)$ \\
\hline $4 / 1(1655)$ \\
\hline $4 / 1(1700-1730)$ \\
\hline $4 / 3(0800)$ \\
\hline $4 / 4(1030)$ \\
\hline $4 / 4(1218)$ \\
\hline $4 / 1(1500)$ \\
\hline $4 / 1(1800)$ \\
\hline $4 / 2(0900)$ \\
\hline $4 / 2(1200)$ \\
\hline $4 / 2(1500)$ \\
\hline Blank (0900) \\
\hline $4 / 3(1500)$ \\
\hline $4 / 4(0900)$ \\
\hline $4 / 4(1200)$ \\
\hline $4 / 1(1500)$ \\
\hline $4 / 1(1630)$ \\
\hline $4 / 1(1800)$ \\
\hline $4 / 2(0900)$ \\
\hline $4 / 2(1200)$ \\
\hline $4 / 3(0800)$ \\
\hline $4 / 3(0900)$ \\
\hline $4 / 3(1500)$ \\
\hline $4 / 4(0900)$ \\
\hline $4 / 4(1200)$ \\
\hline
\end{tabular}

\section{Responses: Duration}

\begin{tabular}{|l|}
\hline 45 minutes \\
\hline 40 minutes \\
\hline 37 minutes \\
\hline 26 minutes -2 \\
\hline 25 minutes -2 \\
\hline 24 minutes \\
\hline 23 minutes \\
\hline 22 minutes \\
\hline 21 minutes \\
\hline
\end{tabular}




\begin{tabular}{|l|}
\hline 20 minutes -5 \\
\hline 18 minutes -4 \\
\hline 15 minutes -2 \\
\hline 10 minutes \\
\hline $0630-1030$ \\
\hline$\sim 5-30$ minutes \\
\hline Blank -2 \\
\hline
\end{tabular}

\section{Responses: Description of Task Observed}

\begin{tabular}{|l|}
\hline Briefing on Lessons Learned Dropped Generator - Arkansas (ANO)-2 \\
\hline Informal discussion about Pumps - Work \\
\hline Shift turnover \\
\hline 8 o'clock phone brief (via Phone/ Webx) \\
\hline IRT Discussion \\
\hline 100 hr. Stand Down \\
\hline 1800 Shift Brief \\
\hline 1500 OCC Shift Turnover Brief \\
\hline 1500 Brief- 2 \\
\hline 1200 Brief \\
\hline 0900 Brief \\
\hline OCC-6 \\
\hline OCC Update Meeting-2 \\
\hline OCC Update Meeting + 100 hr. Safety Stand down \\
\hline Daily Critical Path Meeting \\
\hline IRT Meeting \\
\hline
\end{tabular}

\section{Responses: High level function task supported}

\begin{tabular}{|l|}
\hline Lesson Learned (OE) \\
\hline Outage-4 \\
\hline Outage Status-3 \\
\hline Outage Info-2 \\
\hline Outage/ Plant Status/ Unit \\
\hline Outage OE \\
\hline OCC Brief \\
\hline Information Inflow \& Outflow-8 \\
\hline Information \\
\hline Issue Response \\
\hline Manage Emergent Issues \\
\hline Blank-3 \\
\hline
\end{tabular}

\section{Responses: Number of participants - Inside OCC}

\begin{tabular}{l} 
34 Total: 15 Seated, 19 Standing \\
$32-2$ \\
29 Total: 16 Seated, 13 Standing \\
\hline 28 Total: 13 Seated, 15 Standing
\end{tabular}




\begin{tabular}{|l|}
\hline $28-2$ \\
\hline 26 Total: 18 Seated, 8 Standing \\
\hline 26 Total: 14 Seated, 12 Standing \\
\hline 26 Total: 11 Seated, 15 Standing \\
\hline 26 Total: 13 Seated, 13 Standing \\
\hline 26 Total \\
\hline 25 Total: 12 Seated, 13 Standing \\
\hline 25 \\
\hline 24 Total: 15 Seated, 9 Standing \\
\hline 24 total: 12 Seated, 12 Standing \\
\hline 24 \\
\hline 22 Total: 17 Seated, 5 Standing \\
\hline 17 Total: 14 Seated, 3 Standing \\
\hline Inside OCC \\
\hline Blank-6 \\
\hline
\end{tabular}

\section{Responses: Number of participants - Outside OCC:}

\begin{tabular}{|l|}
\hline 10 \\
\hline$?$ \\
\hline Blank -17 \\
\hline
\end{tabular}

\section{Responses: Category of task}

\begin{tabular}{|l}
\hline Briefing - 19 \\
\hline Conversation -1 \\
\hline Conversation, Briefing -1 \\
\hline Collaboration-1 \\
\hline Other: Turnover -1 \\
\hline Blank-3 \\
\hline
\end{tabular}

\section{Responses: Where was task initiated?:}

\begin{tabular}{|l|}
\hline Within the OCC -22 \\
\hline From outside the OCC-2 \\
\hline MOCC-1 \\
\hline IRT Room-1 \\
\hline
\end{tabular}

\section{Responses: Is task regularly scheduled?:}

Scheduled - 22

Impromptu-5 


\section{Responses: For scheduled, what frequency?:}

\begin{tabular}{|l|}
\hline$@, 3$ hours-17 \\
\hline @ 12 hours-1 \\
\hline Daily-1 \\
\hline Blank-6 \\
\hline Depends on Issue-1 \\
\hline
\end{tabular}

\section{Responses: Communication methods:}

\begin{tabular}{|l|}
\hline Face to Face-10 \\
\hline Face to Face, White Board-2 \\
\hline Face to Face, Desktop Computer, Other: Hardcopies \\
\hline Telephone, Note: No Visual Support including Brief Sheets \\
\hline White Board (S/G Drawing), Desktop Computer \\
\hline Face to Face/ Desktop computer: Info covered online \\
\hline $\begin{array}{l}\text { Face to Face, White Board, Desktop Computer: Dual screens per desk, Other: Always used note pads } \\
\text { to give individual status }\end{array}$ \\
\hline Face to Face, Other: Aides used White Board and Printed Sheet \\
\hline Face to Face, White Board, Other: Large Screens \\
\hline Face to Face, White Board, Other: Big Screen: Eye in the Sky Video Com On Low Press Turs \\
\hline Face to Face, White Board, Other: Large Screens/ Videos \\
\hline Other: Used Star Board \\
\hline Telephone, Other: Webex \\
\hline $\begin{array}{l}\text { Face to Face, Telephone (Several Phone Calls), White Board (Sketch, Schedule), Desktop Computer } \\
\text { (IRT Log) }\end{array}$ \\
\hline
\end{tabular}

\section{Responses: Workplace factors:}

\begin{tabular}{|l|}
\hline Background noise-2 \\
\hline Background noise: ventilator?, Inadequate tools \\
\hline Inadequate tools \\
\hline Inadequate space-2 \\
$\begin{array}{l}\text { Inadequate space, Background noise: Ringing phones, Inadequate tools, Distractions from nearby } \\
\text { work: Phone calls }\end{array}$ \\
\hline $\begin{array}{l}\text { Inadequate space, Background Noise (Phone conversations), Distractions from nearby work (Phone } \\
\text { rang } 5 \text { times) }\end{array}$ \\
\hline Inadequate space, Background noise-2 \\
\hline Inadequate space, Background noise Inadequate tools -6 \\
\hline Inadequate space, Background noise: Ventilation \\
\hline Inadequate space, Background noise, Inadequate tools, Distractions from nearby work-2 \\
\hline Inadequate space, Distractions from Nearby Work-3 \\
\hline Blank-4 \\
\hline
\end{tabular}




\section{Responses: Situational factors:}

\begin{tabular}{|l|}
\hline OE Brief \\
\hline Informal discussion \\
\hline Complex problem, Other: Issue drives front area support \\
\hline Time Pressure, Complex Problem \\
\hline Other: Recent industry events drove this brief \\
\hline Blank-16 \\
\hline N/A-5 \\
\hline
\end{tabular}

\section{Responses: Visual factors:}

Displays too small, Limited use of screen, poor angle

Displays too small, Poor angle, Other: Desks face each other

Displays too small for staff standing

Displays too small, Poor angle, Other: Always had small font for all status schedules

Display too small: use of static schedule, Poor angle, Other: Little/ No use of large displays

Displays too small, Other: very little use of displays

Displays too small, Poor angle-9

Other: Poor sound quality

Other: Not used-6

Blank-3

\section{Responses: Observed delays:}

To find information

Other: Traffic

Due to equipment: Background music was still on

Due to Equipment

Blank-15

N/A-7

\section{Estimate of delay:}

\begin{tabular}{|l|}
\hline Varied by slide \\
\hline$\sim 50$ min \\
\hline 7 minute delay \\
\hline 5 min \\
\hline Blank-21 \\
\hline N/A \\
\hline
\end{tabular}

\section{Responses: Key players involved:}

\begin{tabular}{|l|}
\hline Shift Manager \\
\hline Shift Manager \& Others \\
\hline Functional Area Station Leaders (Senior VPs), CNO, Show Contractors \\
\hline OCC Staff \\
\hline OCC Manager-2 \\
\hline
\end{tabular}




\begin{tabular}{|l|}
\hline OCC Manager, OCC/IRT Staff \\
\hline OCC Manager, Other: OCC Staff-4 \\
\hline $\begin{array}{l}\text { OCC Manager, IRT Team Leader, Radiation Protection, Station Management, Operations, other: Nuc } \\
\text { Safety/Chemistry/Containment Lead }\end{array}$ \\
\hline OCC Manager, Radiation Protection, Operations, Other: OCC Staff-4 \\
\hline OCC Manager, Radiation Protection, Station Management, Operations, Other: OCC Staff \\
\hline OCC Manager, Operations, Other: OCC Staff-2 \\
\hline Other: Management \\
\hline OCC Manager, IRT Team Leader, Radiation Protection, Operations, Other: OCC Staff-2 \\
\hline IRT Team Leader, 9 Front Area Support including IRT Lead \\
\hline IRT Team Leader, Station Management, Operations \\
\hline Blank-2 \\
\hline
\end{tabular}

\section{Responses: Frequent task counting:}

No one stopped talking while phone conversation occurred

Blank-25

\section{Survey Comments Received:}

\begin{tabular}{|l|}
\hline a. \\
(1) Phone rang 5 times, \\
(2) People needed to shift to opposite side of room to view for brief, \\
(3) No remote to change screen shots, \\
(4) A computer had another view that was needed, but was unable to share shot on the \\
main screen. \\
(5) User was not familiar with technology. \\
\hline b. Discussion about pump work \\
\hline c. Little use of larger displays \\
\hline d. (1) Could use Go-To-Meeting to share visual displays \\
(2) Ringing telephones and background conversations (only for first couple of minutes) \\
(3) Plant status per unit, basic functional area updates, OE, Expectations and Financials \\
(4) Only one phone in room used to broadcast information \\
\hline e. Blank \\
\hline f. (1) Phone calls \\
(2) Reinforce OE info from AND \& Calloway \\
(3) Reinforce safety Requirements \\
\hline g. (1) 23 personnel in OCC \\
(2) Status update by area \\
(3) Reading status off sheet paper \\
(4) Q \& A during \\
(5) Visual support...very limited/ bad angles \\
(6) Limited visual support/ too small to see \\
(7) Boards and monitors at eye level vs. up higher for easy viewing above heads \\
(8) Phone call accepted during brief \\
\hline h. (1) Phone calls - 1 \\
(2) Use of acronyms - common \\
(3) Standing personnel does not include OCC managers
\end{tabular}




\begin{tabular}{|c|c|}
\hline i. & $\begin{array}{l}\text { (1) Phone calls - } 3 \\
\text { (2) Critical Path Sheet - too small } \\
\text { (3) No use of new technology (large screens) } \\
\text { (4) Use of acronyms }\end{array}$ \\
\hline j. & $\begin{array}{l}\text { (1) Phone calls - } 5 \\
\text { (2) Personnel (SRM) did not know board was his } \\
\text { (3) Personnel brief their crews from note pads } \\
\text { (4) Rx Head - Refuel Effort - use of tv screen/video feed } \\
\text { (5) Radio Noise } \\
\text { (6) Information/ Status Boards have some redundancy item (i.e. Procurement \& Eng \& } \\
\text { Maint.) }\end{array}$ \\
\hline k. & $\begin{array}{l}\text { (1) Phone calls - } 4 \\
\text { (2) High level issues } \\
\text { (3) Standards/ Expectations Role Down } \\
\text { (4) Acronym Use }\end{array}$ \\
\hline I. & $\begin{array}{l}\text { (1) Phone calls }-3 \\
\text { (2) Radios not turned down } \\
\text { (3) Use of acronyms }\end{array}$ \\
\hline $\mathrm{m}$. & $\begin{array}{l}\text { (1) Phone calls }-4 \\
\text { (2) Low talkers difficult to hear }\end{array}$ \\
\hline $\mathrm{n}$. & $\begin{array}{l}\text { (1) Phone calls - } 7 \\
\text { (2) Difficult to hear low talkers } \\
\text { (3) Use of acronyms } \\
\text { (4) Ventilation White Noise (Every Brief) } \\
\text { (5) IRT manager briefed OCC Staff: No use of technology or visual aides to support } \\
\text { information transfer }\end{array}$ \\
\hline o. & $\begin{array}{l}\text { (1) Phone calls - } 0 \\
\text { (2) OCC not fully informed of decision with IRT issue with } 5 / 6 \\
\text { (3) Need identified for jobs behind baseline (i.e. } 10 \& 30 \text { hours behind) - no visual support } \\
\text { to plot status }\end{array}$ \\
\hline & $\begin{array}{l}\text { List of Brief Topics Covered: } \\
\text { - Ready for Brief } \\
\text { - Plant Status, Temp/Press, Protected Systems, Time to Boil, SDC, TTB - } 27 \text { minutes } \\
\text { - Protected systems -> Shutdown Risk Update } \\
\text { Phone Rang Here } \\
\text { - Safety Update - "Swarm of Bees" } \\
\text { - Injuries } \\
\text { - Dropped Items } \\
\text { - } \quad \text { Update Crafts } \\
\text { Radiological Safety }\end{array}$ \\
\hline
\end{tabular}




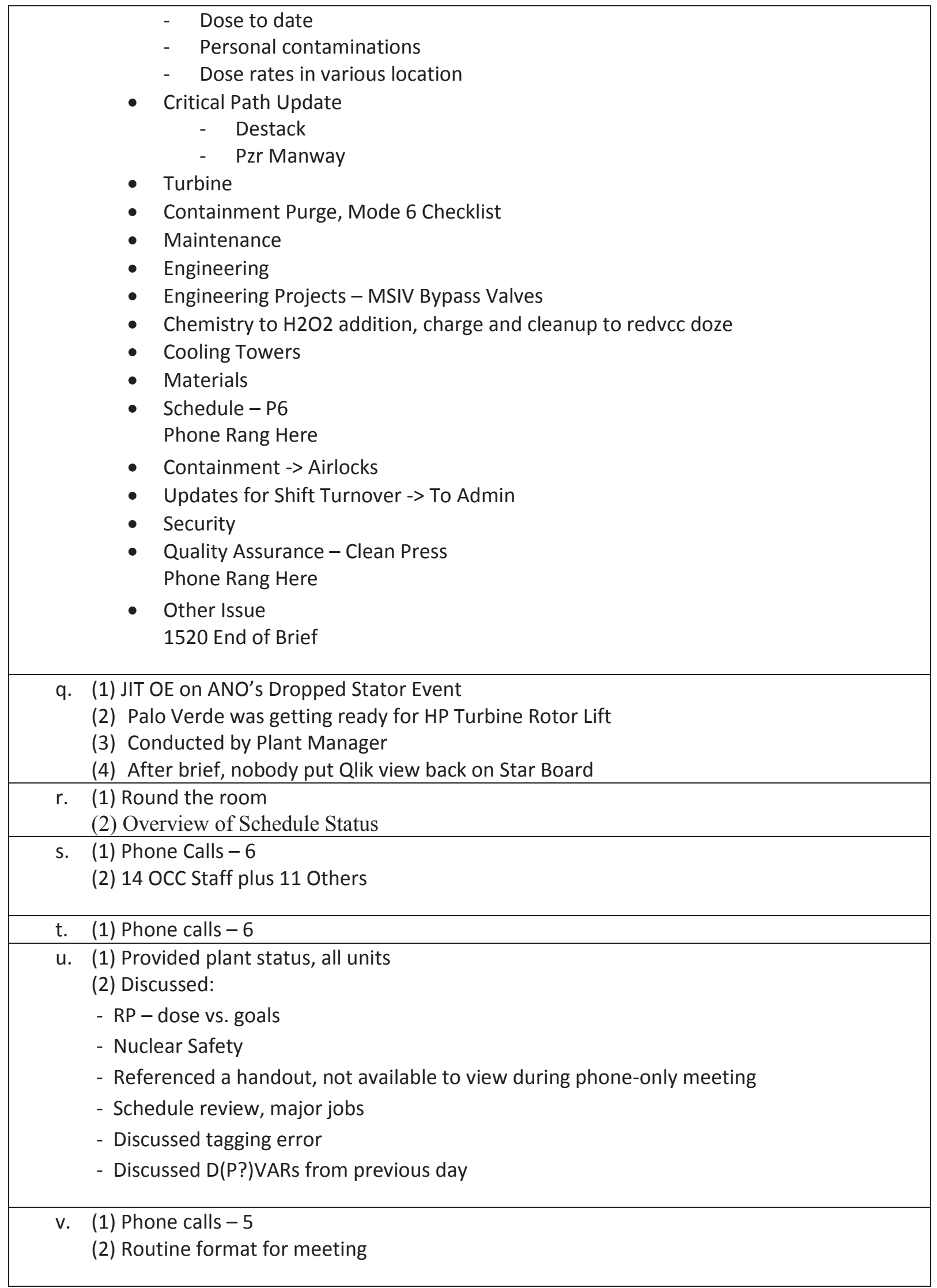


w. (1) Phone calls - 5

(2) Discussed:

- Round the Room

- Underground pipe issue

- Work through turnover jobs

CH-V203/5 Leakage Plans

x. (1) Phone calls - 7

(2) IRT Reported

(3) RMAZ - Yellow

(4) Core Offload I/P

(5) HP Turbine Rotor Lift

y. (1) This room was thrown together last minute, needs improvement (2)Events of 45 min. meeting:

- S/G Secondary High Hydrazine Concentrations

- IRT Issue

- 8 members start, $10 @ 0945$

- Sent 1 member to OCC to talk to OPS OCC Staff

- Sketch on Whiteboard for visual aid, no way to save

- Stick and Ball Schedules (On White Board)

- 0945 Phone Call for Info Feed

- 0950 Phone call to Containment Coordinator to check blower size

- 0952 Phone call to inquire about larger blowers

- 0953 Phone call from containment. 261 ppb hydrazine

- OE was reviewed, R13 had a similar issues

- 0957 Phone call from Manager

- Keith Baker - management Oversight - Phone call about blowers

- 1007 Phone call to Manager to update (Monreco May)

- Work with schedulers to determine impact for alternative option

- Need to perform an inspection

- OPS, RP, Engineering, Chemistry

- Use IRT log to communicate trend

- 1015 - Started Appendix C of IRT Procedure, Issues Response Plan

- IRT Team Room - No printer, No radio

- 0600 IRT assigned this problem, problem first identified $\sim 1500$ on 4/3

- At $\sim 1015$, meeting ended, Attendees returned to 3 core staff

- Issue is for \#1 S/G, \#2 also planned

- Knowledge management could be improved

z. (1) IRT reported status 
Appendix B - Palo Verde Spring 2013 Outage Observation Data

(2) 20 minute update, 20 minutes safety

(3) Reinforced safety standards 
Appendix C

Comprehensive IRT Process Maps 


\section{Outage Control Center (OCC) \& Issue Response Team (IRT) Organizational Relationship}

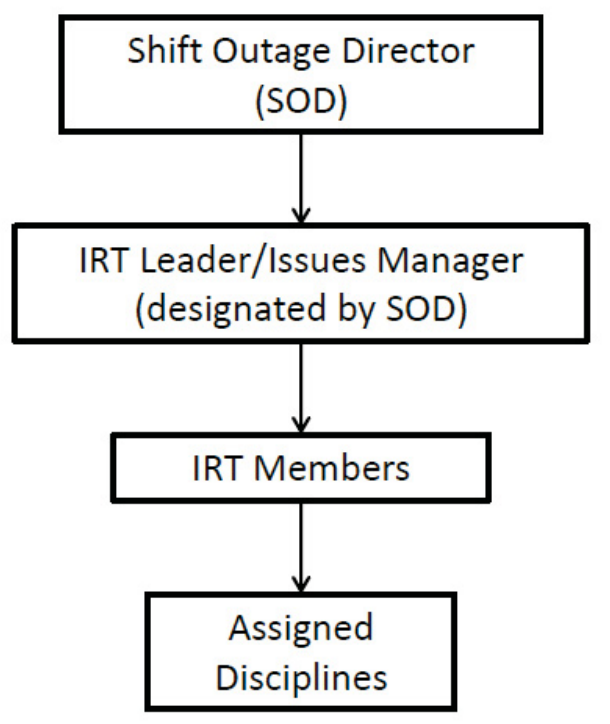




\section{Issue Discovery \& 4.2 Assignment}

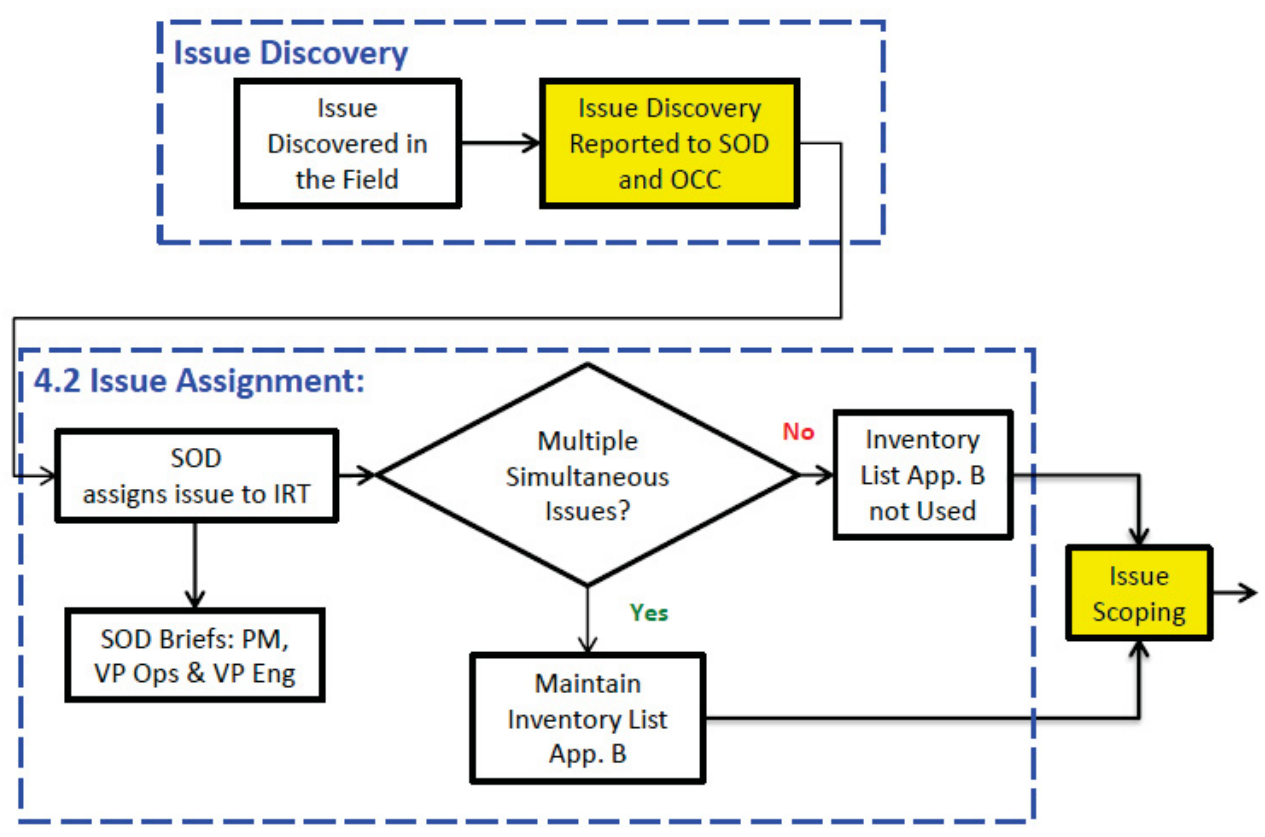

IRT Process Maps - APS, 2013 


\subsection{Issue Scoping, Decision Making, \& Recovery Plan}

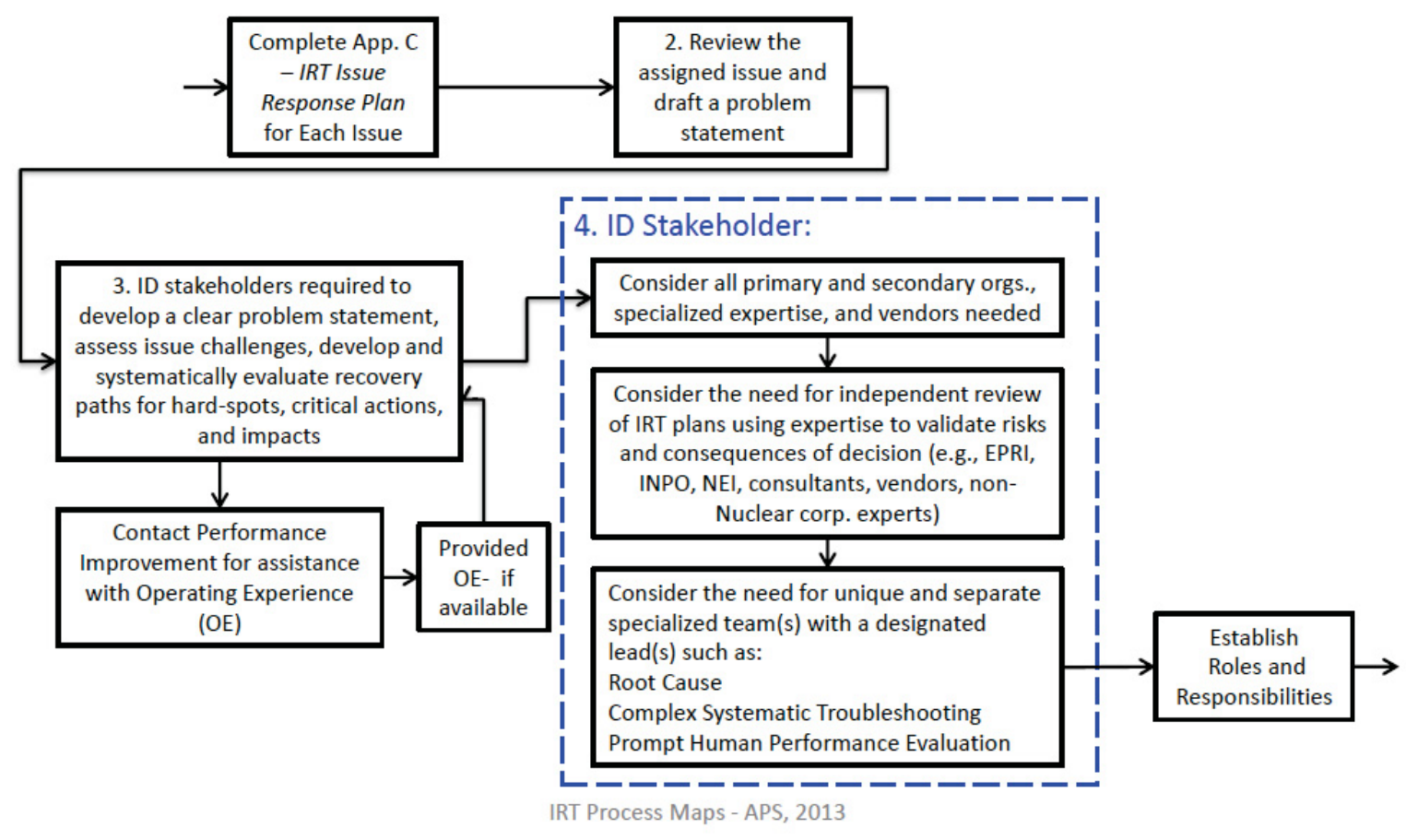




\subsection{Issue Scoping, Decision Making, \& Recovery Plan (Cont.)}

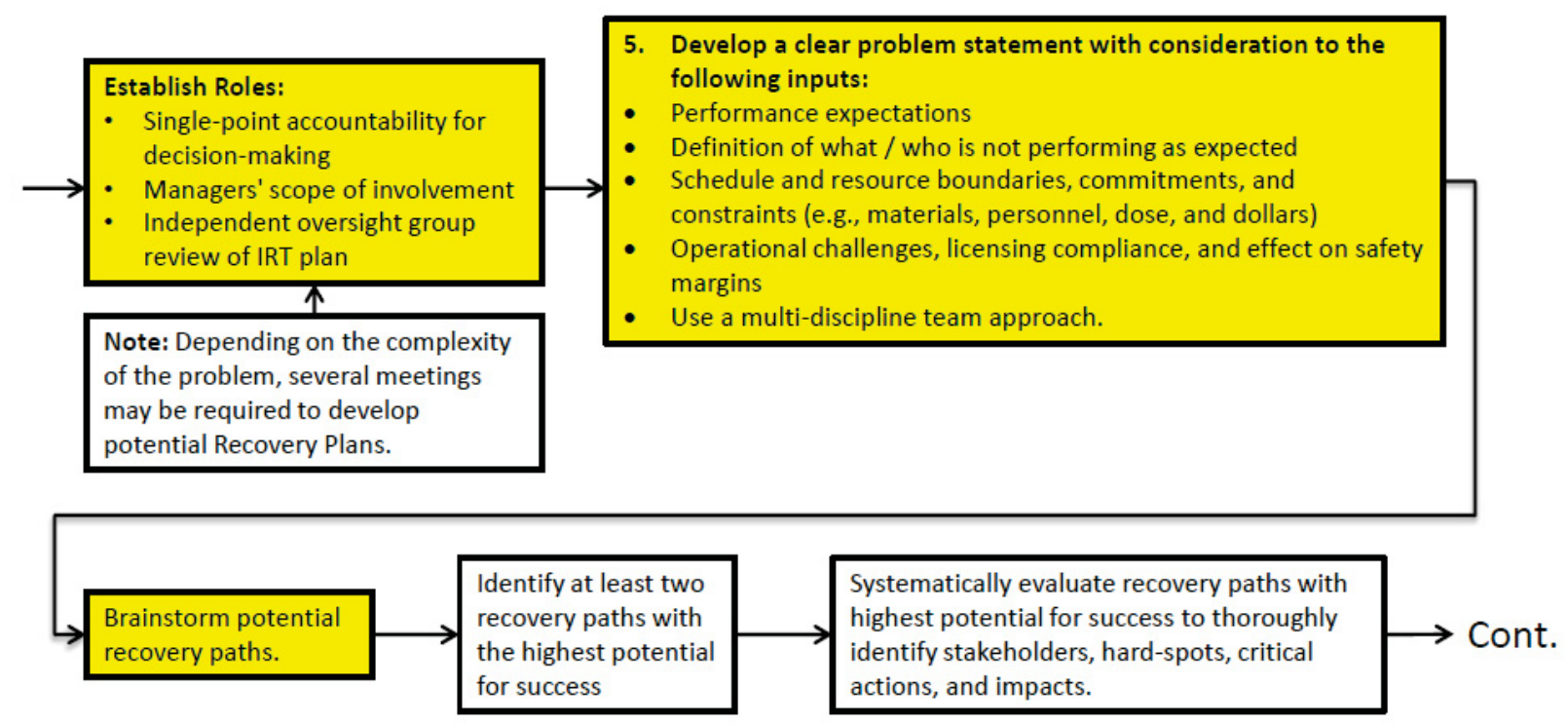




\subsection{Issue Scoping, Decision Making, \& Recovery Plan (Cont.)}

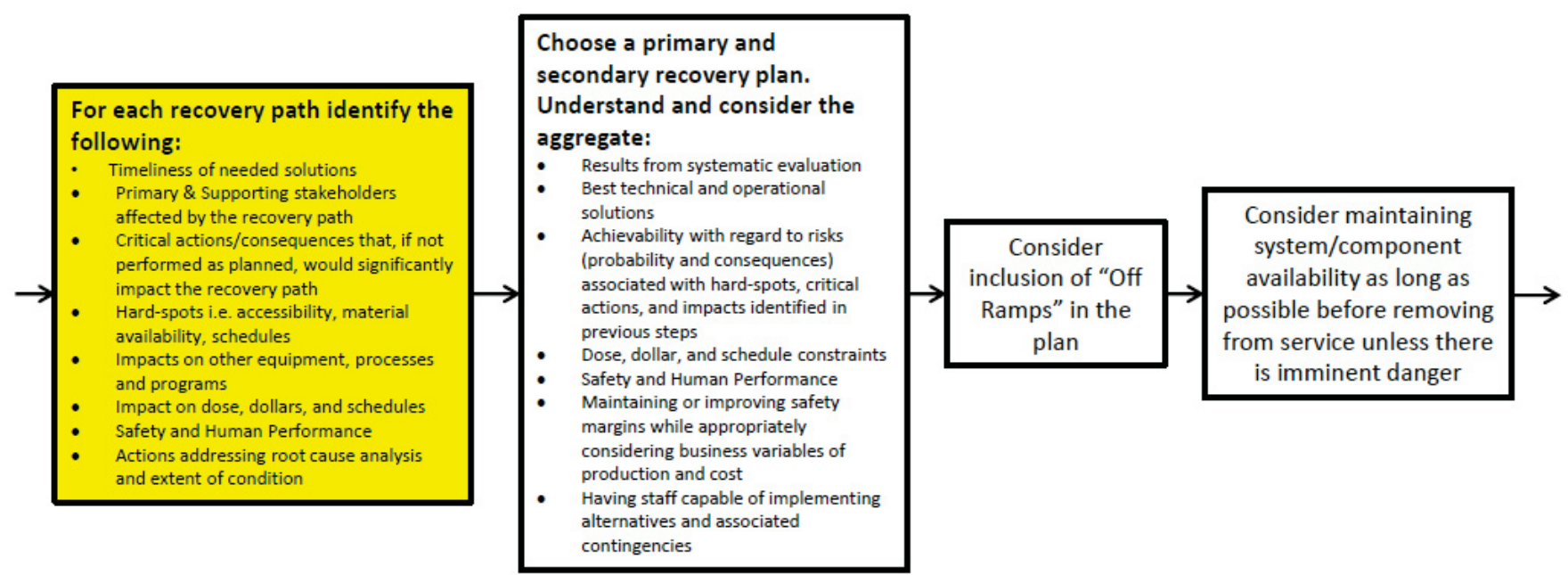




\subsection{Issue Scoping, Decision Making, \& Recovery Plan (Cont.)}

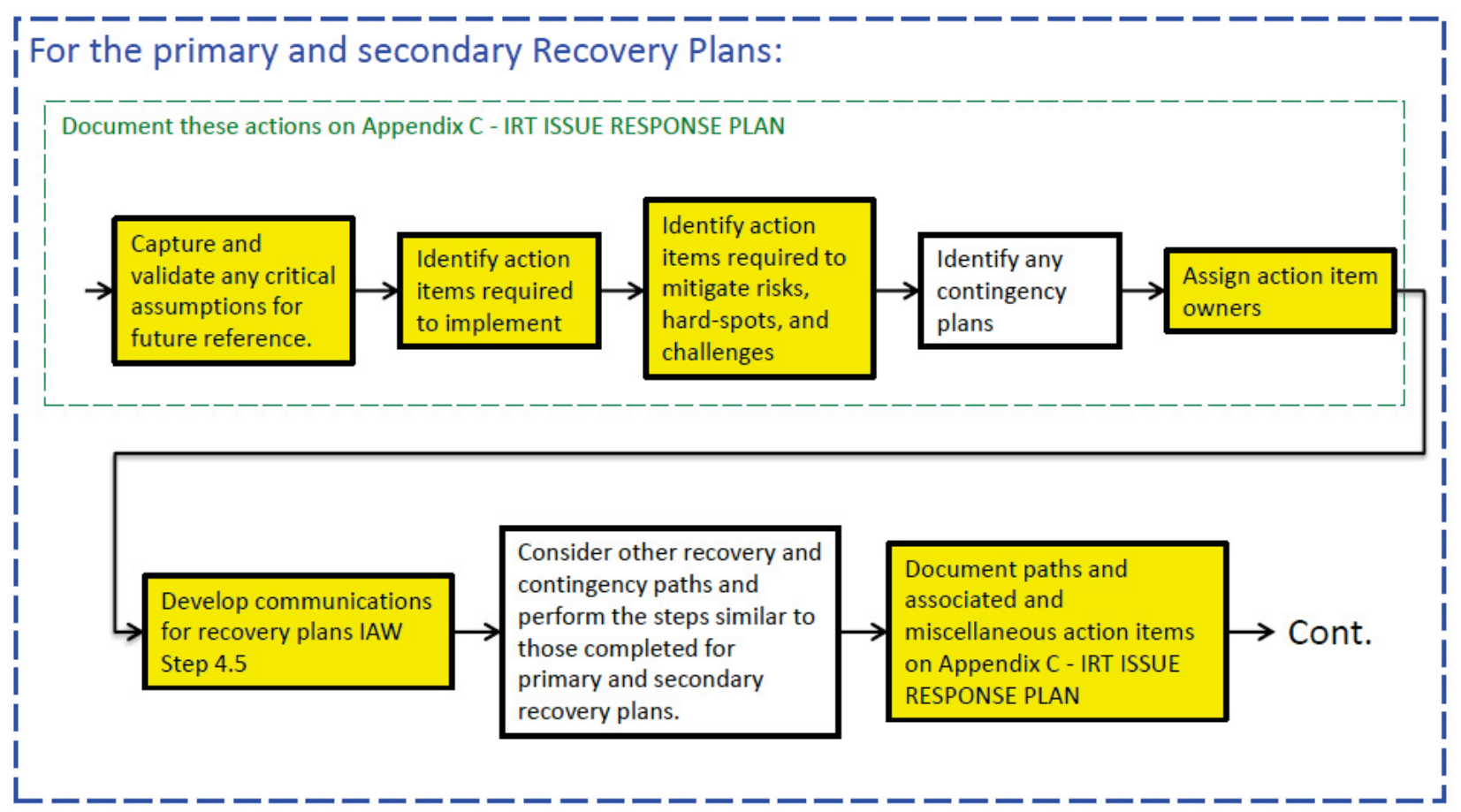

IRT Process Maps - APS, 2013 


\section{4 - Recovery Plan Implementation:}

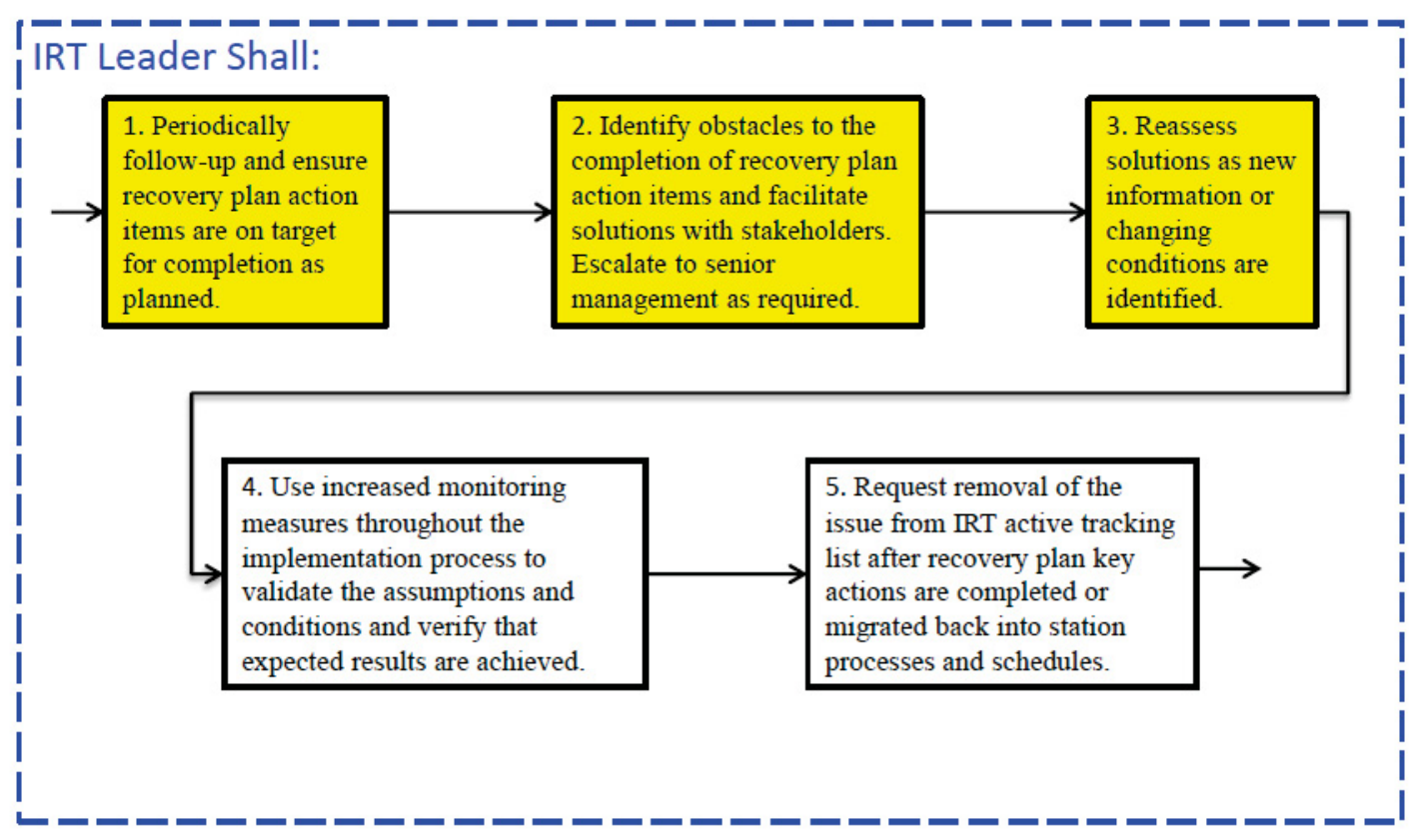

IRT Process Maps - APS, 2013 


\section{5 - Communicate Recovery Plan:}

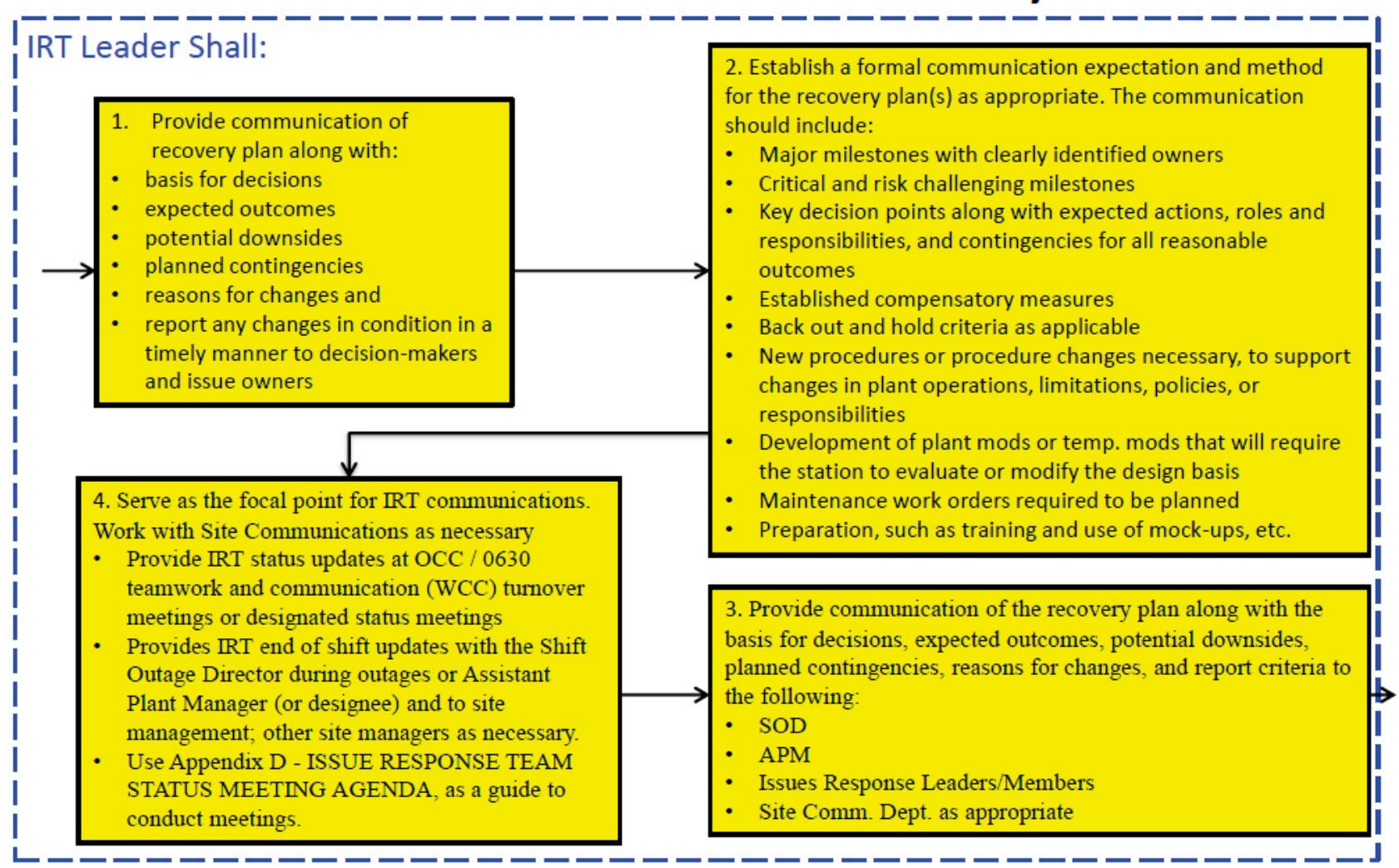

IRT Process Maps - APS, 2013 


\section{6 - Independent Review:}

1.. Consider the need for an independent review of

recovery plans using

identified areas of expertise to

validate the risks,

consequences, and

contingency actions of plan

implementation.
Consider using external and unbiased review sources, (e.g., OSRC, EPRI, INPO, PRB,

Management Oversight Board, NEI, consultants,

equipment vendors, and other corporate experts).

\begin{tabular}{|l|l|l|}
\hline $\begin{array}{l}\text { Perform an } \\
\text { independent } \\
\text { review. Start as } \\
\text { early as possible } \\
\text { and complete } \\
\text { before } \\
\text { irreversible } \\
\text { actions are taken. }\end{array}$ & $\begin{array}{l}\text { Document independent } \\
\text { review results, comments } \\
\text { and resolutions including } \\
\text { basis for not } \\
\text { incorporating specific } \\
\text { comments on Appendix C } \\
\text { - IRT ISSUE RESPONSE } \\
\text { PLAN. }\end{array}$ \\
\hline
\end{tabular}

Perform an

independent

early as possible

and complete

irreversible

actions are taken.

\section{7 - Assignment of Issues to IRT Leaders:}

1. The APM and/or SOD will fully activate the off-line OCC.

The following groups should be considered when staffing

teams:

- Engineering

- Maintenance

- Operations

- Work Management

- Supply Chain

- Standards

- Training

- Performance Improvement

IRT Process Maps - APS, 2013 


\subsection{Recovery Plan Closure}

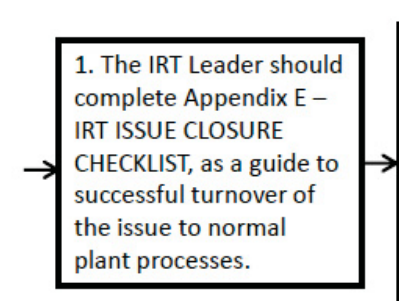

2. Once recovery actions
required for issue resolution
are planned, scheduled, and
migrated back into business
function and work
schedules, the issue is a
candidate for removal from
the IRT active issue list.
3. Issues are removed from the IRT active issue

list with permission of

the Shift Outage Director

(or designee) (Outage),

the Assistant Plant

Manager (or designee) or

the Unit Shift Manager

(On-line).
4. Remaining actions on the IRT Response Plan need to have specific owners and due dates entered in the Corrective Action Program (CAP) or have scheduled activity identified in the approved schedule.

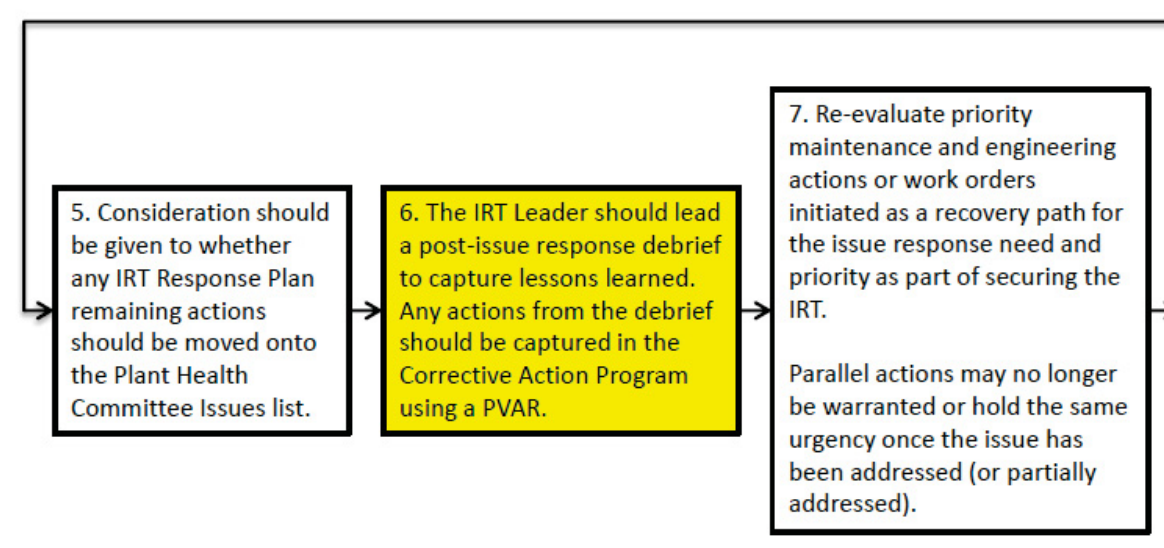

IRT Process Maps - APS, 2013
8. Operations and other group compensatory actions created in response to the issue

should be evaluated to ensure they are still warranted. If so, they need to be properly embedded in an existing plant

$\rightarrow$ process to ensure they are retained and conditions for securing defined (Temporary procedure, shift turnover sheet, temporary notes, Operability Determination, Standing Orders, etc.). 
Appendix D

Demonstration Scenarios 


\section{Scenario \#1, 2R17 SIA-V-908 leak}

Issue - On October 8, 2012 Operations personnel identified a pipe leak at Safety Injection (SI) loop drain valve 2PSIAV908. Maintenance personnel removed the insulation and discovered a pipe leak near a welded connection upstream of 2PSIAV908, a Shutdown Cooling (SDC) Train-A cooling drain valve. SDC Train A was declared inoperable. This unplanned maintenance caused a refueling Outage Delay.

\section{Event Timeline}

1. Operations Personnel identify a pipe leak. Condition needs to be communicated to the OCC.

a. Current Method-Operator leaves the area and contacts his supervisor to report the problem. Supervisor may go to the location and put eyes on issue. Supervisor recognizes the potential outage impact and informs the OCC via telephone.

Time: 15-30 min

b. Proposed Method-Operator contacts the OCC utilizing a handheld device. Instant video dialog is established and OCC staff can see real time video of the leak.

c. Location: Valve/pipe mockup in HSSL (old)

Participants: Field Worker - (INL Staff 1) and OCC SOM (INL Staff 2)

Technology: iPad - Field Worker, SMART Board \#1 - OCC SOM, WiFi, Oval Path Software or Face Time.

Time: 2-3 min

2. Operator who discovered the condition creates a condition report.

a. Current Method-Operator returns to his workstations and creates a condition report (PVAR for Palo Verde) on a desktop application and submits for processing.

Time: 20-30 min

b. Proposed Method - Operator creates a condition report on his handheld device via a mobile application. Monitoring software in OCC picks up PVAR related to outage

c. Location: Valve/pipe mockup (HSSL old) and OCC (HSSL new) Participants: Field Worker (INL Staff 1) and OCC SOM (INL staff 2) Technology: iPad - Field Worker, SMART Board \#1 - OCC SOM, WiFi, Oval Path Software Time: 5 min

3. Operator marks the discovered condition with a deficiency tag.

a. Current Method-Operator creates a deficiency tag at his work location in the service building and goes back to the scene of the problem to hang it. Time: $15-20 \mathrm{~min}$

b. Proposed Method - Operator obtains a deficiency tag created directly from his mobile device application and printed at a station in the plant

c. Location: Printer near valve/pipe mockup (HSSL old)

Participants: Field Worker (INL staff 1)

Technology: iPad - Field Worker, WiFi, Oval Path Software, wireless label printer Time: $2 \mathrm{~min}$

4. Operator creates a work request to repair the leak. 
a. Current Method - Operator initiates a work request in the Work Management system. Time: 15-20 min

b. Proposed Method - The Work request is partially generated automatically from an option in the condition reporting application, additional information is added via the handheld device.

c. Location: Valve/pipe mockup (HSSL old)

Participants: Field Worker (INL staff 1 )

Technology: iPad - Field Worker, WiFi, Oval Path Software

Time: 3-5 min

5. OCC assigns this emergent issue to the IRT (reset for participants)

6. IRT starts working on the issue, collecting information and resources.

a. Current Method - Utilizing face to face meetings, the IRT online log and a white board in the IRT team room.

b. Proposed Method - Utilizing a SMART board and IRT specific templates to organize and share information regarding the issues resolution. First show blank template followed by showing partially completed template. (INL staff 1)

i. Template page for Overview

ii. Template page for photos/videos of issue

iii. Template page to track assigned actions

iv. Template page for drawings

v. Template page for related work packages

vi. Template page to track the status of materials

vii. Template page to track the schedule impacts of various courses of action

viii. Template to record safety significance, Tech Spec LCOs, or other regulatory commitments

ix. Template page for a log of activities (similar to current IRT online log)

c. Location: IRT Team Room (HSSL new)

Participants: IRT Lead (INL Staff 1)

Technology: SMART Board \#1 - IRT Lead, Bridgit

Time: This new method is not designed to create time savings rather to demonstrate how capturing of rich data allows for improved communication and information sharing with team members.

7. IRT periodically reports status to OCC

a. Current Method - IRT team leader brings notes to OCC and reports verbally.

b. Proposed Method - IRT team establishes a real time collaboration session between SMART boards in the OCC and IRT team room and shares information gathered from template pages

c. Location: IRT and OCC (Both in HSSL new)

Participants: IRT Lead (INL Staff 1) and OCC SOM (INL staff 2)

Technology: SMART Board \#1 - IRT Room, SMART Board \#2 OCC, Bridgit 
Time: This new method is not designed to create time savings rather to demonstrate how capturing of rich data allows for improved communication and information sharing with team members.

8. IRT periodically communicates status to managers or other stakeholders

a. Current Method-Telephone conversations, email

b. Proposed Method - IRT team invites manager to join a collaboration session and shares information via the templates to the managers desktop or i-pad.

c. Location: IRT room (HSSL new)and Managers Office (Ron's office) Participants: IRT Lead (INL staff 1 ) and manager (INL staff 2) Technology: SMART Board \#1 - IRT Lead, Desktop computer, Bridgit

Time: Note - this new method is not designed to create time savings rather to demonstrate how capturing of rich data allows for improved communication and information sharing with team members.

9. IRT need to collaborate with subject matter experts while working the problem

a. Current Method - Telephone conversations, email and face-to-face meetings

b. Proposed Method - IRT team invites SME to join collaboration session via desktop or ipad.

c. Location: IRT (HSSL new) and off site (HSSL old)

Participants: IRT Lead (INL staff 1 ) and SME (INL staff 2)

Technology: iPad - SME, SMART Board \#1 - IRT Lead, WiFi, Bridgit

Time: This new method is not designed to create time savings rather to demonstrate how capturing of rich data allows for improved communication and information sharing with team members.

\section{Scenario \#2, 1R17 S/G Hydrazine Concentrations}

Issue - On April 4, 2013 S/G Hydrazine concentrations were too high to permit secondary side inspections. IRT was evaluating several potential options, keep blowers aligned and wait for levels to come down or drain and refill the $\mathrm{S} / \mathrm{G}$ with deminerialized water.

\section{Event Timeline}

1. Workers take samples on the $S / G$ and determine levels are too high to enter for inspection. Condition needs to be communicated to the OCC.

a. Current Method - Worker leaves the area and contacts his supervisor to report the problem. Supervisor recognizes the potential outage impact and informs the OCC via telephone.

b. Proposed Method - Same as Current.

2. Worker who discovered the condition creates a condition report.

a. Current Method - Operator returns to his workstations and creates a condition report (PVAR for Palo Verde) on a desktop application and submits for processing.

Time: $20-30 \mathrm{~min}$ 
b. Proposed Method - Operator creates a condition report on his handheld device via a mobile application. Monitoring software in OCC picks up PVAR related to outage

c. Location: Valve/pipe mockup (HSSL old) and OCC (HSSL new) Participants: Field Worker (INL Staff 1) and OCC SOM (INL staff 2)

Technology: iPad - Field Worker, SMART Board \#1 - OCC SOM, WiFi, Oval Path Software

d. Time: $5 \mathrm{~min}$

3. OCC assigns this Issue to the IRT

4. IRT starts working on the issue, collecting information and resources.

a. Current Method - Utilizing face to face meetings, the IRT online log and a white board in the IRT team room.

b. Proposed Method - Utilizing a SMART board and IRT specific templates to organize and share information regarding the issues resolution.

i. Template page for Overview

ii. Template page for photos/videos of issue

iii. Template page to track assigned actions

iv. Template page for drawings

v. Template page for related work packages

vi. Template page to track the status of materials

vii. Template page to track the schedule impacts of various courses of action

viii. Template to record safety significance, Tech Spec LCOs, or other regulatory commitments

ix. Template page for a log of activities (similar to current IRT online log)

c. Location: IRT Team Room (HSSL new)

Participants: IRT Lead (INL Staff 1)

Technology: SMART Board \#1 - IRT Lead, Bridgit

Time: This new method is not designed to create time savings rather to demonstrate how capturing of rich data allows for improved communication and information sharing with team members.

5. IRT periodically reports status to OCC

a. Current Method - IRT team leader brings notes to OCC and reports verbally.

b. Proposed Method - IRT team establishes a real time collaboration session between SMART boards in the OCC and IRT team room and share information gathers in template pages

c. Location: IRT and OCC (Both in HSSL new)

Participants: IRT Lead (INL Staff 1) and OCC SOM (INL staff 2)

Technology: SMART Board \#1 - IRT Room, SMART Board \#2 OCC, Bridgit

Time: This new method is not designed to create time savings rather to demonstrate how capturing of rich data allows for improved communication and information sharing with team members.

6. IRT periodically communicates status to managers or other stakeholders

a. Current Method-Telephone conversations, email 
Appendix D - Demonstration Scenarios

b. Proposed Method-IRT team invites manager to join a collaboration session and shares information via the templates to the managers desktop or i-pad.

c. Location: IRT room (HSSL new)and Managers Office (Ron's office)

Participants: IRT Lead (INL staff 1 ) and manager (INL staff 2)

Technology: SMART Board \#1 - IRT Lead, Desktop computer, Bridgit

Time: This new method is not designed to create time savings rather to demonstrate how capturing of rich data allows for improved communication and information sharing with team members.

7. IRT need to collaborate with subject matter experts while working the problem

a. Current Method - Telephone conversations, email and face-to-face meetings

b. Proposed Method - IRT team invites SME to join collaboration session via desktop or ipad.

c. Location: IRT (HSSL new) and off site (HSSL old)

Participants: IRT Lead (INL staff 1 ) and SME (INL staff 2)

Technology: iPad - SME, SMART Board \#1 - IRT Lead, WiFi, Bridgit

Time: This new method is not designed to create time savings rather to demonstrate how capturing of rich data allows for improved communication and information sharing with team members.

\section{AOCC Support Group Status Displays}

a. Current Method - Dry erase boards are used to track issues for various groups such as Engineering, Maintenance and Procurement. This method does not allow for easy prioritization of issues, tracking of completed issues or knowledge retention. Current method is only visible or updatable in one location.

b. Proposed Method - Utilize templates created on SMART Boards to track issues. New issues can be added. Issues on the board can be color coded and ordered by priority. Completed issues can be retained. Complete picture can be archived at the end of the outage for knowledge management purposes. Software can convert hand written entries into text. Software can convert the display to a .pdf for sharing with others via email.

c. Advantages - Improved usability, improved readability, ability to share display with any remote location. Ability to remotely update the display. Ability to save information.

d. Location: Staff Office and OCC (Both in HSSL new)

Participants: Outage support staff (INL Staff 1 ) and OCC SOM (INL staff 2) Technology: SMART Board \#1 - OCC, SMART Board \#2 - Support Staff, Bridgit

Time: Time is saved by allowing support staff to remotely update the OCC status board without travelling from their normal work location to the OCC. 
Appendix D - Demonstration Scenarios

\section{AOCC Update Briefs and Revolving Status Displays}

a. Current Method - Status Displays are printed on a plotter and taped to the wall or available on desktop computers. Update Briefs rely on verbal communication, no visual displays are utilized.

b. Proposed Method - Use templates to display information on large monitors in the OCC during routine briefs. After the brief, information that was presented will cycle on a timer. Information is updated with each briefing held in the OCC or when a significant change occurs. This method will also allow remote participants to view information presented during the briefs.

c. Advantages - Reduced chance of out of date information being used. Reduced visual clutter in the OCC. Allows some staff to view briefs remotely reducing personnel in a crowded OCC.

d. Location: OCC (HSSL new)

Participants: OCC SOM (INL staff 1 )

Technology: SMART Board \#1 - OCC, SMART Board \#2 - Support Staff, Bridgit

Time: Time is saved by allowing support staff to remotely view OCC update briefs without travelling from their normal work location to the OCC. Additionally, rich data allows for improved communication and information sharing with team members.

\section{AOCC Work Status Monitoring}

a. Current Method - Schedulers print a hard copy of the schedule each night after midnight and post in the OCC. OCC staff updates the hard copy with markers throughout the day with status obtained by in person reports or telephone status reports.

b. Proposed Method - The use of computer based procedures and electronic work packages will allow OCC staff access to real time, passive status of ongoing work in the field. OCC staff will be able to call up and view actual steps of a procedure as they are completed. Additionally, portable wireless cameras may be installed near critical job sites to allow OCC staff to monitor job status without relying on field workers to call in status updates.

c. Advantages - Passive, real time monitoring of work status does not rely on field workers or support staff to update the OCC. OCC staff is no longer required to chase down updates. Software can monitor and alert OCC staff when delays occur.

d. Location: Valve/pipe mockup (HSSL old) and OCC (HSSL new) Participants: Field Worker (INL Staff 1) and OCC SOM (INL staff 2) Technology: iPad - Field Worker, SMART Board \#1 - OCC SOM, WiFi, Oval Path Software, Electronic Work Package Time: Time savings realized by not requiring physical status reporting to the OCC. OCC staff will be aware of potential delays quicker. 
Appendix D - Demonstration Scenarios

\section{Automatic Pending Support Notifications}

a. Current Method - Procedure users must look ahead in the procedure to identify when support from other organizations such as QA, RP or Chemistry will be required and call for and find an available staff member to support the task.

b. Proposed Method - Embedded triggers in computer based procedures or electronic work packages automatically send notifications to support staff via calendar, text or email at predetermined time points alerting them of pending tasking.

c. Advantages - Does not rely on procedure user looking ahead to identify required support. Procedure user does not have to break away from performing work to make the support request. Improved utilization of support staff resources.

d. Location: Valve/pipe mockup (HSSL old) and OCC (HSSL new) Participants: Field Worker (INL Staff 1) and Support Staff (INL staff 2) Technology: iPad - Field Worker, iPad - Support Staff, WiFi, Oval Path Software, Electronic Work Package

Time: Time savings realized by not requiring worker to stop working to contact support group. Time saved by support group by allowing more efficient resource planning. 